\title{
Microglia and monocytes in inflammatory CNS disease: integrating phenotype and function
}

\author{
Alanna G. Spiteri ${ }^{1,2,3,4}$. Claire L. Wishart ${ }^{1,2,3,4} \cdot$ Roger Pamphlett $^{5,6} \cdot$ Giuseppe Locatelli $^{7}$. Nicholas J. C. King ${ }^{1,2,3,4,8,9} \mathbb{D}$
}

Received: 17 August 2021 / Revised: 11 November 2021 / Accepted: 11 November 2021 / Published online: 1 December 2021

(c) The Author(s) 2021

\begin{abstract}
In neurological diseases, the actions of microglia, the resident myeloid cells of the CNS parenchyma, may diverge from, or intersect with, those of recruited monocytes to drive immune-mediated pathology. However, defining the precise roles of each cell type has historically been impeded by the lack of discriminating markers and experimental systems capable of accurately identifying them. Our ability to distinguish microglia from monocytes in neuroinflammation has advanced with single-cell technologies, new markers and drugs that identify and deplete them, respectively. Nevertheless, the focus of individual studies on particular cell types, diseases or experimental approaches has limited our ability to connect phenotype and function more widely and across diverse CNS pathologies. Here, we critically review, tabulate and integrate the diseasespecific functions and immune profiles of microglia and monocytes to provide a comprehensive atlas of myeloid responses in viral encephalitis, demyelination, neurodegeneration and ischemic injury. In emphasizing the differential roles of microglia and monocytes in the severe neuroinflammatory disease of viral encephalitis, we connect inflammatory pathways common to equally incapacitating diseases with less severe inflammation. We examine these findings in the context of human studies and highlight the benefits and inherent limitations of animal models that may impede or facilitate clinical translation. This enables us to highlight common and contrasting, non-redundant and often opposing roles of microglia and monocytes in disease that could be targeted therapeutically.
\end{abstract}

Keywords Microglia $\cdot$ Monocyte-derived cells $\cdot$ Immune-mediated pathology $\cdot$ Neuroinflammation $\cdot$ Neurodegeneration $\cdot$ Encephalitis

Alanna G. Spiteri and Claire L. Wishart contributed equally to the publication.

Nicholas J. C. King

nicholas.king@sydney.edu.au

1 Viral Immunopathology Laboratory, Infection, Immunity and Inflammation Research Theme, School of Medical Sciences, Faculty of Medicine and Health, The University of Sydney, Sydney, NSW 2006, Australia

2 Sydney Cytometry Facility, The University of Sydney and Centenary Institute, Sydney, NSW 2006, Australia

3 Ramaciotti Facility for Human Systems Biology, The University of Sydney and Centenary Institute, Sydney, NSW 2006, Australia

4 Charles Perkins Centre, The University of Sydney, Camperdown, NSW 2050, Australia

\section{Introduction}

Inflammation of the central nervous system (CNS) is a feature of many neurological disorders including infectious, autoimmune, sterile inflammatory, demyelinating and

5 Brain and Mind Centre, School of Medical Sciences, Faculty of Medicine and Health, The University of Sydney, Camperdown, NSW 2050, Australia

6 Department of Neuropathology, Royal Prince Alfred Hospital, Camperdown, NSW 2050, Australia

7 Theodor Kocher Institute, University of Bern, Bern 3012, Switzerland

8 The University of Sydney Institute for Infectious Diseases, The University of Sydney, Sydney, NSW 2006, Australia

9 The University of Sydney Nano Institute, The University of Sydney, Sydney, NSW 2006, Australia 
neurodegenerative diseases [35, 58, 140, 194, 288]. Tissueresident and infiltrating myeloid cells, such as microglia and monocytes, are recruited to foci of infection, injury or inflammation in many of these CNS pathologies (Fig. 1), suggesting a role for these cells in the pathophysiology of disease [29]. Microglia and monocytes are both members of the mononuclear phagocyte system that carry out essential tissue-specific functions, critical for homeostasis and the response against pathogen evasion [139, 159, 261, 299]. Although the precise contributions of microglia and monocytes to tissue damage and repair in CNS disease remain poorly resolved, they nevertheless represent potential candidates for targeted therapeutics.

Microglia are tissue-resident macrophages of the CNS parenchyma. These cells arise from uncommitted $\mathrm{KIT}^{+}$ erythromyeloid precursors $[181,316]$, which seed the brain from the yolk sac at embryonic day 9.5 in the mouse [126], well before other glial cells and the formation of the blood-brain barrier (BBB) [130, 181]. They are subsequently renewed in situ independently of bone marrow (BM) hematopoietic stem cells (HSC) [3]. However, more recently, other views challenging the sole yolk sac origin of microglia have emerged [55].

In the healthy homeostatic CNS, microglia comprise the predominant myeloid population, followed by nonparenchymal CNS macrophages [182], collectively called CNS- or border-associated macrophages (CAMs or BAMs) [20, 235, 259]. Relative to BAM/CAMs, microglia uniquely express transmembrane protein 119 (TMEM119) [26], hexosaminidase subunit beta (Hexb) [174, 214, 215], P2Y G-protein-coupled 12 (P2RY12) [41], sialic acid-binding immunoglobulin-type lectin H (Siglec-H) and Spalt-like transcription factor 1 (Sall1) [45], express low levels of CD45 compared to leukocytes outside the CNS, and have a distinct morphology and anatomical location [20, 163, 235, 259, 317]. This makes their identification in the homeostatic brain fairly straight-forward. However, during inflammation in response to CNS perturbation, microglia become reactive or activated, a state in which they upregulate CD45, partially or totally retract their cytoplasmic extensions and increase their somatic volume to adopt a more amoeboid morphology [266, 303]. Microglia are also joined by a substantial infiltrate of BM-derived monocytes [298], both of which similarly express typical myeloid markers $[19,204,298$, 299, 332] (such as CD68, Fig. 1). This hampers the accurate discrimination of these cell types during neuroinflammation in the mouse and human CNS.

Monocytes are peripheral myeloid cells derived from the fetal liver during embryogenesis and are continuously renewed throughout postnatal life from HSCs in the adult BM [115]. In the mouse, 'inflammatory' monocytes (Ly6C ${ }^{\text {hi }}$ ) and 'patrolling' monocytes $\left(\mathrm{Ly} 6 \mathrm{C}^{\mathrm{lo}}\right)$ have been identified [114]. In humans, 'classical' monocytes (equivalent to
Ly6 $\mathrm{C}^{\text {hi }}$ monocytes in mice) make up the majority of the circulating monocyte pool, with the remaining portion made up by intermediate and 'non-classical' monocytes $\left(L y 6 C^{\text {lo }}\right.$ monocytes in mice) [251].

During homeostasis, circulating Ly6 $\mathrm{C}^{\text {hi }}$ monocytes traffic through semi-permeable CNS regions, such as the choroid plexus and dura mater, where they increase the local complexity of BAMs $[128,317]$. The BBB prevents the infiltration of monocytes and other peripheral immune cells into the CNS parenchyma under homeostatic conditions [230]. During inflammation, however, BBB breakdown and leakiness permits the infiltration of monocytes into the parenchyma. Such infiltrating monocyte-derived cells (MC), like monocyte-derived macrophages (MDM) and dendritic cells (moDC), can adopt a microglia-like phenotype upon entry into the inflamed brain. While these cells do not necessarily upregulate genes expressed by homeostatic microglia $[25,66]$, the phenotypic similarities between populations of resident and infiltrating myeloid cells may approximate one another in neuroinflammation, hampering accurate identification of their respective functions in disease [298, 299].

Animal models employing more recent and precise experimental approaches, such as microglia-depletion drugs, cell type-specific markers, gene silencing, lineage tracing, and in vivo imaging techniques, have been used to distinguish microglia and monocytes in various neuropathologies to understand their functional roles [26, 88, 91, 214, 220, 299, 343]. While animal models may fail to fully replicate all aspects of human disease, they have been indispensable in understanding specific pathogenic mechanisms and the effect of therapeutics on particular aspects of disease. We now understand microglia and monocytes to be highly heterogeneous in phenotype and function, having both protective and pathogenic roles that contribute to disease onset, progression and/or recovery.

Here, we integrate and contrast human and animal findings from studies investigating viral encephalitis, CNS injury, neurodegenerative disease and autoimmune neuroinflammation to elucidate key agonistic and antagonistic features of microglia and their BM-derived monocyte counterparts across these neuropathologies. We focus on studies using more selective approaches, including transcriptomic profiling, high-dimensional cytometry and myeloid cell depletion to more accurately dissect their functional roles in neurological disease. In doing so, we identify common pathogenic or protective cell type-specific functions and phenotypes that may aid the development of targeted therapeutics across CNS diseases.

\section{Viral encephalitis}

Neuroinflammation resulting from viral infection of the CNS parenchyma (i.e., viral encephalitis) carries $\sim 5-30 \%$ 


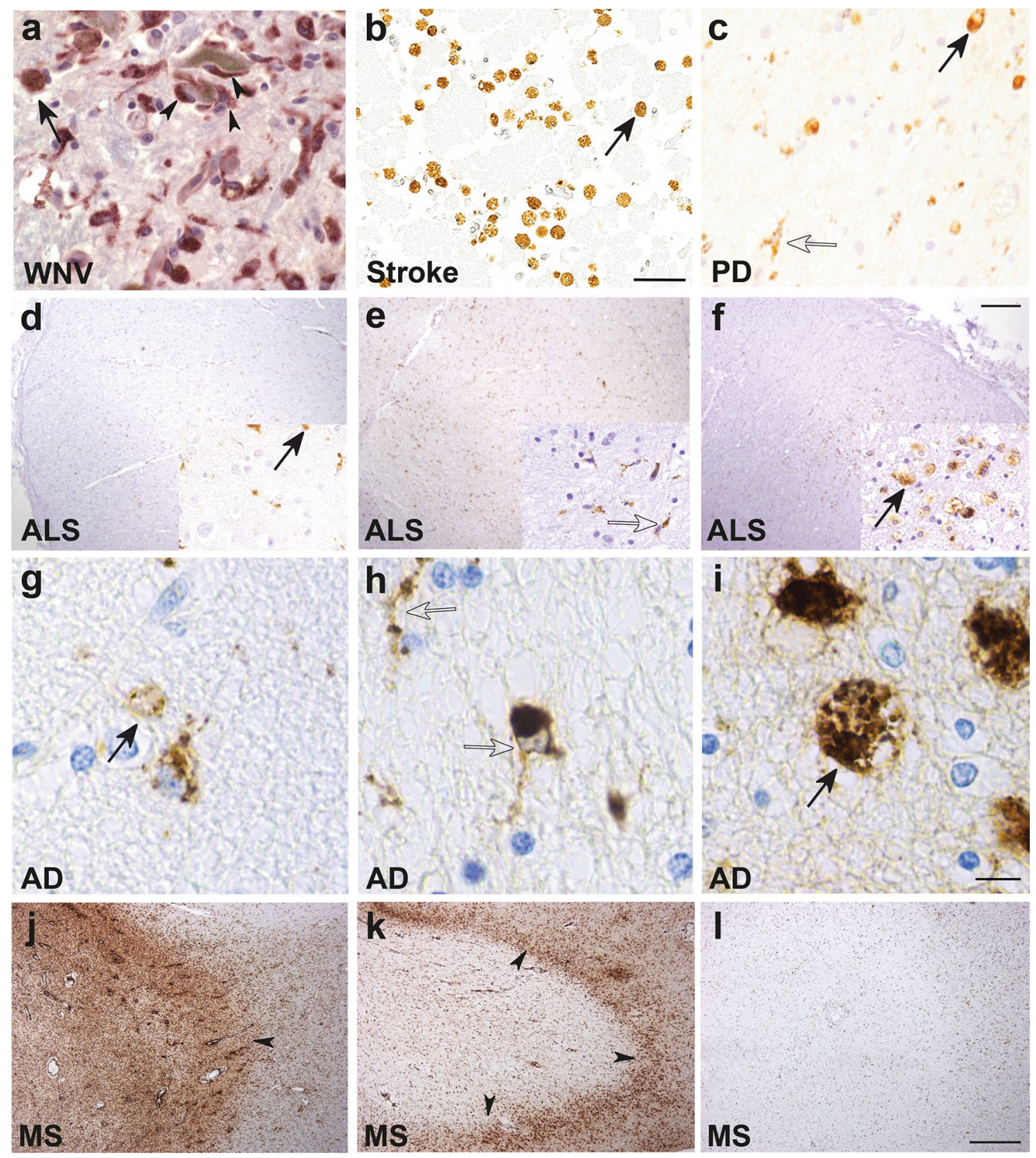

Fig. 1 Macrophage/microglial CD68 tissue staining in human CNS pathologies. Ameboid (solid arrows, likely macrophages and/or reactive microglia) and ramified (open arrows, likely microglia) $\mathrm{CD} 68^{+}$ myeloid cells are shown in various neuropathologies: a West Nile virus (WNV) [247]. Macrophage/microglia engulfing a degenerating neuron (arrowheads) in the substantia nigra in a patient with fulminant WNV encephalitis (400X magnification). b Cortical stroke [94]. Foamy macrophages/microglia are present in a cerebral infarct (several weeks old) (scale bar represents $50 \mu \mathrm{m}$ ). c Parkinson disease (PD) [65]. Ramified microglia and macrophages with enlarged cytoplasm and short stout processes are present in the substantia nigra (400X magnification). d-f Amyotrophic lateral sclerosis (ALS) [38].
The three images show the variable extent of microglia activation in the corticospinal tract in patients with ALS assessed as either mild (d), moderate (e) or severe (f) (scale bar represents $250 \mu \mathrm{m}$ ). g-i Alzheimer disease (AD) [148]. The three images show the rounded ameboid microglia (g), ramified microglia (h) or foamy macrophages (i) that can be seen in AD brains (scale bar represents $10 \mu \mathrm{m}$ ). $\mathbf{j}-\mathbf{I}$ Multiple sclerosis (MS) [193]. Three images show variable inflammatory activity in MS, with either numerous foamy macrophages within a demyelinating plaque $(\mathbf{j})$, macrophages at the rim of a plaque (arrowheads) (k), and an inactive plaque with only a few ramified microglia (l). All images reproduced with permission 
fatality rate, with survivors experiencing severe neurological sequelae and memory deficits that may worsen over time $[111,209,272,329,340]$. Upon entry into the parenchyma, viruses infect and replicate in neurons and/or glia, initiating an inflammatory response. The production of various soluble factors by resident brain cells recruits a range of leukocytes from the periphery, including monocytes and lymphocytes, which carry out effector functions necessary for viral clearance [188]. In severe viral encephalitis, large numbers of microglia and peripherally-derived MDMs can be seen in human post-mortem tissue (Fig. 1a). However, this response is not always beneficial and an overexuberant inflammatory response may also drive neuropathology [185]. For instance, in West Nile virus (WNV) encephalitis, the infiltration of MDMs is particularly associated with injury to brain cells, tissue swelling and the development of seizures [120-123]. In modelling these responses in the CNS, murine models inoculated with a relevant neurotropic virus are commonly used, although this may not necessarily reflect true disease in the human.

\section{Relevance of murine models to human viral encephalitis disease}

While extensive research has uncovered various processes involved in the pathogenesis of viral encephalitis, there are significant differences between mouse models and human disease. To begin with, researchers use a variety of inoculation routes for the same virus, including intradermal, subcutaneous, intravenous, intramuscular, intracranial or intranasal. These routes of inoculation model different aspects of pathology, but vary in invasiveness and viral dose, with very few replicating the usual route of infection by the homologous virus in humans [39, 72, 80, 184, 337]. This has a significant impact on (1) local innate and immune defensive responses, (2) spread of virus locally or systemically, and (3) presentation of viral antigen in local draining lymph nodes versus wide dissemination throughout the animal, all of which may substantially alter the outcomes of infection [39, 337].

The choice of mouse and virus strain may further influence disease pathogenesis and the outcome of infection. Investigators use different mouse strains, frequently, C57BL/6 or BALB/c, for example, which have widely disparate responses to viruses. Genetically modified, usually transgenic or knockout animals, are also commonly used, which take little account of the compensatory changes that may occur in the absence or presence of a particular gene and which consequently demonstrate very different immune responses to infection $[39,80]$, with local availability often dictating the choice of strain for these studies. It is also common for different laboratories to use different strains of the same virus, often a specifically laboratory-adapted strain, often dictated by the availability of the appropriate biosafety facilities (e.g., BSL-2 versus BSL-3), or a virus monogamous to the model host, or one that is seldom encountered by it [141], potentially compounding this still further. Mice are almost always used at an age convenient to the model being studied, with weaning, the formation of the BBB, puberty and sexual maturity, being common temporal landmarks for infection $[8,123,368]$. This is often to enable reliable infection (e.g., some neurotropic viruses will only infect mice prior to the formation of the BBB), but differences in immune system maturity can significantly influence the immune response to infection. Furthermore, until recently in immunological work, it has been common to use only female mice, which ignores the effect of sex differences on the immune response. Finally, there is increasing awareness of the effects of the cellular circadian clock and diet on cellular metabolism driving immune responses [195, 307, 308], with differences in housing conditions and significant variability in macronutrient composition of ad libitum 'standard' chow between institutions.

Variables of this kind make infallible comparison between experimental models difficult, even before considering their applicability in humans. However, the stochastic incidence and clinical presentation of established illness and its subsequent chronicity in human disease, often after any antecedent pathogenesis can be recorded, the variable availability and timing of investigative modalities, access to samples, usually restricted to body fluids, occasional biopsies and/or post-mortem tissue, with tissue degradation due to post-mortem delays often reducing the reliability of results, also impose significant limitations on its detailed study, ultimately increasing our reliance on experimental animal models as an important complementary approach to investigating human disease. Needless to say, many of these benefits and drawbacks also apply to the study of other neurological diseases.

\section{Microglia in viral encephalitis}

\section{Neuroprotective role of microglia in acute-phase viral encephalitis}

Historically, using non-selective techniques, microglia were argued to have a neurotoxic role in encephalitis, producing inflammatory cytokines and orchestrating immune-mediated pathology $[53,263]$. With the recent development of PLX5622, a colony-stimulating factor 1 receptor (CSF1R) inhibitor that causes rapid microglia depletion [295], the functions of microglia in viral encephalitis have been extensively revised. Despite other CSF1R inhibitors (i.e., PLX3397 and BLZ945) being available before PLX5622, few studies investigating viral encephalitis utilised these earlier compounds. PLX5622 is generally formulated into 
chow or administered via oral gavage. It enables sustained microglial depletion without breaching the $\mathrm{BBB}$, without toxicity and without initiating an inflammatory response, as seen with other microglial depletion methods [295, 299, 331]. However, this reagent is not microglia-specific, as other cells also express CSF1R [131]. Despite a lack of confirmatory evidence [134], it was suggested that PLX5622 also causes functional impairments in peripheral lymphoid and myeloid compartments [198]. This molecule likely also affects BAMs, as reported in the case of PLX3397 [317], placing an important caveat on the interpretation of data where PLX5622 is assumed to be purely microglia-specific.

Microglia ablation in Mouse Hepatitis Virus (MHV), Japanese Encephalitis Virus (JEV), Theiler's Encephalomyelitis Virus (TMEV), Pseudorabies Virus (PRV) and WNV encephalitis models has demonstrated a clear neuroprotective role of these cells in the acute phase of infection [96, 107, 274, 279, 335, 344], and alternative microglial depletion methods in Vesicular Stomatitis Virus (VSV) infection have produced similar findings [59, 234]. In some of these studies, microglial depletion resulted in increased weight loss, increased viral burden and persistence, as well as increased viral spread in the CNS and into the periphery [96, 107, 335, 344]. A detailed comparison of recent work using PLX5622 to deplete microglia in different viral encephalitis models is shown in Tables 1 and 2. Collectively, these findings suggest that microglia are pivotal in controlling virus spread in the CNS, with this protective role required especially in the earlier phases of disease [96, 107, 335, 344]. Nevertheless, there is substantial disparity between studies in the elucidation of the precise mechanisms by which microglia control viral spread, presumably consistent with the divergent evolution of virus-host survival strategies for different viral pathogens. Figure 2 illustrates the putative pathogenic and protective roles of microglia and MDM in viral encephalitis.

Table 1 Comparison of studies using PLX5622 to deplete microglia in various models of viral encephalitis (part 1)

\begin{tabular}{|c|c|c|c|c|c|c|c|c|}
\hline Study & Virus & Infection & $\begin{array}{l}\text { \# days mice were } \\
\text { fed PLX5622 } \\
\text { before infection }\end{array}$ & Mice & $\begin{array}{l}\text { Enhanced } \\
\text { mortal- } \\
\text { ity? }\end{array}$ & $\begin{array}{l}\text { Enhanced } \\
\text { morbid- } \\
\text { ity? }\end{array}$ & $\begin{array}{l}\text { Enhanced } \\
\text { weight } \\
\text { loss? }\end{array}$ & $\begin{array}{l}\text { Enhanced } \\
\text { viral load? }\end{array}$ \\
\hline $\begin{array}{l}\text { Sanchez et al. } \\
{[274]}\end{array}$ & $\begin{array}{l}\text { Daniel's strain of } \\
\text { TMEV }\end{array}$ & intracranial (i.c) & 7 & $\begin{array}{l}\text { C57BL/6 } \\
\text { Males } \\
4 \text { weeks old }\end{array}$ & Yes & Yes & $\begin{array}{l}\text { Not } \\
\text { recorded } \\
(\mathrm{N} / \mathrm{R})\end{array}$ & $\mathrm{N} / \mathrm{R}$ \\
\hline \multirow{3}{*}{$\begin{array}{l}\text { Funk } \\
\text { et al. [107] }\end{array}$} & WNV-NY, strain & \multirow{3}{*}{$\begin{array}{l}\text { footpad (f.p) } \\
\text { i.c }\end{array}$} & \multirow[t]{3}{*}{14} & \multirow{3}{*}{$\begin{array}{l}\text { C57BL/6 } \\
\text { Males } \\
6 \text { weeks old }\end{array}$} & Yes & Yes & Yes & Yes \\
\hline & 3000.0259 & & & & No & $\mathrm{N} / \mathrm{R}$ & No & No \\
\hline & $\begin{array}{l}\text { Attenuated } \\
\text { WNV-NS5- } \\
\text { E218A }\end{array}$ & & & & Yes & N/R & Yes & Yes \\
\hline \multirow[t]{3}{*}{$\begin{array}{l}\text { Wheeler } \\
\text { et al. [344] }\end{array}$} & $\begin{array}{l}\text { Neuroattenuated } \\
\text { variant of the } \\
\text { JHMV strain of } \\
\text { MHV }\end{array}$ & i.c & 7 & $\begin{array}{l}\text { C57BL/6 } \\
\text { Males } \\
\text { 5-6 weeks old }\end{array}$ & Yes & N/R & $\mathrm{N} / \mathrm{R}$ & Yes \\
\hline & $\begin{array}{l}\text { N1347A, an rJ } \\
\text { macrodomain } \\
\text { point mutant } \\
\text { virus }\end{array}$ & intranasal (i.n) & & & Yes & $\mathrm{N} / \mathrm{R}$ & $\mathrm{N} / \mathrm{R}$ & $\mathrm{N} / \mathrm{R}$ \\
\hline & $\begin{array}{l}\text { Recombinant } \\
\text { parental JHMV }\end{array}$ & i.p & & & Yes & $\mathrm{N} / \mathrm{R}$ & $\mathrm{N} / \mathrm{R}$ & N/R \\
\hline $\begin{array}{l}\text { Waltl et al. } \\
\text { [334] }\end{array}$ & $\begin{array}{l}\text { Daniel's strain of } \\
\text { TMEV }\end{array}$ & i.c & 21 & $\begin{array}{l}\text { JAX® } \\
\text { C57BL/6 J (B6) } \\
\text { Female } \\
4 \text { weeks old }\end{array}$ & Yes & Yes & Yes & Yes \\
\hline Seitz et al. [279] & $\begin{array}{l}\text { WNV-NY99 } \\
\text { p3 strain of JEV }\end{array}$ & f.p & 14 & $\begin{array}{l}\text { Swiss-Webster } \\
\text { Female } \\
7-10 \text { weeks old }\end{array}$ & $\begin{array}{l}\text { Yes } \\
\text { Yes }\end{array}$ & $\begin{array}{l}\text { N/R } \\
\text { N/R }\end{array}$ & $\begin{array}{l}\text { No } \\
\text { No }\end{array}$ & $\begin{array}{l}\text { Yes } \\
\text { Yes }\end{array}$ \\
\hline Fekete et al. [96] & $\begin{array}{l}\text { PRV-Bartha } \\
\text { derivative, } \\
\text { PRV-Bartha- } \\
\text { Dup-Green }\end{array}$ & $\begin{array}{l}\text { intraperito- } \\
\text { neal (i.p.) or } \\
\text { directly into } \\
\text { the epididymal } \\
\text { white adipose } \\
\text { tissue }\end{array}$ & 21 & $\begin{array}{l}\text { C57BL/6 J } \\
\text { Gender not } \\
\text { specified } \\
12-18 \text { weeks old }\end{array}$ & $\mathrm{N} / \mathrm{R}$ & Yes & $\mathrm{N} / \mathrm{R}$ & Yes \\
\hline
\end{tabular}




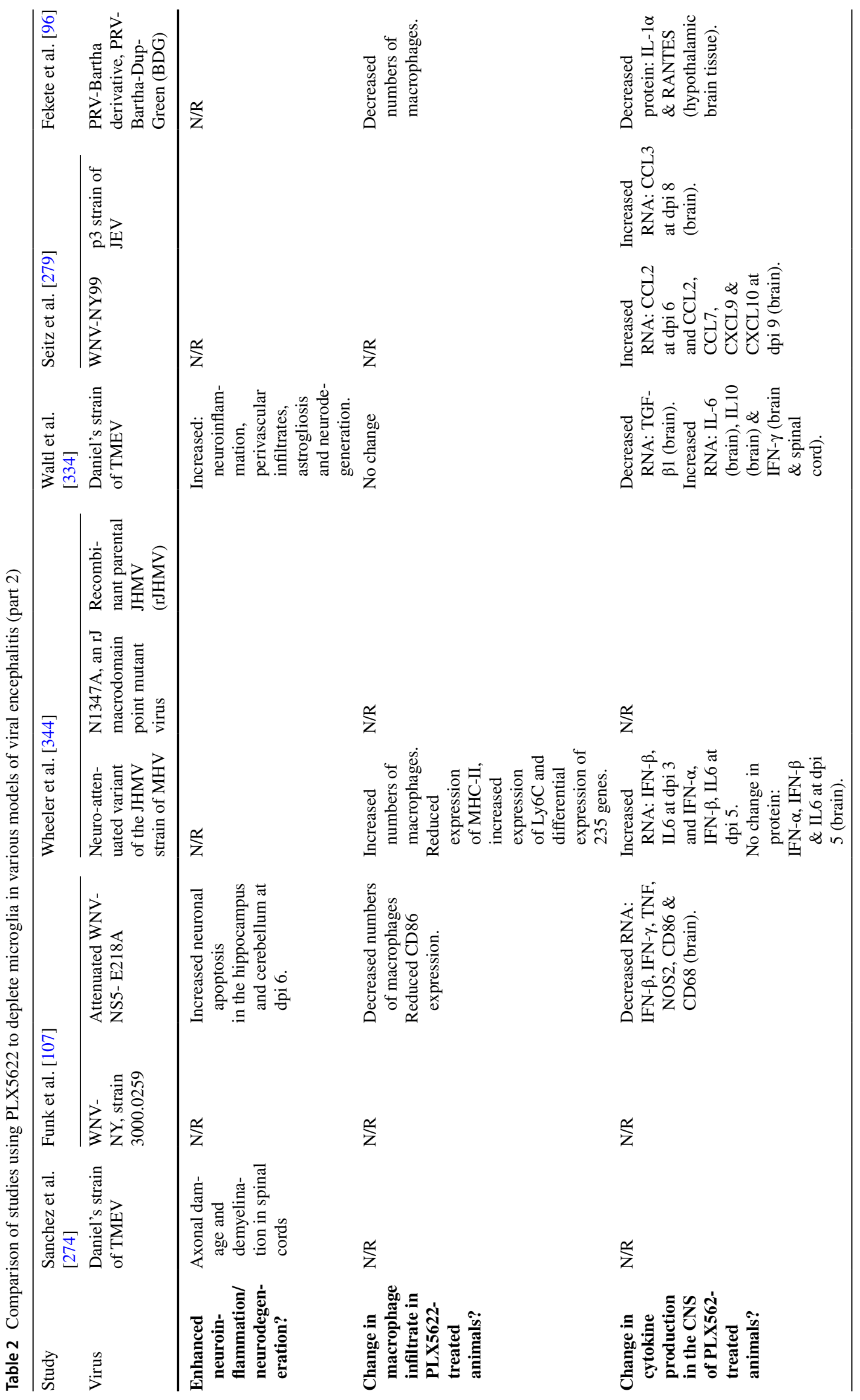

Springer 
Acta Neuropathologica (2022) 143:179-224

185

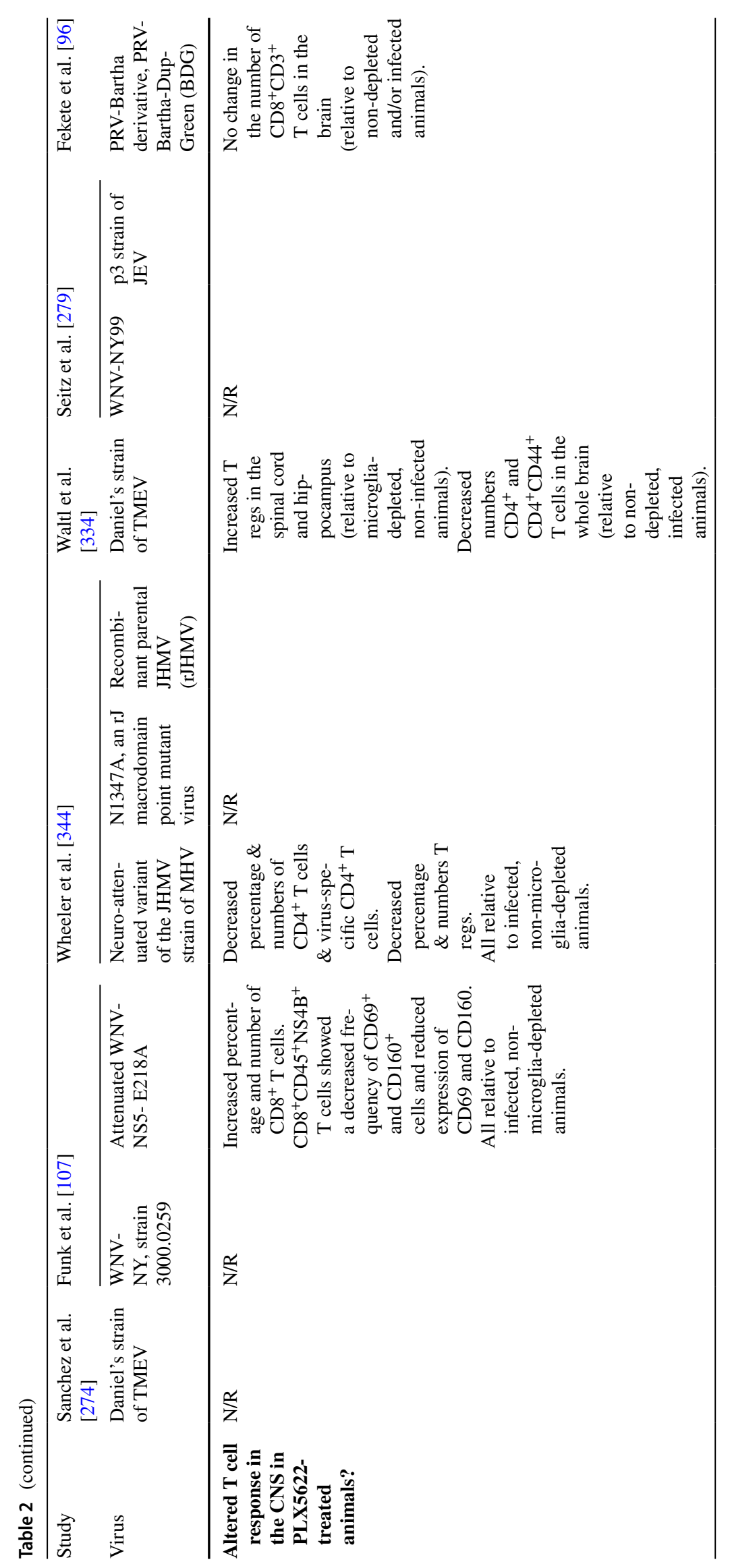

Springer 


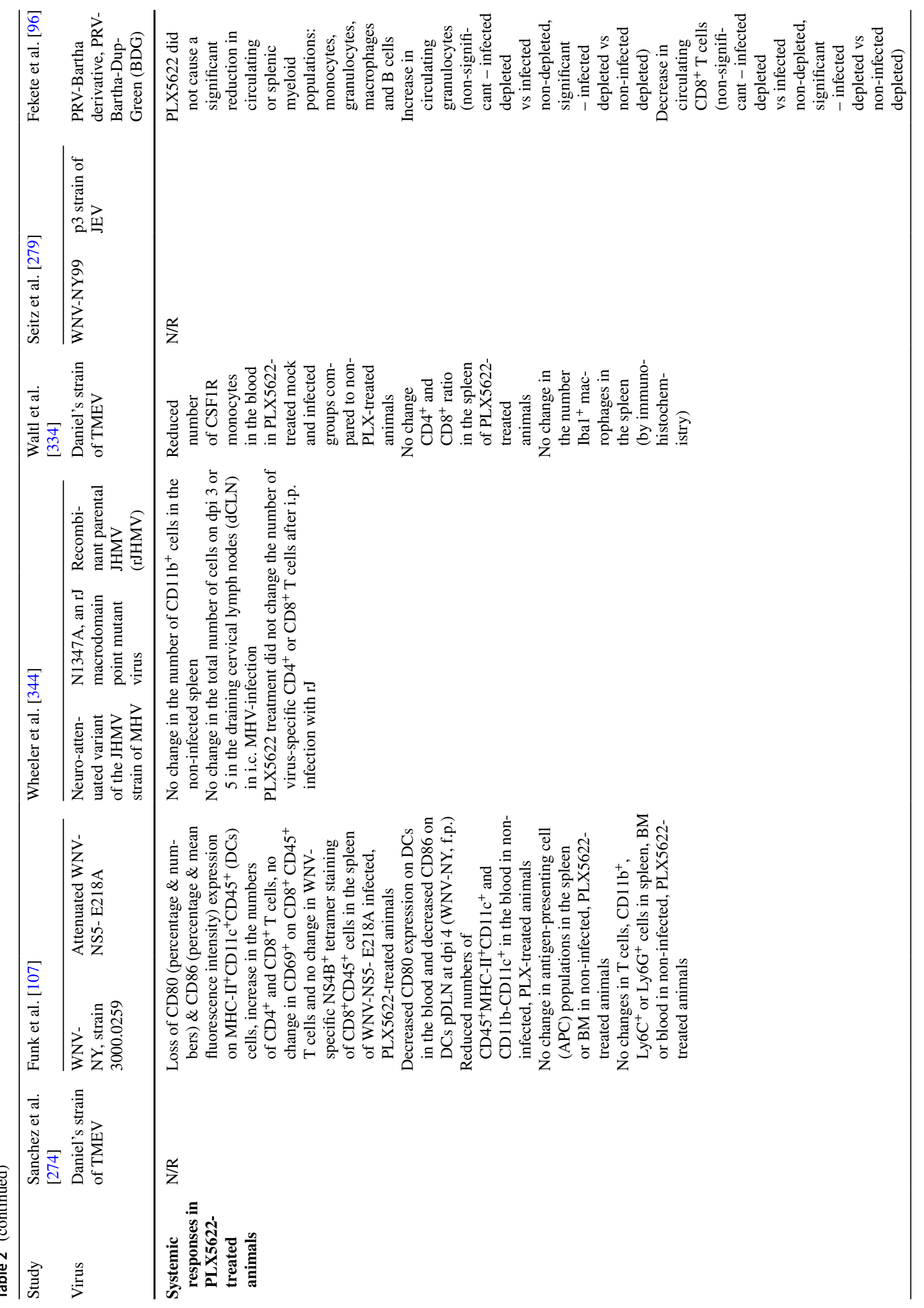




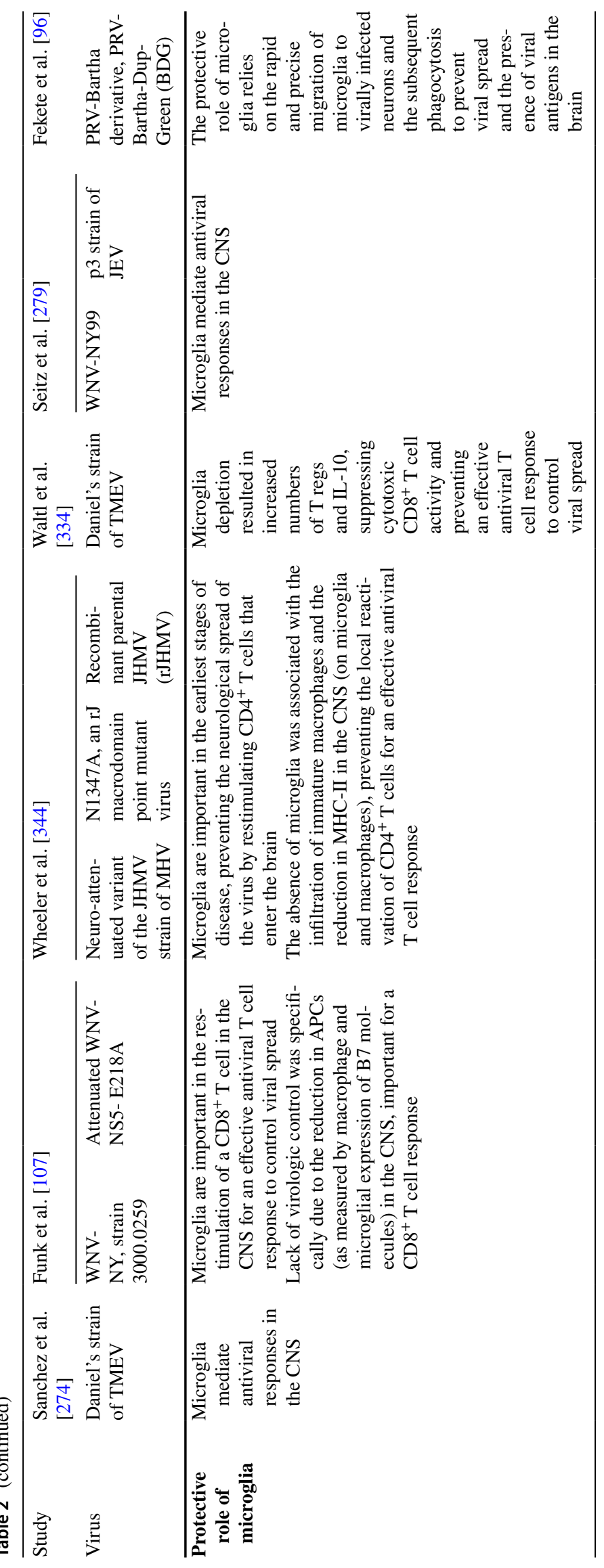




\section{a Protective}

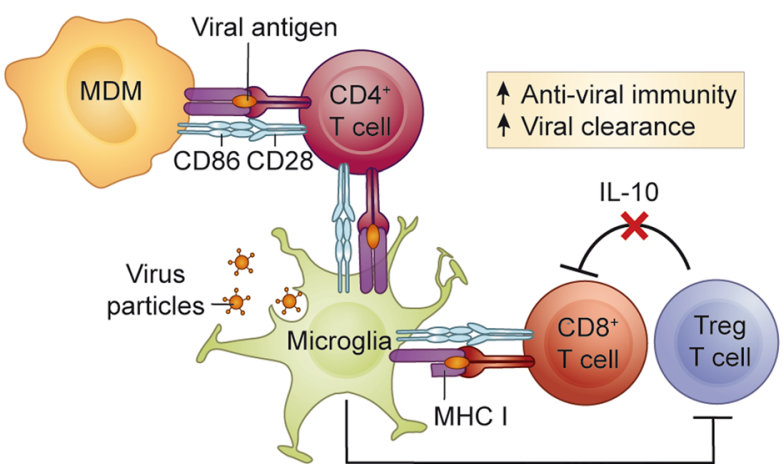

Fig. 2 Protective and pathogenic roles of monocytes and microglia in viral encephalitis. a Protective functions. In viral encephalitis, microglia enhance viral clearance by phagocytosing virus-infected cells. Both microglia and MDMs stimulate anti-viral T cell responses, which is optimized by microglia-mediated regulation of Treg infiltra-

\section{Microglial role in effective T cell responses mediating viral clearance}

The importance of an effective $\mathrm{T}$ cell response in viral clearance and improved disease outcome has been shown in various viral encephalitis models. T cell activation requires antigen presentation and co-stimulation via antigen-presenting cell (APC)-expressed Major Histocompatibility Complex antigen (MHC) and CD80 (B7-1)/CD86 (B7-2), respectively. Strikingly, in the absence of microglia, several studies have shown an ineffective or inadequate $\mathrm{CD} 8^{+}, \mathrm{CD} 4^{+} \mathrm{T}$ cell and/or regulatory $\mathrm{T}$ cell (Treg) response, suggesting a role for microglia in $\mathrm{T}$ cell infiltration and/or activation. However, many of these studies lack specific evidence and do not take into account the indirect effects caused by microgliadepletion agents.

$\mathrm{CD}^{+} \mathrm{T}$ cells A reduction in the number of APCs in the CNS following PLX5622 treatment was thought to contribute to a sub-optimal $\mathrm{CD}^{+} \mathrm{T}$ cell response during $\mathrm{WNV}$ infection, resulting in poor virus control [107], implicating microglia in $\mathrm{CD}^{+} \mathrm{T}$ cell activation (Table 2). However, in this model, both microglia and MDM numbers were reduced in the brain, making it difficult to determine whether microglia or MDMs were responsible for the reduced $\mathrm{T}$ cell activation. Paradoxically, numbers of $\mathrm{CD}^{+} \mathrm{T}$ cells were increased in the CNS in microglia-depleted animals compared to untreated controls, although these $\mathrm{T}$ cells nonetheless displayed reduced expression of 'activation markers', such as CD69 and CD160 [107]. The recent finding that CD69 is a marker of CNS-resident T cells [250] further confounds this interpretation and more precise analysis will be required to

\section{b Pathogenic}

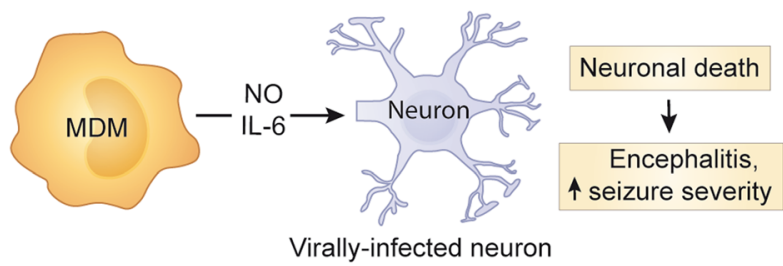

tion. b Pathogenic functions. NO- and IL-6-producing MDMs exacerbate neuronal damage and contribute to immunopathology. MDM, monocyte-derived macrophage; $\mathrm{MHC}$, major histocompatibility complex; $N O$ nitric oxide; $I L$ interleukin; Treg regulatory $\mathrm{T}$ cell

determine the contribution of microglia and/or MDMs to effective $\mathrm{CD} 8^{+} \mathrm{T}$ cell responses in this model.

In addition to decreased APCs in the CNS, the numbers of circulating APCs in the spleen, blood, and pancreaticoduodenal lymph node were also reduced in this model of WNV infection [107]. Thus, reduced peripheral APCs could also have contributed to a sub-optimal systemic $\mathrm{CD} 8^{+} \mathrm{T}$ cell response, although other studies using the same dose and PLX5622 administration route showed no or limited peripheral changes in PLX5622-treated animals (Table 2). Differences in the systemic response to PLX5622 may additionally be due to the age, sex and infection status of mice, or the duration of PLX5622 treatment. Thus, interpretation of studies using PLX5622 to determine the specific functions of microglia must take into account any indirect effects it may cause.

Using alternative experimental systems, including fatemapping and intravital imaging, Moseman et al. [234] clearly identified a role for microglia in $\mathrm{CD} 8^{+} \mathrm{T}$ cell activation. Microglia were required for the cross-presentation of viral antigen from VSV-infected neurons to $\mathrm{CD} 8^{+} \mathrm{T}$ cells to contain virus and prevent its fatal spread. $\mathrm{CD} 8^{+} \mathrm{T}$ cell recognition of MHC class I (MHC-I) on microglia was crucial for survival, while conditional deletion experiments in this model showed that neuronal MHC-I was not required (Fig. 2) [234].

$\mathrm{CD}^{+} \mathrm{T}$ cells Other studies showed a more important role for microglia in $\mathrm{CD}^{+} \mathrm{T}$ cell responses. In TMEV infection, PLX5622-driven microglial depletion resulted in reduced CNS infiltration of $\mathrm{CD}^{+}{ }^{+} \mathrm{T}$ and $\mathrm{CD}_{4} 4^{+} \mathrm{CD} 4^{+} \mathrm{T}$ cells [335], whereas in MHV-infected brains, microglia depletion 
reduced $\mathrm{CD} 4^{+}$and virus-specific, IFN- $\gamma$-expressing $\mathrm{CD} 4^{+} \mathrm{T}$ cells [344] (Table 2). In the latter study, the authors argued that the ineffective $\mathrm{CD}^{+}{ }^{+} \mathrm{T}$ cell response was dependent on reduced microglia/macrophage MHC-II expression and immaturity of infiltrating APC, collectively preventing restimulation of $\mathrm{CD}^{+}{ }^{+} \mathrm{T}$ cells in the CNS (Fig. 2).

T regulatory cells Increased Treg numbers in the CNS resulting from the absence of microglia were also reported in two independent viral encephalitis models (Table 2). Tregs possess several anti-inflammatory mechanisms, including release of interleukin (IL)-10, which dampen the anti-viral immune response and reduce immune-mediated pathology [151]. Thus, their increased infiltration can hamper effective viral clearance. Accordingly, the increased number and percentage of Tregs in the CNS and increased $I l 10$ mRNA expression in TMEV-infected, PLX5622 microglia-depleted mice suggest a role for microglia in regulating the infiltration of Tregs into the brain [335]. In this study, increased Treg numbers were thought to contribute to an ineffective cytotoxic $\mathrm{CD} 8^{+} \mathrm{T}$ cell response, resulting in decreased viral control and reduced survival in the absence of microglia. Importantly, however, the increase in Treg numbers in this study was not statistically different from the non-depleted, infected control mice. Furthermore, while this study concluded that Treg numbers affected the $\mathrm{CD} 8^{+} \mathrm{T}$ cell response, there was a significant increase in IFN- $\gamma$ in the CNS and no change in the number of infiltrating $\mathrm{CD}^{+} \mathrm{T}$ cells in PLX5622-treated animals, suggesting changes in Treg numbers did not affect a functional $\mathrm{T}$ cell response.

Thus, while discrepancies between studies investigating $\mathrm{T}$ cell number and their activation in the CNS may suggest a role for microglia in encephalitis caused by particular viruses, many of these studies lack specific evidence for the contribution of microglia to $\mathrm{CD} 4^{+}, \mathrm{CD} 8^{+}$or Treg responses. Moreover, the wider effects of PLX5622 on the myeloid and lymphoid compartments [198] make it impossible to assess the specific role of microglia using this molecule alone.

\section{The role of microglia in MDM maturation and CNS infiltration}

The absence of microglia in virus-infected brains also affects the number of MDM infiltrating into the CNS, suggesting a role for microglia in the recruitment of monocytes from the blood. This phenomenon may be virus-specific, as studies have reported an increase [344], decrease [96, 107] or no change [335] in the number of immigrating MDMs in these diseases (Table 2). Two studies reporting a differential infiltration of MDMs into the virus-infected CNS reported a reduction in the expression of MHC-II or CD86 on these cells (Table 2), arguably supporting a role for microglia in enhancing MDM antigen presentation upon CNS entry.
However, the possibility that reduced MDM infiltration is a result of PLX5622 targeting CSF1R, which is highly expressed by these cells, is difficult to exclude.

Despite various groups showing reduced numbers of infiltrating MDMs and cytokine production in the CNS of microglia-depleted mice during infection, these animals were still highly susceptible to lethal encephalitis. This appears inconsistent with the observation that inhibiting monocyte infiltration into the WNV-infected brain reduces immunemediated pathology and enhances survival [120, 122], while in contrast, reduced MDM infiltration and decreased Nos2, Ifng and Tnf expression in the brains of microglia-depleted WNV-infected mice did not improve survival [107]. These findings suggest that maintaining a microglial network for early defence is as important as reducing subsequent MDMmediated immunopathology in viral encephalitis.

\section{The role of microglial migration and phagocytosis in virus control}

The purinergic receptor, P2RY12, was shown to have a role in the control of viral spread in encephalitis caused by PRV, an alphaherpesvirus that infects the brain via retrograde synaptic spread from peripheral neurons [96]. Using advanced imaging techniques in P2RY12-deficient $\left(P 2 R Y 12^{-/-}\right)$mice treated with PLX5622 and infected with PRV, this study showed rapid, precise microglial migration to and phagocytosis of virus-infected neurons to reduce CNS spread (Table 2). Microglia/macrophage-mediated engulfment of virus-infected neurons has also been observed in human WNV-infected brains [247] (Fig. 1a). In PRV infection, this process involved microglial migration towards ATP (the ligand for P2RY12) released by infected neurons prior to the appearance of mature virions in the neuronal cytoplasm and before neuronal membranes were compromised. In stark contrast to the transcriptional changes seen in neurodegenerative diseases [174, 179, 191, 214], microglia upregulated P2RY12 by two-fold in this model, demonstrating its importance in CNS infection.

Similarly, during infection with neurotropic VSV, microglia accumulated in the olfactory bulb, forming an 'innate barrier' which impeded viral spread to caudal regions of the brain [59]. Consequently, microglial depletion with BLZ945, a different CSF1R inhibitor, resulted in increased VSV load and spread, transforming a sublethal infection into lethal encephalitis. Here, microglial 'activation' and accumulation relied on neuron-astrocyte crosstalk. Abrogation of IFN$\alpha / \beta$ receptor in neurons and astrocytes, but not microglia, resulted in reduced microglial activation, accumulation, proliferation and enhanced viral spread and mortality. This suggests that IFN- $\beta$ produced in the olfactory bulbs stimulates 
IFN- $\alpha / \beta$ receptor signaling in neurons and astrocytes, indirectly enhancing the microglial anti-viral response.

\section{Role of aberrant synaptic pruning in post-viral cognitive dysfunction}

Patients recovering from viral encephalitis often show severe neurological sequelae, including deficits in memory, visuospatial and verbal learning, and motor and executive functions [111, 209, 272, 329, 340]. Permanent cognitive dysfunction after infectious encephalitis can occur without neuroinvasion, with cognitive deficits worsening over time [237]. In WNV and Zika virus (ZIKV) encephalitis, microglia have been identified as orchestrators of spatial-learning impairments seen in the recovery phase after viral neuroinvasion $[111,324]$.

While the phagocytic role of microglia may be protective in the acute phase of viral infection, the same function can become detrimental post infection. This is shown by the inappropriate removal of hippocampal synapses leading to circuitry dysfunction and spatial-learning deficits in the clinical recovery phase from WNV and ZIKV neuroinvasive disease [111, 324]. Both studies show the importance of complement protein $\mathrm{C} 3$, the hydrolysed fragment of which, $\mathrm{C} 3 \mathrm{a}$, is recognized by microglial-expressed $\mathrm{C} 3 \mathrm{a}$ receptor $(\mathrm{C} 3 \mathrm{aR})$, in the aberrant engulfment of synapses. Discrete immunopathological effects post infection with different flaviviruses were demonstrated by Gaber et al. [109], with WNV infection associated with the enhanced elimination of presynaptic termini and ZIKV infection resulting in neuronal cell death and the enhanced elimination of post-synaptic termini. This study elegantly showed that the persistence of $\mathrm{CD} 8^{+} \mathrm{T}$ cells expressing IFN- $\gamma$ in the brain parenchyma was required for both microglial activation and the neuronal loss and/or synapse elimination resulting in cognitive dysfunction during the recovery from WNV and ZIKV infection. Accordingly, absence of microglial Ifngr prevented the effects of flavivirus-induced hippocampal damage and related clinical deficits [111].

Nonetheless, enhanced microglia-mediated synaptic engulfment during insult, infection or injury may well be a protective mechanism, for instance by preventing excitotoxicity and dampening nonsense signalling activity from damaged or injured neurons [342] or, in the context of neurotropic infection, by limiting trans-synaptic viral spread or aberrant calcium signalling by infected neurons [324]. At the same time, this can also lead to the collateral loss of bystander synapses, a process also observed in CNS pathologies, such as Alzheimer's Disease (AD) and related dementias [62, 104], and in animal models of Multiple Sclerosis (MS) $[10,21]$. While this remains a matter of debate, it has been proposed that $\mathrm{C} 3 \mathrm{aR}$-dependent microglial synaptic engulfment has a role in the functional decline observed in
MS [342], AD [152] and aging (Fig. 4). Much like in WNV infection, synapse elimination occurs predominantly at the presynaptic termini and is dependent on the alternative complement cascade (i.e., C3 hydrolysis). Similarly, impaired learning coinciding with synapse and neuronal loss was abolished in aged mice deficient in C3 [285]. Furthermore, IFN- $\gamma$-induced $\mathrm{C} 3$ expression in an amyloidogenic mouse model reduced plaque load but resulted in increased loss of synapses and cognitive dysfunction [152, 284]. Thus, in various CNS diseases, microglia show conserved pathological mechanisms, which could be targeted for the modulation of disease processes.

\section{Monocytes in viral encephalitis}

The severe neuroinflammatory response associated with viral encephalitis recruits a substantial monocytic infiltrate from the periphery, constituting more than $50 \%$ of all recruited cells in some disease models [122, 123]. This significant infiltration is also evident in severe viral encephalitis in humans at postmortem [11, 247, 273] (Fig. 1a). Together with recruited lymphocytes and resident microglia, monocytes carry out inflammatory and anti-viral effector functions necessary for viral clearance [188]. However, this response is not always beneficial and an overexuberant inflammatory response may contribute to fatal encephalitis. A comparison of the differential roles and associated phenotypes (RNA and protein) of microglia compared to MCs in viral encephalitis can be seen in Table 3 .

\section{Monocyte-mediated viral clearance contributes to secondary tissue damage}

Upon entry into the infected brain, MDMs can present viral antigen and support $\mathrm{CD} 4^{+} \mathrm{T}$ cell-mediated viral clearance or contribute to the killing of infected cells through release of inflammatory mediators, such as NO and IL-6 [16, 22, 54, 200] (Fig. 2). While these responses enhance pathogen clearance, they can also contribute to substantial neurodegeneration [70, 120, 122, 123, 155, 334]. During WNV infection in the mouse, for instance, the infiltration of Ly6 $\mathrm{C}^{\text {hi }}$ monocytes into the infected brain coincides with the onset of fatal encephalitis $[122,123]$. These inflammatory monocytes are recruited to the CNS in a $\mathrm{C}-\mathrm{C}$ Motif Chemokine Ligand 2 (CCL2)- and very late antigen-4 (VLA-4)-dependent manner and exacerbate CNS injury through sustained production of NO $[122,123]$. Inhibiting monocyte infiltration into the brain with anti-CCL2 and anti-VLA-4 antibody blockade or inhibiting their inflammatory activation by inhibition of Nos 2 with aminoguanidine hemisulphate significantly increases survival in infected mice without altering viral titre $[122,123]$, strongly supporting the notion that 


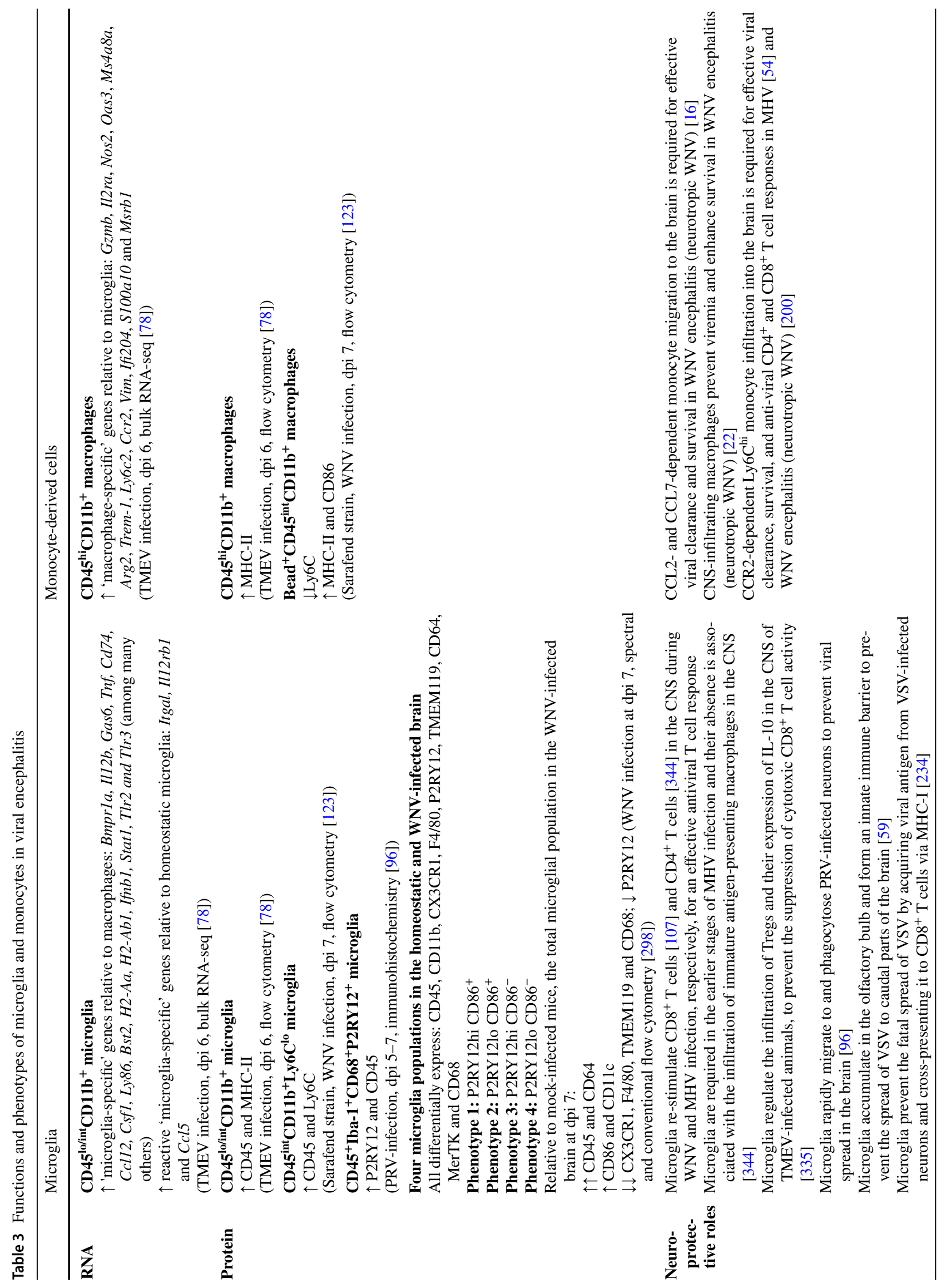


monocytes and MDMs mediate inflammatory damage in WNV infection.

The detrimental role of monocytes in the context of viral encephalitis is likely confined to the CNS parenchyma [122], as these cells play an essential and beneficial role in controlling WNV infection in the periphery prior to their infiltration into the CNS [73], although they also contribute to significant local tissue damage in the periphery in alphavirus infection [363]. This is consistent with studies showing that the reduction of monocytes into the CNS using CCR2-, CCL2-, and CCL7-deficient mice or in vivo clodronate liposome administration increased viral burden when virus was peripherally inoculated [16, $22,200]$. Upon entry into the infected brain, monocytes express MHC-II, CD80 and CD86 and have the capacity to present antigen and stimulate the proliferation of activated T cells [122] (Fig. 2), together supporting their role in inducing anti-viral $\mathrm{T}$ cell responses. It is possible that a detrimental or beneficial response of monocyte-derived cells in WNV encephalitis depends on the virus strain, dose, and route of inoculation. However, considering their relatively late arrival into the CNS parenchyma [122], whether these cells contribute to WNV clearance in the brain is still unclear.

\section{Potential role of monocytes in seizure development}

The recruitment of monocytes into the CNS following infection with TMEV is also thought to significantly contribute to hippocampal neurodegeneration [155] and seizure development during viral encephalitis [70, 334]. This pathological role is emphasized by studies demonstrating that the in vivo depletion of myeloid cells with anti-Gr-1 antibody or with anti-inflammatory agents, wogonin and minocycline, preserved cognitive functions and reduced seizure incidence [70, 155, 334]. Although these studies attributed ameliorated disease signs to reduced monocyte trafficking into the brain, the findings are potentially confounded by non-specific depletion methods; thus, the participation of other cell types cannot be excluded. Using a different monocyte-depletion method with clodronate liposomes (which deplete phagocytes in the bloodstream, spleen, and BM [319-321]), seizure severity was improved but there was no amelioration in hippocampal neurodegeneration [334], suggesting the observed contribution of monocytes to pathology is dependent on the depletion method. Altogether, whether seizures originate innately in embryologically primed, infected neurons or exogenously from parenchymal or other infiltrating cell stimuli remains unclear $[70,120,122,123,155,334]$ and deciphering the functional roles of monocytes in viral 
encephalitis-induced seizures will require more precise investigation.

\section{Ischemic injury and repair}

Stroke, which can be generally divided into haemorrhagic stroke and ischemic stroke, accounts for approximately $10 \%$ of all deaths and $5 \%$ of all disability-adjusted life years worldwide [239]. Ischemic strokes are the most prevalent type of stroke [176], and they are caused by arterial occlusion, which is most commonly caused by large vessel atherosclerosis and plaque rupture, cardioembolism, and small vessel disease (typically linked to hypertension) $[176,330]$. In general, however, ischemic stroke is a clinically heterogeneous condition determined by the degree, duration, and location of ischemia, as well as age, sex, and multi-medication comorbidities [290]. Although rodent models may reproduce the consequences of an ischemic insult, they often fail to recreate the complex pathophysiology that leads to an endogenous stroke [208].

\section{Relevance of murine models to human ischemic stroke}

Animal models of ischemic stroke carry significant limitations in replicating the aetiology and time course of human disease. Many researchers have attempted to model disease pathogenesis in young, healthy male rodents $[51,83$, 208], despite the fact that ischemic stroke is most prevalent in older individuals [24, 95] and is strongly linked to systemic diseases, such as hypertension, hypercholesterolemia, obesity, and diabetes mellitus [14]. With the exception of thromboembolic clot models [290], these models also fail to replicate the delayed spontaneous reperfusion reported in $17 \%$ of human thromboembolic strokes [175]. While the sequence of events following cerebral ischemia is similar in humans and rodents, the kinetics of this response also vary substantially [154]. This impacts the therapeutic window for reversible ischemic damage [154], as well as the functional recovery period, which can span years in humans [47]. These discrepancies between stroke animal research and clinical practice have been identified as a leading cause of translational failures $[28,158]$, prompting significant reform in study design and experimental model selection in the field $[33,100$, 157, 207].

These limitations have recently been addressed by either inducing stroke in aged animals with pre-existing comorbidities (e.g., diabetes, hyperlipidemia, obesity, infection), reviewed in [217], or using animal models with risk factors that eventually result in spontaneous stroke (e.g., spontaneous hypertensive rat and stroke-prone spontaneously hypertensive rat) [92, 245]. Although these models more accurately mimic human ischemic stroke [290], they nonetheless recreate only individual aspects of this clinically heterogeneous disease [208]. Therefore, investigations attempting to generalize findings from isolated experimental models of ischemic stroke should be interpreted with extreme caution.

Nonetheless, animal models have been invaluable in understanding evolving brain injury following an ischemic insult [84]. Within minutes of blood flow interruption (15-20\% below baseline), irreversible cell death ensues, resulting in the formation of an infarct core [85]. The penumbra, or non-functional tissue around the infarct core, may recover; however, if blood flow is not restored, this "atrisk" tissue will be incorporated into the infarct core [13, 305]. Infarcts often continue to expand even after blood flow is restored to the occluded region, in the process of ischemia-reperfusion injury [244].

The sequence of events following an ischemic injury and involvement of resident and peripheral immune cells is remarkably similar between human disease and its experimental models. Examination of post-mortem human stroke lesions demonstrates that inflammation begins early after ischemic insult [223] and the surrounding penumbral tissue is rapidly surrounded by 'activated' microglia [90]. This inflammatory response is associated with the release of damage-associated molecular patterns (DAMPs) from injured neurons, BBB breakdown, and infiltration of peripheral immune cells, including monocytes and neutrophils, into the ipsilateral hemisphere [90], with macrophages, mononuclear cells, and perivascular cuffing present in $75 \%, 44 \%$, and $42 \%$ of human brains with ischemic infarcts, respectively [223]. Although infiltrating immune cells may act in concert with resident cells to initiate debris clearance and tissue repair processes [369], acute inflammation may persist and transform into chronic, non-resolving inflammation. Inflammatory mononuclear cells and macrophages may persist for up to 53 years following the initial ischemic insult [223] and are often present in chronic lesions (Fig. 1b). Aberrant acute inflammation may also contribute to secondary injury, aggravating tissue damage and increasing lesion volume [160]. As a result, the neuroinflammatory response to ischemic injury is a critical determinant of brain damage and neurological recovery following a stroke. Despite variations in the kinetics the inflammatory response underlying this process [171], animal models show cross-species parallels in the immune response to ischemic injury. 
Fig. 3 Roles of monocytes and microglia in ischemic stroke. In stroke, microglia migrate towards neurons with high intracellular calcium levels to reduce excitotoxicity and neuronal damage. Microglia also prevent bystander tissue damage by inhibiting reactive astrocytes and phagocytosing infiltrating neutrophils. $\mathrm{CXCR}^{+}$MDM are recruited to the site of injury, where they produce microglia-activating mediators, IL- $1 \beta$ and ROS, and stimulate microglia proliferation and the glial scar formation. These inflammatory mediators may also injure neurons and contribute to secondary damage. CNS-infiltrating Ly6C ${ }^{\text {hi }}$ monocytes may also help repair the damaged BBB via the production of collagen- 4 and TGF- $\beta 1$. BBB, blood-brain barrier; CXCR4, CXC chemokine receptor type 4; CXCL12, CXC Motif Chemokine Ligand 12; IL, interleukin; MDM, monocyte-derived macrophage; ROS, reactive oxygen species; TGF- $\beta 1$, transforming growth factor beta 1

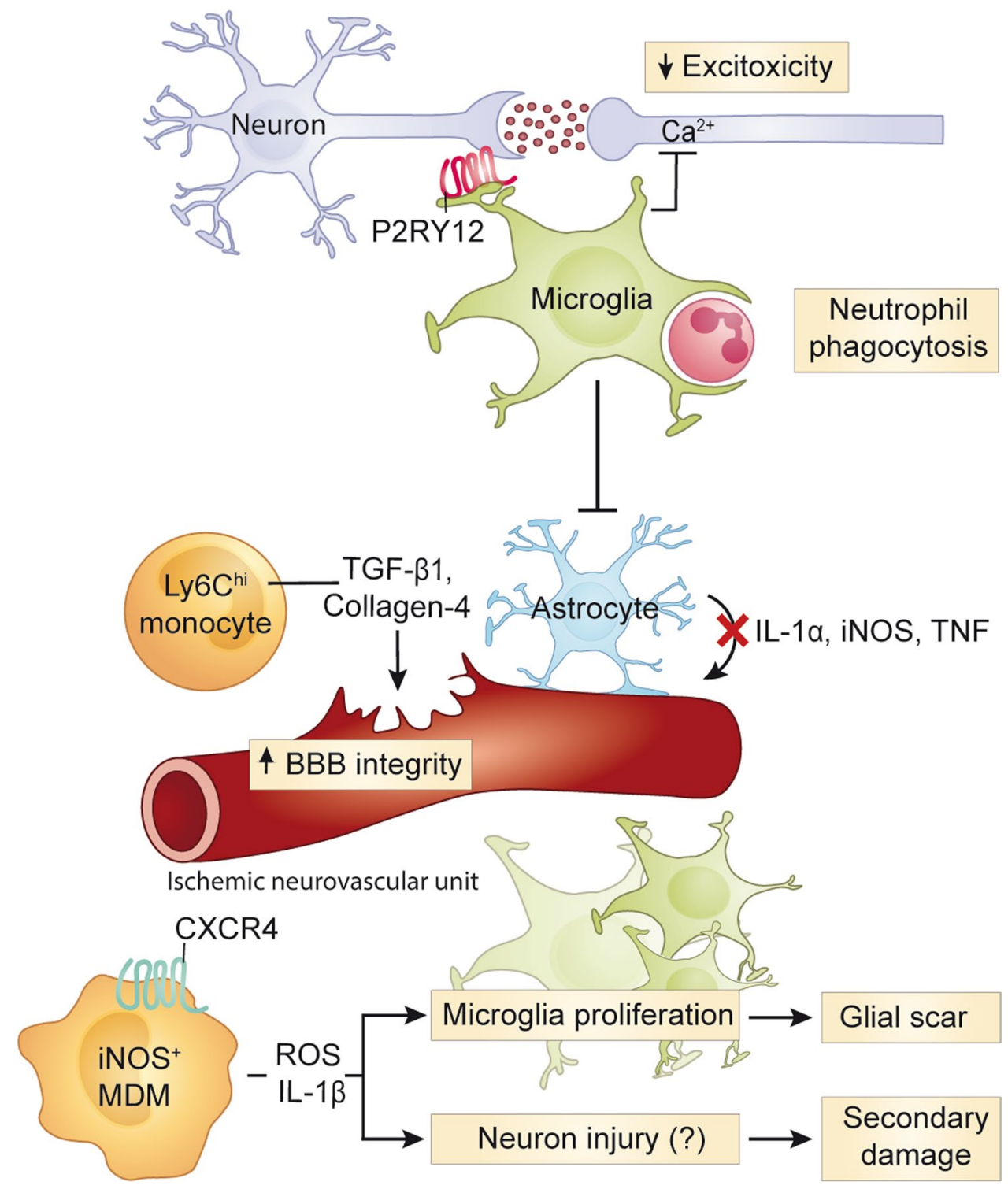

\section{Microglia in stroke}

\section{Microglial modulation of dysfunctional CNS cellular responses in stroke}

The roles of microglia in the early stages of ischemic injury have been largely elucidated by experimental models of ischemic stroke induced by middle cerebral artery occlusion (MCAO), which generates reproducible infarcts in the middle cerebral artery region and allows reperfusion after removal of the occluding filament (i.e., transient MCAO). Although blood flow restoration in transient MCAO does not accurately depict spontaneous reperfusion in human stroke, it is a better representation of mechanical thrombectomy or thrombolysis in the human than endogenous stroke [208]. In models of transient or permanent cerebral ischemia induced by MCAO, microglial depletion increased infarct size and worsened disease outcome, suggesting that microglia play a beneficial role in the early phases of stroke. Studies have suggested that this protective role may include direct cell interactions with surrounding parenchymal cells, resulting in the containment and/or prevention of dysregulated neuron [117], neutrophil [248] and astrocyte [172] responses that occur following ischemic insult (Fig. 3).

Experimental microglia depletion in animals has provided insight into the immune processes that protect against secondary injury, which may also underlie human disease. Two MCAO studies found an increase in neuronal death and infarct size after microglia were depleted by continuous oral injection of PLX3397 starting three weeks before stroke induction $[117,172]$ (Table 4). Increased tissue damage was linked to increased intraneural calcium levels and excitotoxic injury in one study, suggesting that microglia may play a role in protecting neurons from injury associated 


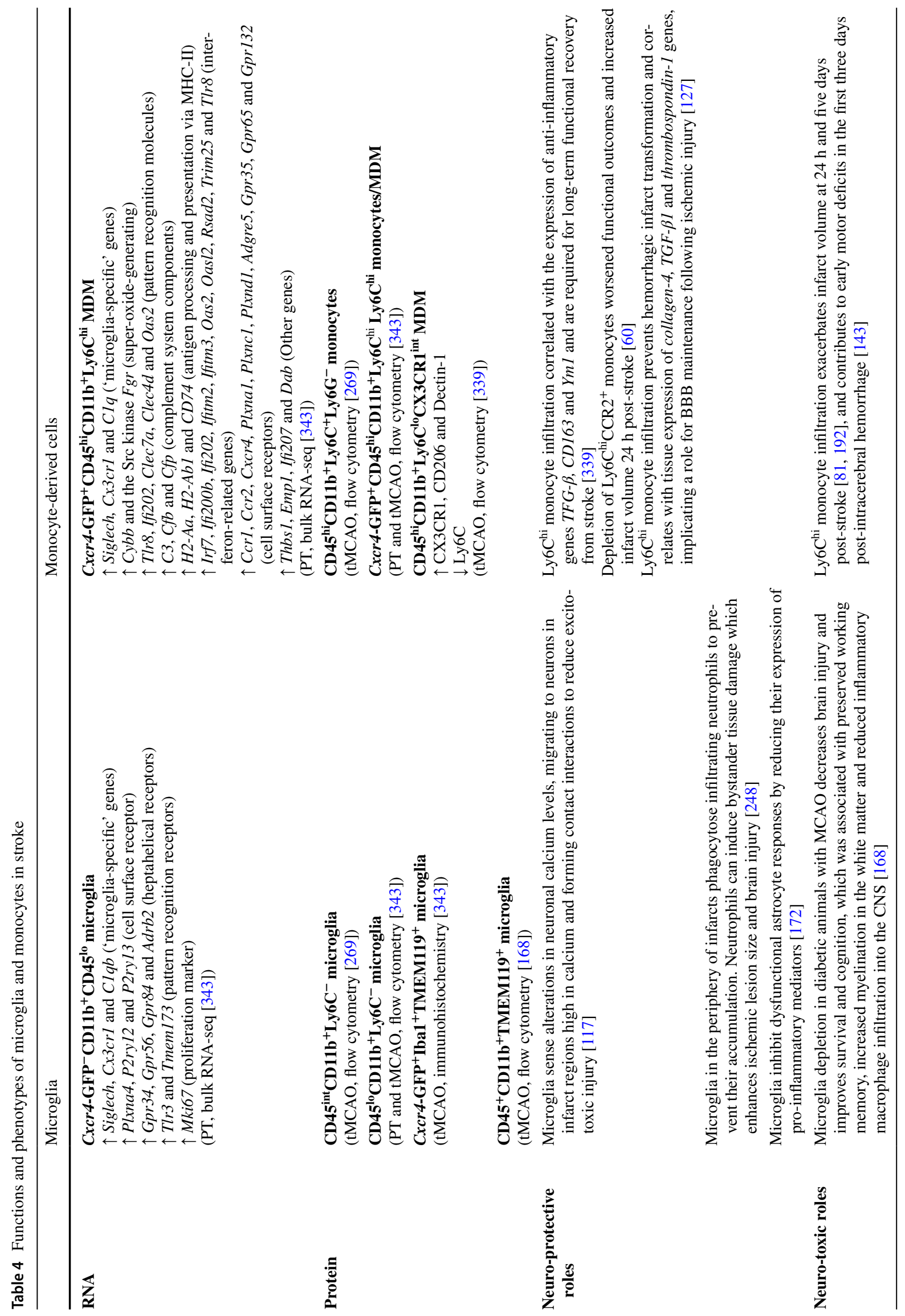


Table 5 Functions and phenotypes of microglia in Alzheimer's disease

RNA Three microglia phenotypes. All express: Hexb and Cst 3

'Homeostatic' phenotype: Cx3crl, P2ry12, Tmem119, Hexb, Cst3, Cx3crl, Ctsd, Csf1r, Ctss, Sparc, Tmsb4x, P2ry12, P2ry13,

$C l q a$ and $C l q b$

TREM-2-independent, 'intermediate state' microglia phenotype:

$\uparrow$ Tyrobp, Apoe, B2m, Ctsd, Ctsb, Fth1 and Lyz2

$\downarrow$ Cx3cr1, P2ry12, P2ry13 and Tmem119

TREM-2 dependent, damage-associated microglia (DAM) phenotype:

$\uparrow \uparrow$ Tyrobp, Apoe, B2m, Ctsd, Ctsb, Fth1 and Lyz2

$\uparrow$ Cst7, Lpl, Trem2, Axl, Cstsl, Cd9, Csf1, Ccl6, Itgax, Clec7a, Lilrb4 and Timp2

$\downarrow \downarrow C x 3 c r 1, P 2 r y 12, P 2 r y 13$ and Tmem119

(5xFAD at 3 and 8 months, single-cell RNA-seq [179])

Microglia neurodegenerative phenotype (MGnD)

$\downarrow \downarrow$ P2ry12, Tmem119, Gpr34, Jun, Olfml3, Csf1r, Hexb, Mertk, Rhob, Cx3cr1, Tgfbr1, Tgfb1, Mef2a, Mafb, Jun, Sall1 and Egr1

('homeostatic' genes)

$\uparrow$ Spp1, Itgax, Axl, Lilrb4, Clec7a, Ccl2, Csf1 and Apoe ('inflammatory' genes)

(APP-PS1 at 7, 10 and 17 months. MGnD is also seen in ALS (SOD1 ${ }^{\mathrm{G} 93 \AA}$ mice) and in MS (acute EAE), single-cell RNA-seq [191])

Protein Three microglia phenotypes:

Phenotype 1: Clec $7 \mathrm{a}^{-} \mathrm{P} 2 \mathrm{ry} 12^{+}$(not associated with $\mathrm{A} \beta$ plaques)

Phenotype 2: $\mathrm{Clec} 7 \mathrm{a}^{\text {lo }} \mathrm{P} 2 \mathrm{ry} 12^{\text {lo }}$ (in close proximity to $\mathrm{A} \beta$ plaques)

Phenotype 3: $\mathrm{Clec}^{+} \mathrm{a}^{+} \mathrm{P} 2 \mathrm{ry} 12^{-}$

Transition from Clec $7 \mathrm{a}^{-}$to $\mathrm{Clec} 7 \mathrm{a}^{\text {int }}$ to Clec $7 \mathrm{a}^{\text {hi }}$ correlated with increased mRNA expression of Apoe and suppression of homeostatic molecules

(APP-PS1, immunohistochemistry [191])

Three FCRLS ${ }^{+}$CD11b $^{+}$microglia phenotypes:

Phenotype 1: $\mathrm{Clec}^{-} \mathrm{a}^{-}$

Phenotype 2: $\mathrm{Clec} 7 \mathrm{a}^{\text {int }}$

Phenotype 3: $\mathrm{Clec} 7 \mathrm{a}^{+}$

(APP-PS1, flow cytometry [191])

Iba- $^{+}$CD11 $^{+}$TIMP2 $^{+}$microglia

Co-localized with $\mathrm{A} \beta^{+}, C s f 1$ and $L p l$

(5xFAD, immunohistochemistry \& smFISH ${ }^{\mathrm{a}}$ [179])

Neuro- $\quad$ Microglia encircle A $\beta$ plaques to prevent further growth and dissemination into the parenchyma [63], reducing damage to local protective neurites [295]

roles Microglia may contribute to the phagocytic and enzymatic clearance of the A $\beta$ plaque deposits [82]

TREM 2 expressed by damage-associated microglia is thought to directly recognise A $\beta$ to enhance engulfment and lysosomal degradation of the protein $[338,357,366]$

TREM2-dependent microglia functions are required to prevent seeding of plaques earlier in $\mathrm{AD}$, whilst later on enhance the consolidation of $\mathrm{A} \beta$ into highly compact plaques [222]

Neuro- $\quad$ Microglia cause synapse and neuronal damage, injury, or loss, resulting in memory loss and cognitive decline [152, 284, 291,

toxic 294-296]

roles Microglia contribute to the formation and growth of A $\beta$ plaques [294, 295]

Microglial secretion of tau-laden exosomes help seed and spread tau aggregates throughout the CNS [12, 61]

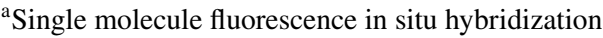

with high intracellular calcium levels [117] (Fig. 3). Importantly, the increased infarct damage did not occur if microglia were allowed to repopulate by removal of PLX3397 before stroke induction, thus emphasising their protective role in stroke. Microglia rapidly migrated to infarct sites and formed contact interactions with neurons with high intracellular calcium levels, likely reducing excitotoxic damage. At the interface between microglia and neurons, the purinergic receptor P2RY12 was highly expressed. P2RY12 is considered a homeostatic microglia marker because of its downregulation in neurogenerative and neuroinflammatory models, including amyotrophic lateral sclerosis, AD (Table 5) and MS (Table 6) [174, 179, 191, 214], which have been more extensively investigated than encephalitis (Table 3) and stroke (Table 4). Considering P2RY12 is upregulated by microglia in stroke [117] and is required for the control of viral spread in PRV encephalitis [96], it may not be a general homeostatic microglia marker as currently proposed. The transcriptomes and proteomes of microglia and MC in viral encephalitis, stroke, AD and MS are listed in Tables 3, $4,5,6$, respectively.

In a different MCAO study, enhanced brain injury in the absence of microglia was associated with an increased production of pro-inflammatory mediators by astrocytes (IL-1 $\alpha$, 


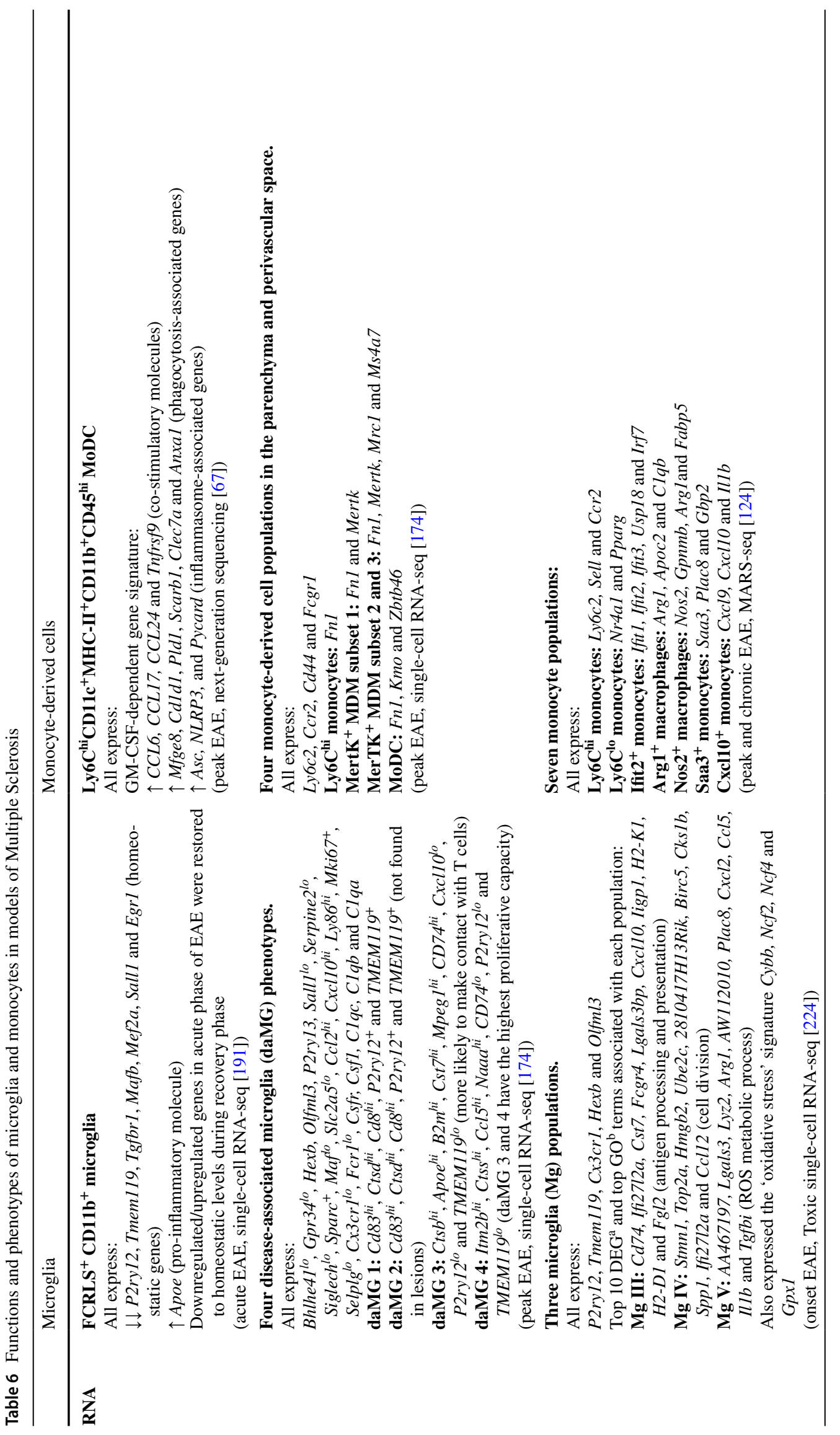




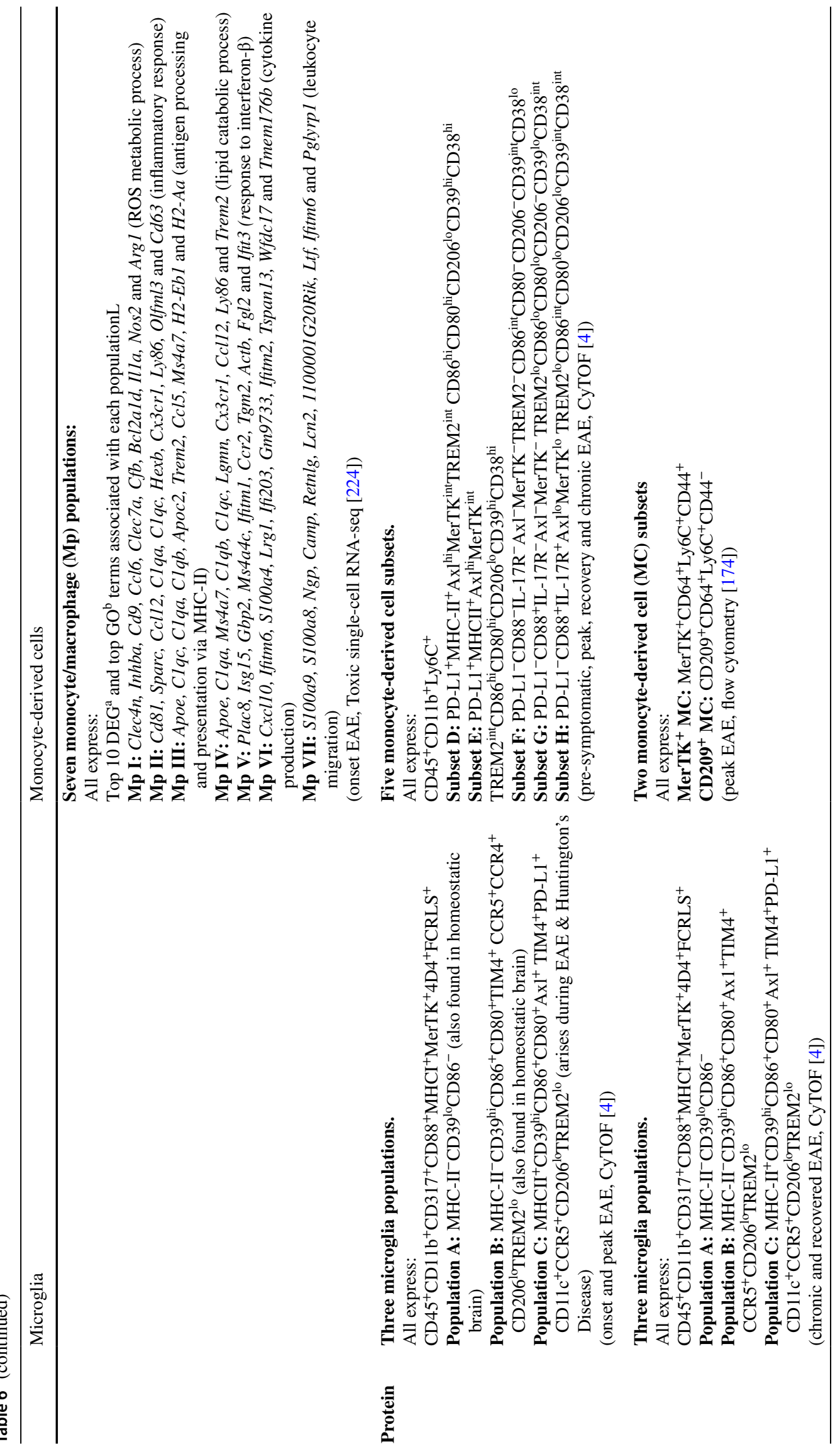




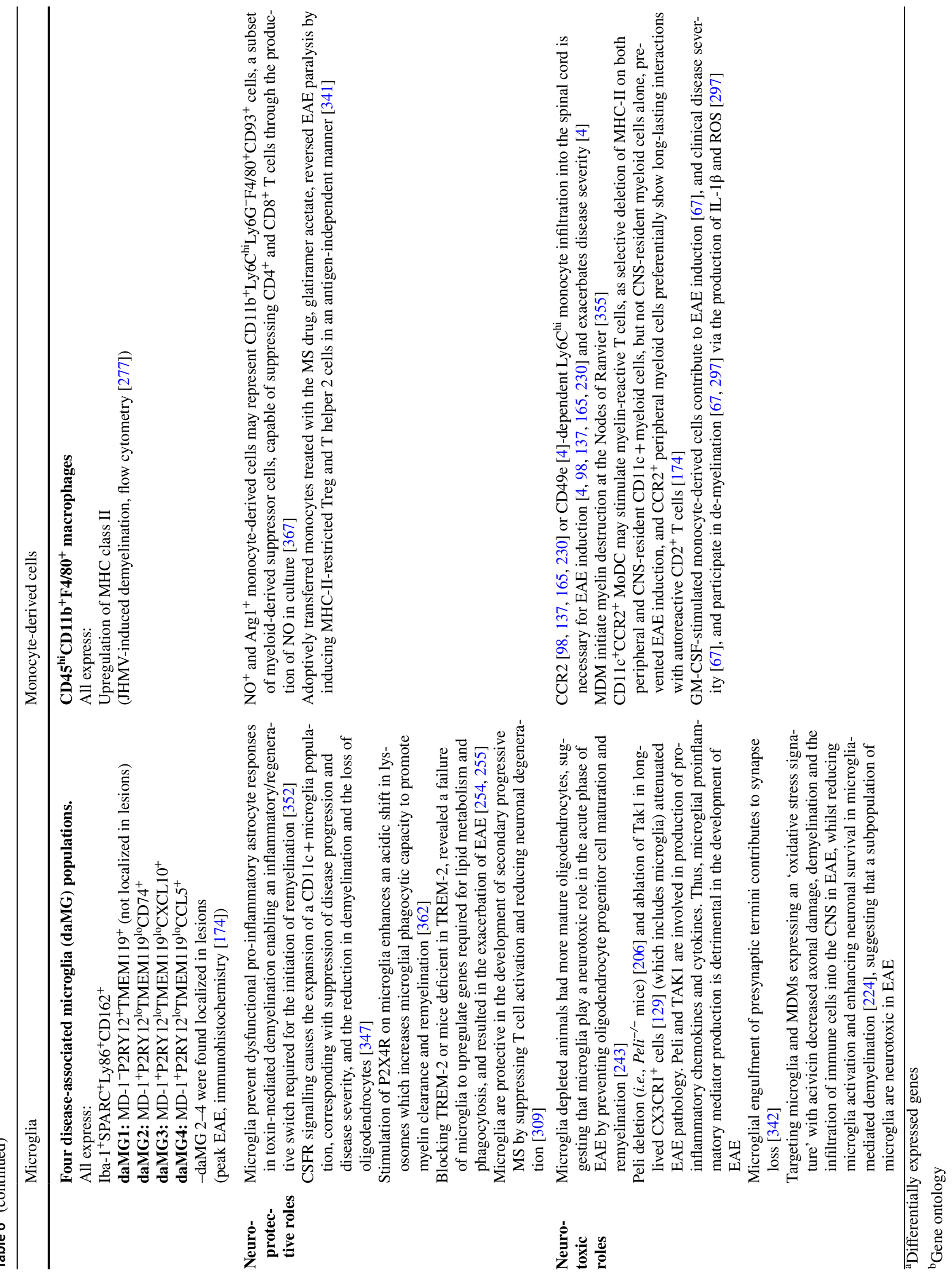


IL-1 $\beta$, iNOS, IL-6 and TNF), implicating a role for microglia in inhibiting dysfunctional astrocyte responses [172] (Fig. 3 and Table 4). Moreover, after PLX3397-mediated microglia depletion, MCAO in either $\mathrm{Rag}^{---} \mathrm{\gamma c}^{-/-}$mice (which lack T, B, Natural Killer and Natural Killer T cells), or in mice treated with Bindarit (which inhibits CCL2-mediated monocyte infiltration) resulted in enhanced infarct injury compared to mice without PLX3397, emphasizing that the absence of microglia, rather than the presence of a particular infiltrating immune cell type, exacerbates brain injury [172].

Besides the described protective interactions with astrocytes and neurons, microglia also exert beneficial functions in the brain by phagocytosing infiltrating neutrophils, thereby preventing their pathogenic accumulation and subsequent damage to the surrounding tissues and vasculature [248]. Indeed, inhibition or genetic deletion of neutrophil elastase, blocking neutrophil recruitment and/or infiltration, or inhibiting neutrophil-derived matrix metalloproteinase-9, all reduce lesion progression [170, 218, 248, 301]. Accordingly, depletion of microglia before stroke induction increased neutrophil numbers in the CNS and exacerbated tissue damage [248]. Thus, microglia crucially minimise pathogenic neutrophil accumulation to limit ongoing secondary oxidative damage of surrounding re-perfused vasculature and brain tissue [248] (Fig. 3 and Table 4).

However, the beneficial roles played by microglia after ischemic stroke are mostly based on studies in young mice, which do not reflect changes in the aging immune system that would occur in the majority of stroke patients. Studies investigating these age-related changes in the immune responses to MCAO have demonstrated that, although older and young mice have a similar inflammatory response profile, the magnitude of this response differs considerably [9]. Given that aging microglia exhibit greater inflammatory alterations [292], it is possible that these cells carry out deleterious immune responses following ischemic injury that are not evident in young animals.

\section{Pathogenic role of microglia in the context of diabetes co-morbidity}

Importantly, approximately $70 \%$ of stroke patients have pre-existing conditions, such as diabetes and high blood pressure, with diabetes being associated with significantly worsened recovery and post-stroke cognitive impairment $[168,315]$. To study the link between microglia, stroke, and diabetes, Jackson et al. [168] used an intracerebroventricular injection of short hairpin RNA to silence $C s f r 1$ and ablate microglia prior to the induction of stroke via transient MCAO in young mice with diet and streptozotocin-induced type 2 diabetes mellitus [168]. It is known that an increased ratio of pro- to anti-inflammatory microglia in diabetic animals correlates with the development of post-stroke cognitive impairment [167]. In contrast to studies in mice without comorbidities, microglial depletion in diabetic animals decreased ischemia-mediated brain injury (Table 4), indicating a diminished protective role of microglia in diabetes [168]. This study emphasizes the importance of pre-existing co-morbidities in both understanding the role of microglia in stroke pathology and the potential translation of microgliatargeted treatments for this disease. Microglia studies in older mice with diabetes or other systemic cerebrovascular illnesses, such as hypertension or atherosclerosis, are critical for translating these findings to clinical practice, as the majority of ischemic strokes occur in older individuals [24, 95] with underlying cerebrovascular disease [14].

\section{Monocytes in stroke}

\section{Monocyte contribution to tissue damage and repair}

The immune response to ischemic injury critically involves the infiltration of peripheral immune cells, including monocytes and neutrophils $[116,171]$. Monocyte activation has a significant impact on disease outcome following CNS injury, in particular, the secondary damage following ischemic stroke. The differential protective or pathogenic roles of monocytes in experimental models of ischemic stroke, as well as their associated phenotypes, are compared in Table 4.

In response to ischemic injury, infiltrating monocytes may adopt functional phenotypes facilitating debris clearance, wound healing, and tissue repair (i.e., pro-resolution phenotypes) [360]. However, these cells may also adopt a pro-inflammatory phenotype whose sustained production of inflammatory mediators risks secondary damage to surviving tissue. Following ischemic injury and haemorrhagic stroke, for instance, monocytes recruited to the injured brain cause inflammatory damage and functional impairment via their sustained production of TNF and IL-1 $\beta$ [81, $143,192,269]$. The pathological role of these cells is further emphasized by studies in CCR2-deficient mice in which the reduced monocyte influx into the injured brain substantially reduces inflammation and secondary damage [81, 192]. However, the same cells subsequently contribute to tissue repair. In CCR2-deficient mice or following early monocyte depletion by clodronate liposomes in stroke, the resultant reduced expression of tissue repair proteins, including TGF- $\beta 1$ and collagen- 4 , was associated with neurovascular unit instability and later haemorrhagic transformation [127], demonstrating the importance of these cells in healing after stroke.

Thus, although a pro-inflammatory monocyte phenotype is thought to contribute to secondary damage, this functional specification can also activate immune system processes involved in wound healing and tissue repair 
[360]. This may involve other cell types. For instance, microglial activation and proliferation is necessary in the formation of a glial scar around injured tissue [271]. Using two experimental models of ischemic stroke (photothrombosis and transient MCAO), it was recently suggested that monocytes expressing inflammatory mediators IL- $1 \beta$ and $C y b b$-derived reactive oxygen species (ROS) facilitated microglial proliferation and enhanced wound healing [343]. This damaging phenotype was, however tightly regulated. Following their initial pro-inflammatory activity, monocytes were physically enclosed in a glial scar facilitated by chemotactic CXCR4-CXCL12 signalling, thereby limiting monocyte-driven secondary injury [343]. Notably, the tissue infiltration patterns of monocytes and microglia differed among stroke models, potentially suggesting that multiple experimental models are necessary to fully comprehend the activities of these two cell types in disease. Nonetheless, the beneficial outcome of myeloidmediated inflammation in these ischemic stroke models contrasts with that of experimental models of MS or viral encephalitis, where a sustained oxidative stress phenotype is detrimental [122, 224], and points towards the importance of local regulatory mechanisms in preventing aberrant inflammatory damage.

The seemingly paradoxical protective and pathogenic functions of monocytes may be further explained by the recruitment of multiple populations that differentially contribute to damage and repair as monocytes. Such populations may be differentially recruited to the site of ischemic injury in a manner similar to that occurring in mechanical injury: following mechanical spinal cord injury, 'protective' proresolution monocytes ( $\mathrm{Ly} 6 \mathrm{C}^{\mathrm{lo}} \mathrm{CX} 3 \mathrm{CR} 1^{\text {hi }}$ ) were thought to gain access to the CNS from the choroid plexus and migrate to the injured spinal cord parenchyma through the central canal, whereas detrimental pro-inflammatory monocytes $\left(\mathrm{Ly}_{6 \mathrm{C}}{ }^{\text {hi }} \mathrm{CCR} 2^{+}\right.$) were proposed to transmigrate via the spinal cord leptomeninges in a CCL2-dependent manner [281]. The differential expression of Ly6C may underlie these differences, as high expression of Ly6C would better enable the emigration of inflammatory cells from the CNS leptomeningeal vasculature [310]. CNS region-specific signals may also shape their eventual functions within the CNS, with those trafficking through the choroid plexus and cerebrospinal fluid encountering stimuli that shape more anti-inflammatory roles [281]. Whether these CNS environments shape distinct cellular functions of infiltrating cells following stroke warrants further investigation. Indeed, in other disease models such as EAE, it is evident that the cytokine milieu in the choroid plexus shapes the pro- or anti-inflammatory specification of infiltrating monocytes [164].

It is crucial to remember that inflammation can be both harmful and beneficial to recovery from ischemic injury, and that any therapeutic window may be limited to a specific time period when inflammation is pathogenic. Although this therapeutic window is well-defined experimentally [171], the time course of lesion evolution is protracted in humans and complicated by recurrent ischemic episodes and systemic co-morbidities [223]. The roles, phenotypes, and transcriptomic profiles of both microglia and monocytes in animal models that better re-create the disease co-morbidities that lead to, and modulate the immune response to, ischemic stroke are therefore critically needed.

\section{Neurodegeneration}

Alzheimer's disease is a chronic neurodegenerative disease causing progressive and irreversible cognitive decline. Disease onset can occur at $<65$ (familial early-onset) or $>65$ years of age (sporadic late-onset), with the latter afflicting more than $95 \%$ of patients [87, 213]. Histopathologically, AD is characterized by the formation of intraneuronal neurofibrillary tangles consisting of the hyperphosphorylated microtubule protein, tau, and extracellular deposits of plaques of amyloid- $\beta$ (A $\beta)$, a breakdown product of the transmembrane amyloid precursor protein (APP) [241]. A transgenic system that reproduces either of these two characteristic AD pathologies is the most common approach to modelling AD in mice. In transgenic mouse models, $A \beta$ plaques are generally generated by mice overexpressing five human familial $\mathrm{AD}$ gene mutations (i.e., 5xFAD mice) or the APP-presenilin 1 gene (i.e., APPPS1 mice) [142]. Tauopathy is generally modelled in mice over-expressing human transgenic tau. However, these animal models do not reflect the entire biology of human AD, which presents inherent limitations to the translation of laboratory findings into a clinically relevant setting.

\section{Relevance of murine models to human AD}

Modelling all aspects of AD pathology in an experimental animal setting is difficult. This can be attributed in part to (1) the disease being unique to humans, as far as we know, (2) the multifactorial nature of AD having both genetic and environmental etiologies, and (3) the high variability in disease onset, development and progression among patients [86].

Currently, transgenic mouse lines are the most common experimental model for $\mathrm{AD}$, despite each only recapitulating one or few aspects of the human pathology. These transgenic mice express human genes that result in the formation of amyloid plaques (APP or PSEN1) and/or neurofibrillary tangles (MAPT), with other aspects of human pathology incompletely represented, such as memoryassociated cognitive impairments, contribution of aging, 
neuronal loss, widespread neurodegeneration and regional brain atrophy [86, 325]. It is thus little wonder that the success rate of drugs that have gone through clinical trials from 2002 to 2012 show a high failure rate ( 99.6\%) [69]. In 2020, there was $\sim 40$-fold and $\sim$ threefold decrease, respectively, in the number of drugs in development for $\mathrm{AD}$, compared to those in development for malignant neoplasms and diabetes [68]. The high failure rate of agents in clinical trials and relatively limited drug development for AD reflect the biological disconnect and thus restricted translatability between mouse models and human pathology. This is further exacerbated by the limited availability of human biomarkers, longer trial durations and prohibitively high trial costs $[68,86,102]$. Also feeding into this is the fact that mouse models are largely based on the expression of mutations associated with familial early-onset $\mathrm{AD}$, while drugs tested in clinical trials are mainly in patients with sporadic late-onset form of AD. It follows that conclusions based on the interpretation of, and extrapolation from mouse findings should be carefully contextualized and made with caution. However, importantly, notwithstanding their limitations, mouse models have provided substantial insight into the contribution of specific features (i.e., amyloid or tau) in the pathogenesis of AD. Thus, understanding the precise limitations of each model is necessary to better translate laboratory findings into clinically relevant settings.

However, with the increasing incidence of $\mathrm{AD}$ and with it the increased estimated global expenditure needed for $\mathrm{AD}$ care, there is an urgent need to develop models that better reflect the human disease and inform effective preventive and interventive treatment [258]. Improved models of AD are underway. These include the use of primates [276], brain organoids [249] and further transgenic mouse lines. To support this, the National Institutes of Health established the Model Organism Development \& Evaluation for Late-Onset Alzheimer's Disease consortium with the aim of developing 50 new rodent models based on human datasets and that better reflect $\mathrm{AD}$ pathology, with all data generated being publicly available.

\section{Microglia in Alzheimer's disease}

In 1908, Alois Alzheimer argued that microglia were implicated in the pathogenesis of $\mathrm{AD}$, based on observations of altered cell morphology in CNS tissue from patients [7]. Changes in microglia/macrophage morphology and density have been further linked to a variety of neurodegenerative illnesses, including Parkinson's disease (Fig. 1c) and amyotrophic lateral sclerosis (Fig. 1d-f), in addition to $\mathrm{AD}$ (Fig. 1g-i). The likely involvement of microglia in AD pathology, however, was not fully appreciated until the development of genome-wide association studies. This revealed that $60.4 \%$ of AD-risk single-nucleotide polymorphisms are highly expressed by microglia [212, 364], including Apoe, Trem2, Abca7, Cd33 and Crl [221]. More recently, single nuclei RNA sequencing on AD brains showed that out of seven cell types, gene expression changes were shown only in microglia [119]. Given the demonstrable link between microglia-expressed genes and AD, many studies have attempted to elucidate their precise functions in this disease using murine models, although remarkably, genetic studies have implicated microglia in almost every defined neurodegenerative disorder [221].

\section{Role of DAMPs and microglia in promoting low-grade inflammation and neurodegeneration}

While DAMPs are thought to be beneficial in acute inflammation by protecting the CNS from pathogen evasion and tissue damage [178], in AD, the chronic release of DAMPs, mitochondrial-released DAMPs and pro-inflammatory molecules contributes to the onset and progression of neurodegeneration [57, 76, 97, 149, 194, 270, 304, 333, 345]. The underlying mechanism likely involves the binding of these molecules to microglia-expressed receptors, causing self-perpetuating microglial activation with sustained release of pro-inflammatory mediators. This is thought to divert microglia from performing house-keeping functions, promoting a low-grade inflammatory state and CNS damage $[149,333]$. Collateral damage to proximal neurons perpetuates this cycle via the further release of DAMPs [57] and potentially the progression of neurodegeneration. Indeed, the DAMP, high-mobility-group box protein 1 is elevated in the sera of $A D$ patients and correlates with levels of $A \beta$ in the CNS [97]. Notably, microglial-expressed Mac-1, a potential receptor for high-mobility-group box protein 1 , is increased in expression in AD brains [5] with ligand-receptor binding resulting in the production ROS and pro-inflammatory molecules [110]. This suggests a role for this DAMP in perpetuating chronic inflammatory signalling in the CNS and the progression of $\mathrm{AD}$ [57].

It is unclear what causes the initial release of these molecules, which sustains a low-grade inflammatory response in the brain. However, studies have shown that cellular aging, infection, traumatic brain injury, systemic inflammation, chronic inflammatory diseases, obesity and poor oral health occurring during middle adulthood can lead to increased pro-inflammatory signals in the periphery, which may contribute to glial activation and the onset and/or perpetuation of neurodegeneration [93, 105, 149, 333]. Indeed, lipopolysaccharide (a major gram negative bacterial cell wall component)-induced inflammation in mice with amyloidosis or tauopathy increased neuropathology [187, 283]. Targeting neuroinflammatory processes and the activation of 


\section{a \\ Protective}

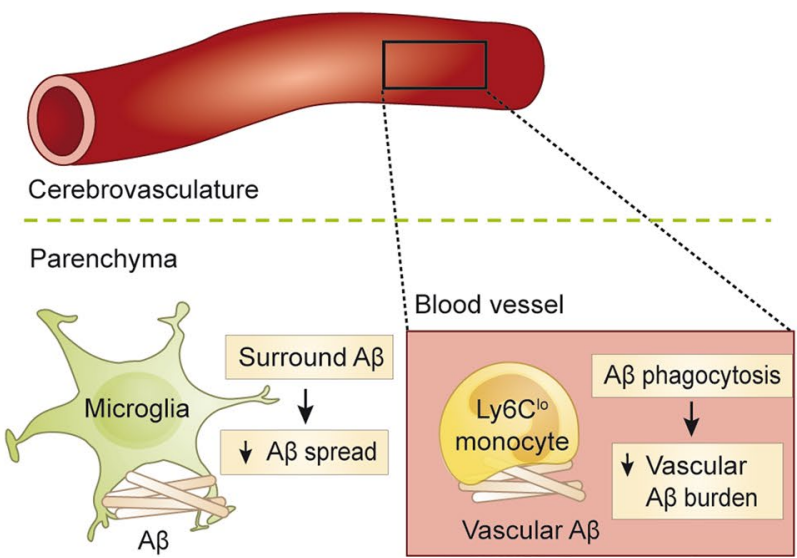

Fig. 4 Protective and pathogenic roles of monocytes and microglia in neurodegeneration. a Protective functions. In AD, microglia and $\mathrm{Ly} 6 \mathrm{C}^{\mathrm{lo}}$ monocytes reduce parenchymal and vascular $\mathrm{A} \beta$ spread, respectively. b Pathogenic functions. Microglia phagocytose C3-tagged synaptic termini via C3R, leading to neurodegeneration

innate immune responses which are paradoxically protective in acute inflammatory scenarios may provide a necessary therapeutic approach to AD.

\section{Role of microglia in the formation and clearance of $A \beta$ plaques}

Both in human $\mathrm{AD}$ and its mouse models, microglia surround $\mathrm{A} \beta$ plaques [216, 226, 365]. Although more human studies are required, the local function of these cells appears to be bidirectional, with microglia having both protective and pathological functions. Microglia are thought to contribute to the formation of plaques while also compacting and clearing $A \beta$ deposits to prevent damage to neighboring neurites. See Table 5 for a comparison of the protective and pathogenic roles of microglia in $\mathrm{AD}$, as well as their diseaseassociated transcriptomes and immune profiles.

Microglia contribute to the phagocytic and enzymatic clearance of $A \beta$ plaques [82] in concert with resident perivascular macrophages $[311,356]$. These cells also have a role in compacting $A \beta$ to potentially prevent their spread and impact on local neurites. Indeed, microglia depletion in four-month-old humanized APP mutant knock-in homozygote $\left(\mathrm{APP}^{\mathrm{NL}-\mathrm{G}-\mathrm{F}}\right)$ mice resulted in reduced plaque compaction and increased plaque volume, number, and size, demonstrating that microglia play an essential role in plaque compaction between four to six months of age in mice [61]. The increased $A \beta$ burden with age suggests that microglia become senescent and are unable to phagocytose $A \beta$ or that

\section{b Pathogenic}

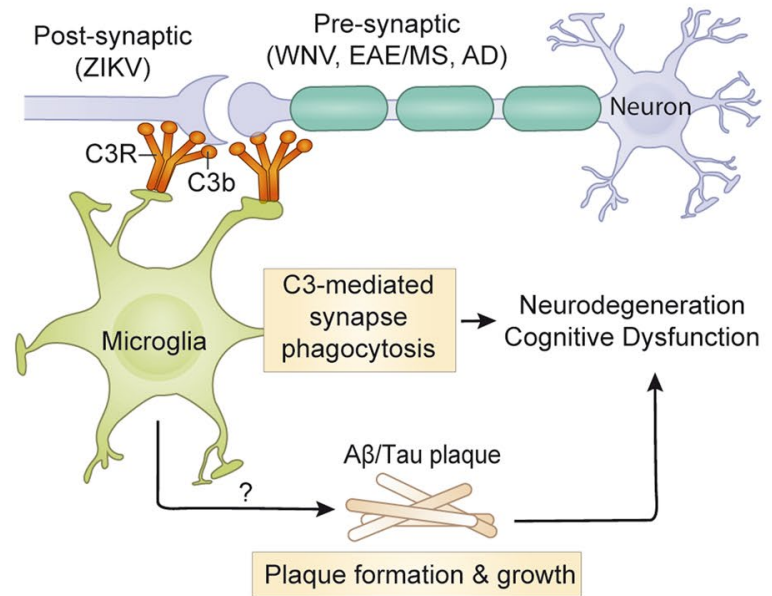

and cognitive dysfunction in post-infectious encephalitis, AD, EAE and MS. $A \beta$ amyloid beta; $A D$ Alzheimer's disease; $C 3$ complement component 3; $C 3 R$ complement component 3 receptor; $E A E$ experimental autoimmune encephalomyelitis; $M S$ multiple sclerosis; ZIKV Zika virus

their ability to do so becomes latent [101, 302]. Indeed, microglia ablation in AD mouse models at 10 months of age had no impact on plaque burden, suggesting that these cells are dispensable for $A \beta$ clearance and plaque formation in the late stage of disease [296]. To overcome this so-called latency, administration or expression of IFN- $\gamma$, TNF or IL-6 in the mouse CNS reduced $A \beta$ deposition [48-50], potentially stimulating microglial phagocytosis and clearance of $\mathrm{A} \beta$ from the brain.

In contrast to the protective roles of microglia in $\mathrm{AD}$, such as the clearance and compaction of $A \beta$, microglia can also contribute to A $\beta$ deposit formation early in disease. Microglial ablation using PLX3397 in two-monthold 5xFAD mice [294] or PLX5622 in 1.5-month-old 5xFAD [295] mice prevented intraneuronal amyloid and neuritic plaque formation [294] and significantly reduced plaque formation [295], respectively (Fig. 4 and Table 5). Ablation of microglia in younger mice before development of cerebral amyloidosis thus reduces $A \beta$ deposition [294], while ablation of microglia later in disease (i.e., in 10-month-old 5xFAD mice) [296], does not alter $A \beta$ load. Interestingly, a fraction of microglia in the thalamus were resistant to 10 weeks of PLX5622 treatment and were associated with the few plaques that had formed [295]. Thus, even a small number of microglial cells are sufficient to initiate plaque pathology. It has been suggested that microglial lysosomes provide a suitable environment for $A \beta$ aggregation. Indeed, $A \beta$ aggregates were found within the lysosomes of microglia in brain regions where plaques 
were not yet formed in non-PLX5622-treated 5xFAD mice [295]. However, $A \beta$ deposition can also be observed in regions of the brain devoid of microglia, including the dura mater, choroid plexus and perivascular space [71, 253], suggesting that microglia may not be the only cells contributing to $\mathrm{A} \beta$ plaque aggregation.

\section{Role of microglia in tau-related pathology}

It has recently been suggested that $\mathrm{AD}$ progression is better correlated with tau pathology, neuronal degeneration, $A \beta$ spreading and synapse loss, rather than $A \beta$ detection alone [222]. While the role of microglia in tau-related pathology is relatively understudied compared to their role in $A \beta$ formation and clearance [328], it has been suggested that microglia may also contribute to tau pathology. Microglial expression of pro-inflammatory mediators and release of extracellular vesicles have been shown to promote the pathological spread of tau.

Consistent with this, tau pathology was reduced by inhibiting microglial activation via overexpression of CX3CL1, a chemokine released by neurons that binds to microglialexpressed CX3CR1 [240] or by administration of antiinflammatory drugs [113]. Conversely, promoting microglia activation via lipopolysaccharide- or virus-induced inflammation promoted tau pathology [187, 304]. Fascinatingly, microglial activation can even induce tau accumulation in wild-type mice with no induced tauopathy [112], strongly supporting the importance of microglia-mediated inflammation in initiating tau pathology. Although the exact mechanisms that cause microglial activation are unknown, it is possible that the low-grade chronic inflammation (described above) that occurs in middle-aged individuals promotes neuroinflammation and the progression of tau pathology [57, 97, 194, 304, 333]. Tau oligomers and monomers can also activate NLRP3 inflammasomes, further perpetuating microglial activation [162] and potential progression of tau pathology. While more human studies are required, it is clear from murine models that microglia have an indirect role in promoting tau accumulation via expression of pro-inflammatory mediators.

Microglia have also been implicated in the pathological spreading of tau via the release of extracellular vesicles [12, $61,328]$. While human and microglia can internalise aggregated or hyperphosphorylated tau for protein degradation, they can also release incompletely degraded or un-neutralised forms back it into the extracellular space, promoting the spread of tau [12, 32, 36, 108, 153]. Indeed, depletion of microglia in mice injected with tau-expressing adeno-associated virus reduced tau propagation, which was hypothesized to occur by ablating microglial-mediated phagocytosis and subsequent re-secretion of tau-laden exosomes for the pathological spread and accumulation of tau.
To study the mechanistic link between microglial-mediated tau propagation and amyloid accumulation, microglia were depleted in $\mathrm{APP}^{\mathrm{NL}-\mathrm{G}-\mathrm{F}}$ mice injected with tau-expressing adeno-associated virus [61]. Intriguingly, microglia were shown to be three times as phagocytic and three times more likely to release tau-containing extracellular vesicles when situated near amyloid plaques [61]. This was associated with enhanced tau propagation in mice with amyloidosis, compared to wild-type mice without amyloidosis [61], highlighting the importance of studying both amyloid- and tau-related pathological features of AD in one model. Interestingly, microglia depletion had no effect on tau in aged mice [27]. This could suggest that microglia become senescent and cannot phagocytose tau, potentially leading to decreased extracellular vesicle production and tau spread. However, results from this study may have been confounded by incomplete microglial depletion, which was only 30\% [27].

Tau accumulation is frequently associated with synaptic loss. Microglia can phagocytose tau-laden synapses or entire neurons [36,75], promoting neurodegeneration and memory loss. As previously mentioned, microglial-expressed complement components, including $\mathrm{C} 1 \mathrm{q}$, are thought to bind to synapses and enable phagocytosis by microglia [75, 103]. While more investigation in the human is required to confirm microglial association with C1q-mediated tagging of synapses, in normal aging [300] and in tauopathy patients [75], $\mathrm{C} 1 \mathrm{q}$ is dramatically upregulated and is shown to co-localize with hyperphosphorylated tau, plaques and neurofibrillary tangles in AD brain sections [1, 219, 282]. Together, this work suggests that while microglia attempt to perform physiological functions, such as clearing pathological tau and $A \beta$ aggregates, these proteins may be incompletely degraded and re-secreted into the extracellular space to spread protein accumulation. These proteins can also bind microglial receptors, promoting pro-inflammatory signalling and diverting microglia from house-keeping functions, thereby causing a self-perpetuating chronic inflammatory response that induces further protein accumulation and tau seeding.

\section{The 'universal' neurodegenerative microglial phenotype}

Recent transcriptomic studies have identified a subset of microglia that adopt unique transcriptional and functional signatures, termed 'disease-associated microglia' (DAM) [179] or 'microglial neurodegenerative' (MGnD) phenotype during neurodegeneration [191]. These microglial signatures are characterised by the downregulation of homeostatic genes (P2ry12, Tmem1 19, Sall1 and Cx3crl) and upregulation of an inflammatory program (Trem2, Apoe, Axl, $\mathrm{Lpl}$ and $\mathrm{Clec} 7 a$ ) (Table 5), several of which have been identified in genome-wide association studies linked to human AD. The DAM phenotype has been proposed to represent a 
universal and intrinsic microglial response program to CNS disease, since it appears to be retained across a number of neurodegenerative and non-neurodegenerative diseases [74, 291]. However, it remains unclear if this intrinsic response program specifically identifies a functionally meaningful subset, and whether it is beneficial or detrimental to disease pathogenesis.

Several studies have suggested that the microglial DAM signature is protective in neurodegeneration. This has been highlighted by the importance of TREM2, a receptor expressed by DAM/MGnD, which exerts its protective function in $\mathrm{AD}$ via ligation of ApoE (apolipoprotein $\mathrm{E}$ ), which binds to loose $A \beta$ aggregates, or direct ligation of A $\beta$ oligomers [286, 295, 338, 357, 366]. This process enables lysosomal degradation and phagocytotic trimming of $\mathrm{A} \beta$ by surrounding microglia, which may be crucial to the compaction (but not removal) of developing $\mathrm{A} \beta$ deposits to protect neurons from injury (Table 5). Accordingly, AD patients carrying mutations in TREM2 genes display less compact $\mathrm{A} \beta$ plaques and fewer plaque-associated microglia but enhanced tau pathology and neuritic plaques [191, 361]. Similarly, in mice with cerebral amyloidosis, genetic ablation of TREM2 abrogated the MGnD phenotype and reduced the microglial response to plaques [191]. This supports a protective role for the $\mathrm{DAM} / \mathrm{MGnD}$ microglial phenotype, with TREM2-dependent functions potentially required initially to prevent seeding of plaques, whilst later enhancing the consolidation of $A \beta$ into compact aggregates to protect neurons from $A \beta$-induced injury. This protective function appears to be independent of other microglia-mediated functions which are detrimental to neurons, such as their contribution to synapse loss.

Other studies instead argue that the microglial DAM/ MGnD phenotype is damaging. It is known that homeostatic microglia support neuron maintenance [211,306]. Thus, the phenotypic transition observed in DAMs may harm neurons by causing low-grade inflammation and lowering neurotropic support, which may contribute to increased tau phosphorylation [82]. In support of this, gene expression analysis showed that pathways related to neuronal function (i.e., glutamate receptors, synaptic vesicles, and neuronal membranes), were downregulated in the hippocampus of $5 x F A D$ mice [295]. This pattern was reversed in the absence of microglia, suggesting that these cells restrict gene expression pathways crucial to neuronal function in AD [295]. Furthermore, complement activation, which is important for microglial phagocytosis, can exacerbate synaptic loss $[152,284,291]$ and contribute to memory loss and cognitive decline [75] (Table 5). Consequently, microglia depletion before or after the formation of $A \beta$ pathology in mouse models of AD resulted in improved contextual memory, further implicating microglia in neuronal and/or synaptic loss [294-296].
The ability of microglia to return to homeostasis during AD may be impaired by the downregulation of the microglial receptors CX3CR1 and CD200R, which bind to neuronal ligands and act as immune checkpoints that maintain microglia homeostasis [30]. Furthermore, DAM-expressed factors, such as apolipoprotein, colony-stimulating factor 1 (CSF1) and secreted phosphoprotein 1, act as autocrine ligands on DAM-expressed receptors, together sustaining and perpetuating the neurodegenerative phenotype [291]. Thus, both protective and pathogenic functions are likely to be carried out simultaneously by the DAM phenotype.

\section{Relevance of DAM/MGnD to human AD}

The importance of the DAM/MGnD phenotype must be more carefully considered in the context of human pathology. In contrast to mouse studies, single cell nuclei extraction from frozen human brain tissue revealed 13 distinct microglial clusters [119]. While a population of clusters, namely AD1, closely reassembled the mouse DAM/MGnD phenotype, it was only abundant in human samples containing $\mathrm{A} \beta$ and not tau. Conversely, AD2 did not overlap with $\mathrm{AD} 1$ and was more frequently observed in human brain samples showing both tau and amyloid pathology [119]. These data highlight the usefulness of amyloidosis mouse models in exploring the human AD1 (DAM-like) phenotype; however, it demonstrates that the additional presence of tau in the CNS could induce a different microglial phenotype. This may explain why single-cell RNA-seq analysis on 16,242 live microglial cells isolated from the aging and AD human brain demonstrated an overall weak correlation with the DAM signature [246]. Together this work demonstrates, firstly, that there exist other microglial subsets in $\mathrm{AD}$ besides the $\mathrm{DAM} / \mathrm{MGnD}$ phenotype, and secondly, that human microglia are heterogenous, thus limiting the translation of the DAM signature from animal models. This therefore highlights the need for improved mouse models that better replicate human $\mathrm{AD}$ and/or that further investigation is required of other non-DAM/MGnD phenotypes in the diseased mouse brain.

In support of these conclusions, other microglial phenotypes beyond the DAM/MGnD have been discovered in murine models of CNS pathology [106, 264]. Perhaps these different microglial transcriptional programs feature in different aspects of AD pathology, as shown in a human study where it was thought that one microglial transcriptional program contributed to tau pathology and two others to $\beta$-amyloid pathology [252].

The role of microglia in AD is clearly complex. Nevertheless, despite the disconnect between human and mouse models, without experimental modelling, we would never have understood certain aspects of the human pathology. Current murine models suggest that microglia contribute to the 
formation of plaques and tau aggregates, as well as neuronal damage and synapse loss. On the other hand, microglia have a role in phagocytosing pathological tau and compacting $\mathrm{A} \beta$ aggregates to prevent local neuritic damage. This may reflect an overall attempt to protect the brain by slowing down damage, but ultimately persistent and low-grade inflammatory signals, as well as the continued accumulation of $A \beta$ and tau aggregates, interfere with CNS functions. Taken together, several lines of evidence indicate that microglia play a substantially pathogenic role in $\mathrm{AD}$, which appears to be in stark contrast to the overall effect of these cells in viral encephalitis and stroke. One obvious explanation for this lies in the acute versus chronic nature of these diseases.

\section{Monocytes in Alzheimer's disease}

The role of peripherally derived monocytes in neurodegenerative disorders such as AD has long been debated. It is unclear if and to what extent monocytes infiltrate the brain in neurodegenerative disorders, which feature low-grade inflammation rather than the severe, acute inflammation seen in viral encephalitis and ischemic stroke. This problem is complicated further by the difficulties of distinguishing peripherally-derived monocytes from resident microglia in human tissues histologically (Fig. 1g-i), as previously noted in other diseases.

\section{The contentious involvement of monocytes in AD pathology}

Findings supporting a neuroprotective role for monocytes in $\mathrm{AD}$ pathology are conflicting and have been confounded by the use of experimental systems that condition the brain for monocyte infiltration, thereby preventing the accurate representation of disease pathophysiology. For instance, studies utilizing whole body irradiation chimeras, an experimental technique that is now recognized to condition the brain for monocyte infiltration [2, 3, 230], as well as transplant of BM-derived cells, reported that Ly6 $\mathrm{C}^{\text {hi }}$ monocytes infiltrate the $\mathrm{AD}$ mouse brain and accumulate around $\mathrm{A} \beta$ plaques. These infiltrating cells were thought to ameliorate disease evolution by phagocytosis and clearance of $A \beta$ from the brain parenchyma [287] or by promotion of CCR2-mediated microglial accumulation in amyloid plaques and degradation of $A \beta$ [89]. Although it is unclear whether transplanted cells or monocytes engrafted the AD brain, this hypothesis was supported by observations that CCR2 deficiency worsened AD pathology [89, 238], presumably due to an inability to recruit Ly6C ${ }^{\mathrm{hi}}$ monocytes from the BM [280]. However, subsequent parabiosis experiments using head-protected irradiation chimeras [229] or chemotherapy-induced myeloablation [227], which avoid the brain conditioning discussed above, demonstrated that $\mathrm{Ly} 6 \mathrm{C}^{\mathrm{hi}}$ monocytes are not recruited to the brain parenchyma during the course of $\mathrm{AD}$. Subsequent studies further revealed that parenchymal $A \beta$ burden is unaltered in CCR2-deficient mice [229, 238], further exonerating Ly6 $\mathrm{C}^{\text {hi }}$ monocytes from the responsibility for clearing $\mathrm{A} \beta$ in $\mathrm{AD}$. Moreover, in a transgenic CD11b-HSVTK mouse model, in which ganciclovir administration "paralyses" $\mathrm{CD}_{11} \mathrm{~b}^{+}$cells including microglia (i.e., where proliferation and activation is blocked), engrafted BM-derived monocytes failed to accumulate around $A \beta$ plaques and did not reduce $\mathrm{A} \beta$ plaque burden [262]. Taken together, these findings suggest that Ly6 $\mathrm{C}^{\text {hi }}$ monocytes either do not infiltrate the brain parenchyma in large enough numbers to alter parenchymal $\mathrm{A} \beta$ burden, or these cells do not participate in $\mathrm{A} \beta$ phagocytosis or clearance once in the brain.

Despite their lack of local involvement in the brain, blood monocytes may play an important role in the periphery. It is estimated that approximately $50-62 \%$ of $A \beta$ diffuses into the blood $[252,261]$ and is thus cleared from the CNS [336, 353]. Monocytes in the peripheral circulation showed a reduced $\mathrm{A} \beta$ uptake capacity with age and in $\mathrm{AD}$ patients [56], implying that impaired $A \beta$ uptake by monocytes may play a role in the aetiology of AD. Several human AD risk gene variants have been linked to monocytes, including those related with TREM2 and $C D 33$ [34, 52], the latter of which is linked to diminished $A \beta$ internalization by peripheral monocytes [34].

The importance of peripheral monocytes in $\mathrm{A} \beta$ clearance is supported by experimental studies demonstrating that peripheral Ly6 $\mathrm{C}^{\text {lo }}$ monocytes likely contribute to $\mathrm{A} \beta$ clearance from the cerebral vasculature, thereby indirectly reducing parenchymal $\mathrm{A} \beta$ burden [227] (Fig. 4). By intravital two-photon imaging, patrolling $\mathrm{Ly} 6 \mathrm{C}^{\mathrm{lo}}$ monocytes were shown to participate in $\mathrm{A} \beta$ clearance from the leptomeningeal vasculature [227]. These cells selectively crawl along $A \beta$-laden veins and scavenge $A \beta$ from the lumen. Depletion of these cells by deletion of $N r 4 a 1$, a transcription factor controlling the differentiation and survival of $\mathrm{Ly} 6 \mathrm{C}^{\mathrm{lo}}$ monocytes [144], corresponded with increased $A \beta$ deposits in the cortex and hippocampus [227], implicating a critical role for vascular $\mathrm{A} \beta$ clearance by patrolling monocytes. The protective function of Ly6 $\mathrm{C}^{\mathrm{lo}}$ monocytes in $\mathrm{AD}$ may also explain why CCR 2 deficiency exacerbates disease severity $[89,238]$, as Ly6 $\mathrm{C}^{\text {lo }}$ monocytes, which differentiate from recruited CCR $2{ }^{+}$Ly $6 \mathrm{C}^{\text {hi }}$ monocytes in the bloodstream, would no longer be recruited to this function [323, 359]. On the other hand, yolk sac-derived perivascular macrophages also clear $\mathrm{A} \beta$ from the vasculature [147] in a CCR2-dependent manner [229], and impaired $A \beta$ clearance by these cells would presumably also contribute to the accelerated disease progression observed in CCR2-deficient mice.

In addition to their role in $A \beta$ pathology, monocytes may participate in the low-grade, systemic inflammation that can accompany aging and cognitive decline in $\mathrm{AD}$. Although 
overall peripheral blood monocyte counts do not appear to vary over disease course, there are population shifts in monocyte subsets in patients with AD [312]. This is evidenced by a decrease in classical monocytes (Ly6C ${ }^{\text {hi }}$ in mice) and an increase in intermediate and non-classical monocyte populations (Ly6C ${ }^{\text {lo }}$ in mice) with disease progression, which coincided with a shift in monocyte pro-inflammatory gene expression (including IL6, TNF and ILLB) [312]. Moreover, IL-33 signalling shown to reduce synaptic impairment and subsequent memory deficits in APP/PS1 mice was impaired in lipopolysaccharide-primed and $\mathrm{A} \beta$-stimulated monocytes from patients with $\mathrm{AD}$ dementia [275], further suggesting that an altered monocyte phenotype may contribute to AD pathology.

\section{Demyelinating disease}

Multiple sclerosis is an inflammatory demyelinating disease of the CNS, thought to be of autoimmune aetiology, characterised by chronic neuroinflammation and neurodegeneration. It involves the progressive loss of oligodendrocytes and neurons, resulting in motor and cognitive deficits [322, 326]. Clinical displays of MS are highly heterogeneous and can comprise clinically isolated syndromes, primary progressive forms and relapsing-remitting patterns, the latter causing $\sim 85 \%$ of initial cases and potentially developing into secondary progressive MS over a span of 10-15 years [309, 346]. Relapsing-remitting MS is characterised by episodes of neurological impairment followed by stages of remission and partial neurological recovery, while progressive MS forms involve progressive neurological impairment without phases of remission [326, 346]. The extensive infiltration and activation of peripheral and resident immune cells in MS suggests these cells are key mediators of lesion formation [77, 210, 278] (Fig. 1j-1). However, mirroring the heterogeneity of clinical presentation, different classes of lesion exist, depending on disease type, duration, cellular players and anatomical compartment [205, 256], making this complex scenario challenging to mimic in a single animal system $[40,186,196]$.

\section{Relevance of murine models to human MS}

Similar to other CNS pathologies, MS is a uniquely human disease, and as such can only be partially modelled in experimental animal systems [186]. Significant caution is thus necessary in interpreting results from animal models, in particular from the widely used murine Experimental Autoimmune Encephalomyelitis (EAE) model. Inflammation in EAE is primarily mediated by MHC class IIrestricted autoreactive $\mathrm{T}$ cells that are induced by injection of encephalitogenic antigens (e.g., myelin basic protein, myelin oligodendrocyte glycoprotein, MOG, or proteolipid protein, PLP), in conjunction with an adjuvant, or passively, via peripheral administration of encephalitogenic $\mathrm{CD}^{+} \mathrm{T}$ cells [64]. APCs play an important role in the activation of peripherally-primed $\mathrm{T}$ cells, resulting in an inflammatory cascade that leads to oligodendrocyte death, chronic demyelination, and neuronal loss $[64,77]$. While commonly referred to as a single experimental paradigm, EAE development and pathological presentations are critically dependent on the induction method, animal strain and genetic manipulations [40, 186]. Most groups however, utilize C57B1/6 mice, a strain typically developing an acute, monophasic disease useful to study the main inflammatory aspects of acute MS [232]. Depending on the specific model, EAE fails to fully recapitulate the complex pathological presentation of MS, including the differential distribution of lesions between brain and spinal cord, the driving lymphoid cellular components, and the relative extent of demyelination in white matter tracts [265].

Furthermore, most EAE models do not recapitulate the extensive grey matter pathology observed in patients, which show a demyelination pattern often characterized by chronic microglia activation, absence of leukocyte infiltration [46] and pronounced meningeal inflammation [156]. While novel models have recently been developed to study this type of lesion [318], other experimental approaches are better suited to model a subtype of inflammatory grey matter pathology observed in early MS cases [256] and displaying tissueinvading leukocytes supposedly driving local damage [169, $180,203,225]$. At the same time, even though attempts to represent a chronic disease course have been made [23], and mouse strains, such as Biozzi ABH [6] and A.SW [314], show a clinical development resembling progressive MS, most EAE models are not suited to mimic primary/secondary progressive pathology or general disease chronicity. For instance, EAE induction in non-obese diabetic (NOD) mice, often claimed to represent the clinical course of progressive MS, can be used to study some neurodegenerative aspects of the disease, but overall it lacks evidence as a valid chronic model [15]. Taken together, the need remains for novel experimental approaches that better model progressive and chronic MS.

Notwithstanding these drawbacks, EAE has proved of unmatched value for the understanding of several pathological mechanisms evidently occurring in the human disease; furthermore, it still represents the best platform to test novel therapeutic approaches [186]. Research in EAE models has for instance directly led to the development of the disease modifying therapies, glatimer acetate and natalizumab, while other drugs, such as fingolimod, dimethylfumarate and alemtuzumab, have been tested and mechanistically explained, thanks to this model [186]. On the other hand, an important number of therapies stemming from EAE 
studies, in particular most approaches involving manipulation of cytokine actions, have surprisingly and consistently failed successful clinical application, once again showing the context-dependent limitations of EAE [265].

Other aspects of MS, such as demyelination in the relative absence of adaptive immunity-driven inflammation, are alternatively studied using chemical- (i.e., lysolecithininduced) [352] or toxin- (i.e., cuprizone) mediated demyelination models [257]. Other groups have instead used diphtheria toxin-induced death of oligodendrocytes to mimic the formation of lesions in some early MS cases, showing oligodendrocyte apoptosis in the absence of immune cell infiltration [17, 202, 313]. The spontaneous development of demyelination seen with viral infection, e.g., TMEV infection, is also a useful model to study specific neurodegenerative characteristics seen in MS [118].

\section{Microglia in multiple sclerosis}

Akin to many neuroinflammatory diseases, the "empirical observation of microgliosis" implicates a role for microglia in MS pathogenesis [132]. Indeed, the number of 'activated' microglia and macrophages correlates with axonal damage in MS lesions [31, 99, 267, 327]. Interestingly, however, gene expression patterns from human brain data at the tissue-level did not show an enrichment in MS susceptibility genes [161]. Extending the analysis to include data generated from human induced pluripotent stem cell-derived neurons, astrocytes and microglia, revealed the enrichment of MS susceptibility genes in microglia but not astrocytes or neurons [161]. The CLECL1 locus implicated a role for microglia in MS pathogenesis, which was underestimated in tissue-level brain profiles. The role of microglia in MS however remains unclear and might be dependent on the type and chronicity of distinct lesions. Several insights into microglia function could be inferred from animal studies, despite obvious limitations and potential species-related cellular differences [138].

\section{Duality of microglial roles in immune or chemical demyelination}

A detrimental role for CNS-resident macrophages in EAE was first suggested in a transgenic mouse model of so-called "microglial paralysis" (i.e., where proliferation and 'activation' is blocked) in lethally irradiated, CD11b-HSVTK mice engrafted with wild-type BM, that showed reduced EAE disease severity [150]. However, the interpretation of these data was hampered by the observation that CD11b-HSVTK animals also displayed reduced CNS infiltration of peripheral leukocytes. Considering that CCR2 blockade/deficiency [2, 228], clodronate liposome or immune-modifying nanoparticle administration, all of which abrogate CNS infiltration of Ly6C $\mathrm{C}^{\text {hi }}$ monocytes and result in attenuated EAE signs $[121,233]$, this implies a key function of Ly6 $\mathrm{C}^{\text {hi }}$ monocytederived cells in EAE development, leaving a potential pathogenic or protective role for microglia in the CD11b-HSVTK model unresolved. Subsequently, a study in which mice were fed high- and low-dose PLX5622 post-EAE induction showed improved disease signs without affecting peripheral immune cell populations. PLX5622-treated mice also showed an increase in mature oligodendrocytes, suggesting a role for microglia in regulating oligodendrocyte maturation [243] (Fig. 5 and Table 6).

The exact role of microglia in EAE is unclear. However, it appears that microglial 'activation' and production of proinflammatory mediators have a role in the pathogenesis of the disease (Fig. 5). Pellino-1-deficient $\left(\mathrm{Pelil}^{-/-}\right)$mice were refractory to EAE induction [354] (Table 6). Peli1, expressed by microglia in the brain and upregulated during EAE, is an E3 ubiquitin ligase that enhances Toll-like receptor/MyD88 signaling via the degradation of the adaptor protein TRAF3 and the activation of the mitogen-activated protein kinase, with the consequent induction of several pro-inflammatory cytokine (Illb, Tnf, Ill2b) and chemokine (Cxcll, Ccl2, Ccl20) mediators. However, other CNS-resident and infiltrating macrophage populations may also express Peli1, thus deficiency of Peli1, which reduces EAE severity, implicates both microglial and non-microglial cells in the production of inflammatory mediators and the pathogenesis of EAE. Further, non-physiological effects, created in the generation of the Peli1 knockout chimera via lethal irradiation and by disrupting the function of Peli1 during development and adulthood in all cell types cannot be ruled out.

Using more selective tools to target microglia during neuroinflammation, Goldmann et al. [129] generated $C x 3 \mathrm{Crl}^{\mathrm{CreER}}$ :Tak $1^{\mathrm{flfl}}$ mice, whereby TGF- $\beta$-activated kinase 1 (TAK1) was ablated from long-lived CX3CR $1^{+}$cells (which include microglia) [129]. TAK1 is a mitogen-activated protein kinase kinase kinase, upstream from nuclear factor- $\kappa \beta$, which upon activation can induce the production of cytokines, chemokines and adhesion molecules, contributing to inflammation and the recruitment of immune cells. Genetic ablation of TAK1 in long-lived CX3CR $1^{+}$cells attenuated EAE pathology [129]. This was associated with reduced cellular infiltration into the CNS, reduced myelin destruction and axonal loss, and suppression of proinflammatory genes. Using a more targeted approach to study microglia, this study supports the pathogenic role of these cells in EAE via the production of inflammatory mediators. This is in line with studies using less selective tools, i.e., the Peli1 knockout chimera, mentioned above.

More recently, using single-cell technology, a subpopulation of microglia was identified in the CNS of mice at the onset of EAE which produced ROS [224]. The production of ROS contributes to oxidative stress and injury 
a

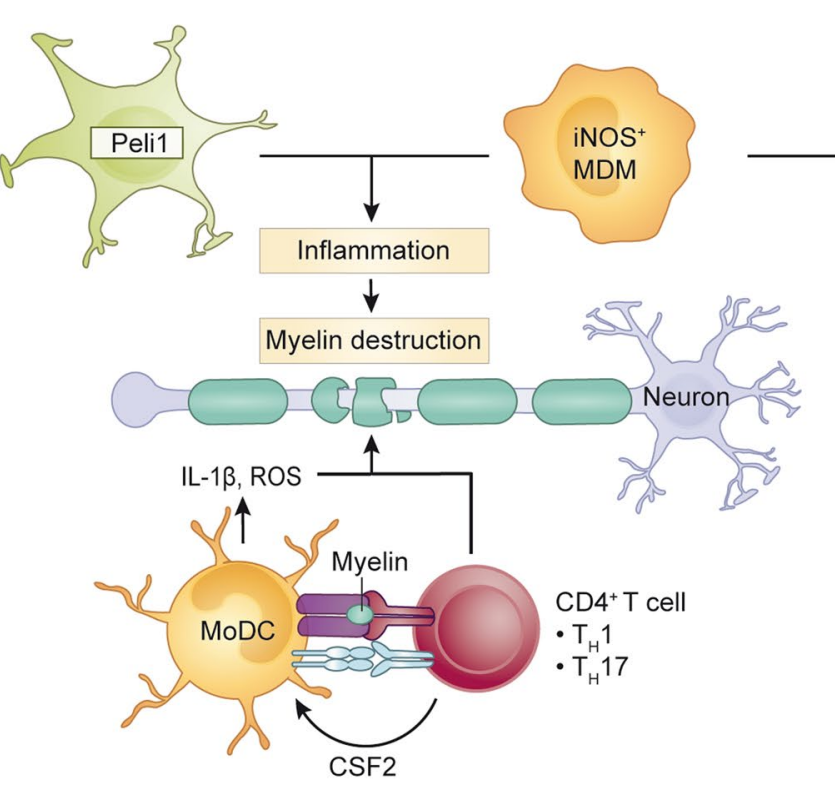

b Protective
Fig. 5 Protective and pathogenic roles of monocytes and microglia in autoimmune neuroinflammation. a Pathogenic functions. Pelimediated microglial expression of pro-inflammatory cytokine and chemokines can exacerbate inflammatory damage to myelin. GMCSF-stimulated moDC activate myelin-reactive $\mathrm{T}$ cells and exacerbate myelin damage via the production of ROS and IL-1 $\beta$. iNOS ${ }^{+}$ MDM producing ROS and NO contribute to myelin destruction but may also transition to arginase- $1^{+} \mathrm{MDM}$ and facilitate the resolution

associated with myelin damage and disease progression in MS. Using Tox-RNA sequencing to transcriptionally profile ROS-producing cells, Mendiola et al. [224] identified an oxidative stress signature ( $C y b b, N c f 2, N c f 4$ and $G p x 1)$ shared by all MC populations and one microglia population in EAE [224]. Targeting these populations with acivicin, which targets $\gamma$-glutamyl transferase to degrade anti-oxidant glutathione, decreased disease severity in four models of EAE and a model of microglia-driven neurodegeneration (induced by a lipopolysaccharides injection in the substantia nigra) [224]. Thus, this study shows that at least one subpopulation of microglia in EAE is neurotoxic, contributing to oxidative stress and pathology.

On the other hand, using $C s f I^{-1-}$ mice to reduce the number of white matter microglia, lysolecithin-mediated demyelination resulted in extensive demyelination and neuronal damage compared to WT controls, suggesting a protective role for microglia [352]. Csf1 ${ }^{-/-}$animals also showed enhanced pro-inflammatory astrocytic responses, indicating that microglia can prevent dysfunctional astrocyte responses necessary for the inflammatory-to-regenerative switch required for the initiation of remyelination (Table 6). Thus, while differences could be due to the of inflammation (b). b Protective functions. Microglia may stimulate re-myelination via P2X4R-mediated phagocytosis of myelin debris. $G M-C S F$ granulocyte-macrophage stimulating factor; $I L$ interleukin; iNOS inducible nitric oxide synthase; $M D M$ monocyte-derived macrophage; $M H C$ major histocompatibility complex; moDC monocytederived dendritic cell; $N O$ nitric oxide; $P 2 X 4 R \mathrm{P} 2 \mathrm{X}$ purinoceptor 4; Peli Pellino E3 Ubiquitin Protein Ligase; ROS reactive oxygen species; $T H$ T helper cell

distinct microglial depletion and/or MS models used, this study nevertheless suggests a protective role for microglia in promoting remyelination to prevent axonal damage, in contrast to the previously discussed reports.

\section{Role of microglial CSF1R, TREM2 and P2X4R in EAE remyelination}

As mentioned above, using high- and low-dose administration of the CSF1R inhibitor, PLX5622, Nissen et al. [243] revealed a pathogenic role for microglia in EAE, as clinical presentation of the disease was reduced upon microglial depletion. Seemingly paradoxically, stimulation of CSF1R was also protective in EAE [347]. Recombinant IL-34 or recombinant CSF1 injected intrathecally via the cisterna magna ameliorated EAE, suppressing disease progression and severity and reducing demyelination and oligodendrocyte loss (Table 6). Notably, this corresponded with the expansion of $\mathrm{CD} 11 \mathrm{c}^{+}$microglia, a population absent from the homeostatic CNS parenchyma but described to emerge in postnatal development in the neonatal brain, in cuprizone-induced demyelination, and in mouse models for neuromyelitis optica and $\mathrm{AD}[42,268,348,350]$. 
A CD11 ${ }^{+}$microglial population further characterized as

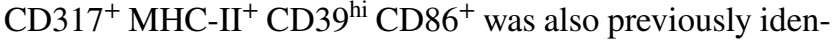
tified by Ajami et al. [4] in the active phase of EAE and downregulated in the chronic phase or upon clinical recovery [4]. These cells seem to be important sources of insulinlike growth factor 1 (IGF-1) and IFN- $\beta$, thus supporting a neuroprotective role for this population [348-350]. Accordingly, deletion of IGF-1 in these $\mathrm{CD} 11 \mathrm{c}^{+}$cells resulted in impaired primary myelination in the developing brain [349]. Thus, reduced demyelination seen with CSF1R stimulation was suggested to be a result of the expansion of a CD11 $\mathrm{c}^{+}$ microglia population, promoting myelination of axons.

Interestingly, EAE severity was enhanced in mice where $\mathrm{CD} 11 \mathrm{c}^{+}$cells were depleted using several genetic approaches [358]. This was thought to be a consequence of a reduction in inducible Tregs due to depleted $C D 11 c^{+}$DCs. However, the worsened disease outcome in the absence of CD11c may have been due to the inhibition of protective functions orchestrated by $\mathrm{CD} 11 \mathrm{c}^{+}$microglia or even MCs.

The purinergic P2 receptor P2X4R, highly expressed by microglia at the peak and recovery phase of disease, has also been implicated in inducing efficient remyelination [362] (Fig. 5 and Table 6). In this work, daily administration of a P2X4R antagonist from the onset of disease exacerbated clinical signs of EAE by polarising microglia into a pro-inflammatory state. Conversely, potentiation of P2X4R using ivermectin, which modulates ion conduction and channel gating of P2X4Rs, ameliorated EAE motor deficits and improved corticospinal tract function. P2X4R signalling correlated with a higher phagocytic capacity by promoting an acidic shift in lysosomes, which could favour myelin clearance required for effective remyelination [362]. This study highlights the disease-ameliorating importance of myelin phagocytosis by microglia. Similarly, microglia pre-stimulated with IL-4 ex vivo and transplanted into the CSF, also resulted in oligodendrogenesis and amelioration of EAE [43]. However, the interpretation of this experiment warrants caution, considering the non-physiological conditions associated with an intraventricular injection of in vitroderived microglia.

TREM-2 is an important receptor involved in phagocytosis, and upon genetic absence or blockade of TREM-2, microglia fail to upregulate genes required for lipid metabolism and phagocytosis, resulting in the exacerbation of EAE [254, 255] (Table 6). These studies further support a role for microglia in the phagocytosis of myelin debris and potentially in subsequent axonal remyelination. Furthermore, gene expression studies in models of EAE support a role for microglia in apoptotic cell [199] and debris clearance [355].

The studies above demonstrate the pathogenic role of microglia in the acute phase of EAE, with polarisation of microglia to an anti-inflammatory phenotype, or expansion of a $\mathrm{CD} 11 \mathrm{c}^{+}$microglia population, reducing disease severity via indirectly promoting remyelination of axons and/or the phagocytosis of myelin debris. In contrast, in the toxin-induced model of demyelination in MS, microglia are protective, since microglial depletion results in an overexuberant astrocytic response and extensive demyelination.

\section{Role of microglia in T cell priming and EAE pathogenesis}

Microglia have also been implicated in presenting antigen to $\mathrm{T}$ cells in the early stages of disease, given that microglia are the first cells to take up myelin antigen [293], and can extend MHC-II ${ }^{+}$cellular processes at the level of the glia limitans to potentially contact invading cells $[173,197]$. T cell stimulation requires co-stimulation by CD80, CD86 and CD40, which are upregulated by microglia, although to a lesser extent than on infiltrating MCs [37]. Recently however, a series of studies utilizing different transgenic approaches elegantly showed that MHC-II expression on CNS-resident microglia/macrophages is dispensable for $\mathrm{T}$ cell priming and EAE pathogenesis [125, 174, 236, 351]. Instead, although this topic remains debated, the aforementioned studies implicated $\mathrm{CDC} 2$ type of APC in the initiation of EAE.

\section{Protective role of microglia in models of progressive MS}

To model the clinical presentation observed in secondary progressive MS patients, the NOD mouse immunized with $\mathrm{MOG}_{35-55}$ peptide has often been used. NOD mice induced with EAE typically develop secondary progression occurring 30 days post immunization, following an acute attack at 14 days and remission by 20 days [309]. In this model, initiating PLX3397 treatment at 20 days post EAE induction increased mortality and exacerbated disease in immunized mice without affecting the timing of the relapse phase. PLX3397 microglia-depleted, $\mathrm{MOG}_{35-55}$-immunized NOD mice displayed enhanced inflammation, demyelination, axonal degeneration and a significant increase in the number of $\mathrm{CD}^{+}$and $\mathrm{Ki}_{6} 7^{+}$proliferating $\mathrm{CD} 4^{+} \mathrm{T}$ cells. These observations potentially suggest an overall protective role for microglia in the development of secondary progressive MS, in contrast to the discussed pathogenic role of microglia in the acute phase of EAE [309] (Table 6).

However, MOG-immunized NOD mice mirror only some of the biological processes observed in chronic MS patients, and caution is obviously needed when translating these results to MS [15]. In a recent study, EAE was passively induced via injection of myelin basic protein (MBP)-specific $\mathrm{T}$ cell blasts in LEWzizi rats. These are Lewis rats on a zitter rat background that partly mimic human aging and MS pathology, showing neurodegeneration, hypomyelination, microglia activation and iron accumulation [346]. Interestingly, there was no exacerbation of disease, compared to Lewis controls, contradicting expectations that pre-existing 
microglia activation and pathology (or 'aging') would be amplified and convert EAE into a chronic progressive disease. Pathology was instead redirected to the mesencephalon, where LEWzizi animals showed $\mathrm{T}$ cell infiltration and enhanced demyelination, presumably due to $\mathrm{T}$ cells targeting pre-damaged areas. While this study suggested that EAE pathogenesis is unaffected by microglia pre-activation and 'aging', further investigations and different models better suited to investigate chronic cell activation are required to confirm this.

\section{Monocytes in autoimmune inflammation}

Monocytes are recruited to plaques in MS [193] (Fig. 1j-1) and have long been considered to play a pathological role in EAE. These cells leave the BM and migrate to the CNS prior to disease onset, with their infiltration preceding the development of paralysis and subsequent clinical manifestations of EAE [183, 228]. As the infiltration of monocytes into the CNS is mostly CCR2-dependent, CCR2-deficient mice have frequently been used to prevent their immigration into the brain and investigate their role in disease [260]. Accordingly, initial experiments with CCR2-deficient mice showed that these animals were resistant to EAE induction $[98,137,165$, 230], which suggested peripheral monocytes play a crucial role in disease pathogenesis. How monocyte-derived effector cells contribute to disease pathogenesis is less clear; such cells may contribute to pathology directly, through inflammation-mediated myelin destruction, or indirectly through activation of autoreactive $\mathrm{T}$ cells via antigen presentation. The protective and pathogenic functions of monocytes in MS, along with their respective immune profiles, are compared to those of microglia in Table 6.

\section{An unlikely role: monocyte antigen presentation for the initiation of EAE}

In EAE, the activation of encephalitogenic $\mathrm{T}$ cells via the presentation of the encephalitogenic antigen is a critical step in disease induction [64]. Antigen is presented by CNS-resident or immigrant APCs, which typically express MHC-II and co-stimulatory molecules, CD80 and CD86, required for $\mathrm{CD}^{+}{ }^{+} \mathrm{T}$ helper $(\mathrm{TH})$ cell activation. Antigen presentation in EAE has been attributed to DC, however, distinguishing brain-resident CDC from peripherally-derived monocytederived DC has challenged the accurate characterization of the antigen-presenting functions of these cell types in EAE $[4,18,136,174,236]$. As both peripherally-derived and CNS-resident myeloid cells have been implicated in antigen presentation to autoreactive $\mathrm{T}$ cells, definitive evidence of a non-redundant role for monocyte-derived APC in activating autoreactive $\mathrm{T}$ cells is lacking. It was recently demonstrated that, in contrast to the resident population, CNS-infiltrating myeloid cells showed prolonged interactions with T cells in the CNS and that their expression of MHC-II was essential for EAE development [174, 236]. Furthermore, myeloidderived DC are critical for the activation and differentiation of TH17 cells [189, 231]. This was further characterized by mass cytometry demonstrating that monocyte-derived subpopulations characteristically expressed phenotypes involved in activating TH1 and TH17 cells at disease onset [4], suggesting these cells play a key role in antigen presentation.

However, the critical antigen-presenting role of moDC in EAE pathogenesis has been challenged by in vitro studies demonstrating that moDC are less capable of presenting myelin compared to $\mathrm{cDC}$, and are therefore redundant in activating autoreactive $\mathrm{T}$ cells $[125,236]$. The suggested relative inability of monocytes to present myelin peptide to autoreactive $\mathrm{T}$ cells has been explained by a lower expression of H2M [125], a non-classical MHC molecule facilitating the processing and presentation of myelin antigen [289]. Nonetheless, the distinction between moDC and cDC in vivo remains challenging because of overlapping phenotypic markers, complicating the resolution of their antigen-presenting functions in vivo and warranting further investigation.

\section{Monocyte subsets participate in inflammatory myelin damage}

In addition to possible antigen-specific $\mathrm{T}$ cell-mediated inflammation, non-specific inflammation also contributes to myelin destruction in MS [77]. Both CNS-infiltrating monocytes and resident microglia have been implicated in this process [133, 242], however, dissecting their respective functions in disease has proved difficult. To distinguish these cells during neuroinflammation, $C \mathrm{cr} 2^{\mathrm{rfp}}:: C x 3 \mathrm{cr} 1^{\mathrm{gfp}}$ reporter mice were used to distinguish $\mathrm{CCR} 2^{+}$monocyte-derived cells from the resident $\mathrm{CX} 3 \mathrm{CR} 1^{+}$population in EAE, based on their differential expression of RFP and GFP [355]. Using this method, resident microglia appeared to be more involved in phagocytosing myelin debris and tissue repair, whereas MDMs in the immediate vicinity of axons at the nodes of Ranvier expressed a pro-inflammatory gene signature [355], suggesting that these cells actively participate in inflammatory myelin damage.

High-parameter technologies have further elucidated the heterogeneity of monocyte phenotypes driving inflammatory damage in EAE. It was recently demonstrated that CNSinfiltrating monocytes adopt a toxic phenotype that likely mediates tissue damage [224]. Oxidative stress results from a metabolic switch during inflammatory activation that sustains the production of inflammatory mediators, such as ROS and NO [109], which is required for pathogen defence functions. In EAE, however, this oxidative stress signature is associated with inflammatory damage, a phenotype 
expressed by more than $50 \%$ of CNS-infiltrating monocytes [224]. The pathogenic function of this oxidative stress phenotype was emphasized by experiments demonstrating that inhibiting ROS production via inhibition of $\gamma$-glutamyl transferase, an upstream modulator of the oxidative stress pathway, reduced disease severity, decreased demyelination and axon damage, and lowered oxidative stress markers in multiple rodent models of MS [224], and may be a potential therapeutic target for human disease. However, these same cells primed to produce reactive species can be polarized from a pro-inflammatory (iNOS ${ }^{+}$) to a tissue-repair (arginase $-1^{+}$) phenotype by the tissue microenvironment and move inflammatory lesions towards resolution, as demonstrated by single-cell fate-mapping. Therefore, therapeutic targeting of these cell types should be approached with caution, especially if the same monocytes expressing a pathogenic phenotype are central to the resolution of inflammation at a later stage in disease [201].

Single-cell RNA-sequencing has further revealed highly specialized monocyte subsets with distinctive functions in disease. Of these subsets, two newly identified $\mathrm{CxcllO}^{+}$and $\mathrm{Saa}^{+}$monocyte subsets expressing a pro-inflammatory signature were observed at the peak of disease [124]. These subsets were almost completely depleted by anti-CCR2 antibody administered at the peak of disease and correlated with an overall clinical improvement, suggesting these cells possess a characteristic pathogenic potential. Of note, these pathogenic monocyte subsets may not be derived from Ly6 $\mathrm{C}^{\text {hi }}$ monocytes, since adoptive transfer of BM monocyte progenitors demonstrated that $\mathrm{Saa}^{+}$and $\mathrm{CxCll} \mathrm{O}^{+}$monocyte subsets differentiated from granulocyte-monocyte progenitors and monocyte-macrophage DC progenitors evidently without passing through a Ly6C ${ }^{\text {hi }}$ monocyte state [124]. However, this transition is rapid during inflammation [73] and may have been missed at a $48 \mathrm{~h}$ time point, since Ly6C on monocytes and $\mathrm{T}$ cells is crucial for endothelial transmigration $[44,145,146,166,310]$. Nevertheless, this highlights the continuing development of our understanding of myeloid cell differentiation and responses in the pathogenesis of EAE and other neuroinflammatory diseases.

While monocytes evidently acquire a multitude of phenotypes in EAE, the inflammatory microenvironment appears to be critical in shaping the functional specialization of these subsets and their contribution to pathology. This may include cytokines, such as GM-CSF, that are produced by autoreactive $\mathrm{T}$ cells surrounding inflammatory lesions. Indeed, GM-CSF signalling is thought to induce a characteristic transcriptional signature in monocytes that is sufficient to drive disease onset $[67,190]$. Monocytes with defective GM-CSF signalling do not participate in myelin destruction [135], suggesting the pathogenic activity of this subset is contingent on GM-CSF signalling by autoreactive $\mathrm{T}$ cells. Temporal and spatial factors in the inflammatory microenvironment further contribute to the functional specialization of infiltrating monocyte-derived cells. For instance, fate-mapping experiments of infiltrating phagocytes revealed that pro-inflammatory polarization $\left(\mathrm{iNOS}^{+}\right)$ of these cells occurred predominantly in the spinal cord lesions [201] and perivascular space [177], whereas those expressing an anti-inflammatory phenotype (arginase- $1^{+}$) resided predominantly in the meninges $[164,201]$. iNOS ${ }^{+}$ cells expressing this characteristic pro-inflammatory signature predominated during the formation of lesions [201], but as lesions progressed towards resolution NOS $^{+}$cells locally adapted their phenotype and transitioned towards an anti-inflammatory phenotype that was thought to guide EAE recovery [201]. When injected into the healthy CNS, these pro-inflammatory iNOS ${ }^{+}$cells shifted their phenotype to an anti-inflammatory $\operatorname{Arg} 1^{+}$phenotype within a few days [201], strongly supporting the notion that the local CNS environment mediates this phenotypic switch. Indeed, in the absence of lesion resolution, monocyte-derived cells expressing an anti-inflammatory phenotype may return to a pro-inflammatory state in response to a chronic inflammatory environment [124], perhaps reflecting a transcriptional adaptation to the complex inflammatory lesion environment in which damage and regeneration are concurrent.

\section{Concluding remarks}

CNS inflammation is an accompanying pathological feature of neurological diseases that can lead to neurodegeneration and progressive neurological deficits. Although multiple immune cell types can inflict injury within the CNS parenchyma, resident and infiltrating myeloid cells are key regulators of disease outcome. However, elucidating the precise contributions of each cell subset to neurological diseases has historically been hampered by the paucity of research tools available to accurately identify these cells in human and murine tissue. The development of new reagents and experimental systems has greatly improved our ability to distinguish resident from infiltrating myeloid cells in inflammation, unravelling the interplay and division of labor between these cell subsets in disease.

In summary, we have highlighted the non-redundant and often opposing mechanisms by which monocytes and microglia dampen or exacerbate immunopathology in murine and human studies of autoimmune neuroinflammation, CNS injury, and viral encephalitis. Although more human studies are required, findings from animal models suggest that both cell types can perform both protective and pathogenic functions, with microglia overall more protective in the acute phase of viral encephalitis and stroke, and seemingly more pathogenic in diseases with chronic neuroinflammation, including $\mathrm{AD}$ and MS, as well as in the recovery phase 
of viral infection. In contrast, the functions of monocytederived cells are not as clear-cut. These cells can perform protective functions that enhance viral clearance and tissue repair, however, and in general, monocyte infiltration occurs at the expense of detrimental tissue damage, albeit in many cases, priming the tissue for repair.

The inherent limitations of animal models must be considered when extrapolating findings to human disease. Nonetheless, this review has emphasized the critical importance of animal studies in understanding certain elements of CNS pathology. Currently translating our understanding of monocyte and microglial diversity into clinically useful therapeutic approaches remains a significant challenge. Accurately identifying temporally dependent myeloid phenotypes and their associated protective or pathological functions, both unique and common to various CNS pathologies, remains a crucial goal of current research. The Grail is in the precise, confident tailoring and harnessing of this specific knowledge.

Acknowledgements We would like to acknowledge Prof Delphine Boche from the Faculty of Medicine, University of Southampton UK for providing the image in Fig. 1b. We also thank Prof Manuel B. Graeber, Prof Inge Huitinga, Dennis Wever and Prof Tanja Kuhlmann for providing high resolution images from cited publications for Fig. 1.

Author contributions AGS and CLW equally contributed to this review. RP collated histological images from previously published articles for Fig. 1. Figure $2-5$ were illustrated by CLW. AGS, CLW, GL and NJCK all contributed to the conceptualisation and writing.

Funding NJCK was supported by a National Health and Medical Research Council Project Grant 1088242 and the Merridew Foundation. AGS is supported by the Australian Government Research Training Stipend Scholarship and The University of Sydney Postgraduate Merit Award. CLW is supported by a Merridew Foundation PhD Scholarship.

\section{Declarations}

Conflict of interest The authors have no conflicts of interest to declare that are relevant to the content of this article.

Open Access This article is licensed under a Creative Commons Attribution 4.0 International License, which permits use, sharing, adaptation, distribution and reproduction in any medium or format, as long as you give appropriate credit to the original author(s) and the source, provide a link to the Creative Commons licence, and indicate if changes were made. The images or other third party material in this article are included in the article's Creative Commons licence, unless indicated otherwise in a credit line to the material. If material is not included in the article's Creative Commons licence and your intended use is not permitted by statutory regulation or exceeds the permitted use, you will need to obtain permission directly from the copyright holder. To view a copy of this licence, visit http://creativecommons.org/licenses/by/4.0/.

\section{References}

1. Afagh A, Cummings BJ, Cribbs DH, Cotman CW, Tenner AJ (1996) Localization and cell association of C1q in Alzheimer's disease brain. Exp Neurol 138:22-32. https://doi.org/10.1006/ exnr.1996.0043

2. Ajami B, Bennett JL, Krieger C, McNagny KM, Rossi FM (2011) Infiltrating monocytes trigger EAE progression, but do not contribute to the resident microglia pool. Nat Neurosci 14:11421149. https://doi.org/10.1038/nn.2887

3. Ajami B, Bennett JL, Krieger C, Tetzlaff W, Rossi FM (2007) Local self-renewal can sustain CNS microglia maintenance and function throughout adult life. Nat Neurosci 10:1538-1543

4. Ajami B, Samusik N, Wieghofer P, Ho PP, Crotti A, Bjornson $\mathrm{Z}$ et al (2018) Single-cell mass cytometry reveals distinct populations of brain myeloid cells in mouse neuroinflammation and neurodegeneration models. Nat Neurosci 21:541-551. https:// doi.org/10.1038/s41593-018-0100-x

5. Akiyama H, McGeer PL (1990) Brain microglia constitutively express beta-2 integrins. J Neuroimmunol 30:81-93. https:// doi.org/10.1016/0165-5728(90)90055-r

6. Al-Izki S, Pryce G, O’Neill JK, Butter C, Giovannoni G, Amor $S$ et al (2012) Practical guide to the induction of relapsing progressive experimental autoimmune encephalomyelitis in the Biozzi ABH mouse. Mult Scler Relat Disord 1:29-38. https:// doi.org/10.1016/j.msard.2011.09.001

7. Alzheimer A, Stelzmann RA, Schnitzlein HN, Murtagh FR (1995) An English translation of Alzheimer's 1907 paper, "Uber eine eigenartige Erkankung der Hirnrinde." Clin Anat 8:429-431. https://doi.org/10.1002/ca.980080612

8. Andrews DM, Matthews VB, Sammels LM, Carrello AC, McMinn PC (1999) The severity of murray valley encephalitis in mice is linked to neutrophil infiltration and inducible nitric oxide synthase activity in the central nervous system. J Virol 73:8781-8790. https://doi.org/10.1128/JVI.73.10.8781-8790. 1999

9. Androvic P, Kirdajova D, Tureckova J, Zucha D, Rohlova E, Abaffy $\mathrm{P}$ et al (2020) Decoding the transcriptional response to ischemic stroke in young and aged mouse brain. Cell Rep $31: 107777$

10. Araujo SES, Mendonca HR, Wheeler NA, Campello-Costa P, Jacobs KM, Gomes FCA et al (2017) Inflammatory demyelination alters subcortical visual circuits. J Neuroinflamm 14:162. https://doi.org/10.1186/s12974-017-0936-0

11. Armah HB, Wang G, Omalu BI, Tesh RB, Gyure KA, Chute DJ et al (2007) Systemic distribution of West Nile virus infection: postmortem immunohistochemical study of six cases. Brain Pathol 17:354-362. https://doi.org/10.1111/j.1750-3639.2007. 00080.x

12. Asai H, Ikezu S, Tsunoda S, Medalla M, Luebke J, Haydar T et al (2015) Depletion of microglia and inhibition of exosome synthesis halt tau propagation. Nat Neurosci 18:1584-1593. https://doi.org/10.1038/nn.4132

13. Astrup J, Siesjö BK, Symon L (1981) Thresholds in cerebral ischemia-the ischemic penumbra. Stroke 12:723-725

14. Avan A, Digaleh H, Di Napoli M, Stranges S, Behrouz R, Shojaeianbabaei G et al (2019) Socioeconomic status and stroke incidence, prevalence, mortality, and worldwide burden: an ecological analysis from the Global Burden of Disease Study 2017. BMC Med 17:1-30

15. Baker D, Nutma E, O'Shea H, Cooke A, Orian JM, Amor S (2019) Autoimmune encephalomyelitis in NOD mice is not initially a progressive multiple sclerosis model. Ann Clin Transl Neurol 6:1362-1372. https://doi.org/10.1002/acn3.792 
16. Bardina SV, Michlmayr D, Hoffman KW, Obara CJ, Sum J, Charo IF et al (2015) Differential roles of chemokines CCL2 and CCL7 in monocytosis and leukocyte migration during West Nile virus infection. J Immunol 195:4306-4318

17. Barnett MH, Prineas JW (2004) Relapsing and remitting multiple sclerosis: pathology of the newly forming lesion. Ann Neurol 55:458-468. https://doi.org/10.1002/ana.20016

18. Bartholomäus I, Kawakami N, Odoardi F, Schläger C, Miljkovic D, Ellwart JW et al (2009) Effector T cell interactions with meningeal vascular structures in nascent autoimmune CNS lesions. Nature 462:94-98

19. Baufeld C, O'Loughlin E, Calcagno N, Madore C, Butovsky O (2018) Differential contribution of microglia and monocytes in neurodegenerative diseases. J Neural Transm (Vienna) 125:809-826. https://doi.org/10.1007/s00702-017-1795-7

20. Bechmann I, Kwidzinski E, Kovac AD, Simburger E, Horvath T, Gimsa U et al (2001) Turnover of rat brain perivascular cells. Exp Neurol 168:242-249. https://doi.org/10.1006/exnr. 2000.7618

21. Bellizzi MJ, Geathers JS, Allan KC, Gelbard HA (2016) Plateletactivating factor receptors mediate excitatory postsynaptic hippocampal injury in experimental autoimmune encephalomyelitis. J Neurosci 36:1336-1346. https://doi.org/10.1523/JNEUROSCI. 1171-15.2016

22. Ben-Nathan D, Huitinga I, Lustig S, van Rooijen N, Kobiler D (1996) West Nile virus neuroinvasion and encephalitis induced by macrophage depletion in mice. Adv Virol 141:459-469. https://doi.org/10.1007/BF01718310

23. Benedek G, Chaudhary P, Meza-Romero R, Calkins E, Kent $\mathrm{G}$, Offner $\mathrm{H}$ et al (2017) Sex-dependent treatment of chronic EAE with partial MHC class II constructs. J Neuroinflammation 14:100. https://doi.org/10.1186/s12974-017-0873-y

24. Benjamin EJ, Blaha MJ, Chiuve SE, Cushman M, Das SR, Deo R et al (2017) Heart disease and stroke statistics-2017 update: a report from the American Heart Association. Circulation 135:e146-e603

25. Bennett FC, Bennett ML, Yaqoob F, Mulinyawe SB, Grant GA, Hayden Gephart $M$ et al (2018) A combination of ontogeny and cns environment establishes microglial identity. Neuron 98:11701183.e1178. https://doi.org/10.1016/j.neuron.2018.05.014

26. Bennett ML, Bennett FC, Liddelow SA, Ajami B, Zamanian JL, Fernhoff NB et al (2016) New tools for studying microglia in the mouse and human CNS. Proc Natl Acad Sci USA 113:E17381746. https://doi.org/10.1073/pnas.1525528113

27. Bennett RE, Bryant A, Hu M, Robbins AB, Hopp SC, Hyman BT (2018) Partial reduction of microglia does not affect tau pathology in aged mice. J Neuroinflammation 15:311. https://doi.org/ 10.1186/s12974-018-1348-5

28. Berge E, Salman RA-S, van der Worp HB, Stapf C, Sandercock $P$, Sprigg $N$ et al (2017) Increasing value and reducing waste in stroke research. Lancet Neurol 16:399-408

29. Biber K, Moller T, Boddeke E, Prinz M (2016) Central nervous system myeloid cells as drug targets: current status and translational challenges. Nat Rev Drug Discov 15:110-124. https://doi. org/10.1038/nrd.2015.14

30. Biber K, Neumann H, Inoue K, Boddeke HW (2007) Neuronal "on" and "off" signals control microglia. Trends Neurosci 30:596-602. https://doi.org/10.1016/j.tins.2007.08.007

31. Bitsch A, Schuchardt J, Bunkowski S, Kuhlmann T, Bruck W (2000) Acute axonal injury in multiple sclerosis. Correlation with demyelination and inflammation. Brain 123(Pt 6):1174-1183. https://doi.org/10.1093/brain/123.6.1174

32. Bolos M, Llorens-Martin M, Jurado-Arjona J, Hernandez F, Rabano A, Avila J (2016) direct evidence of internalization of tau by microglia in vitro and in vivo. J Alzheimers Dis 50:77-87. https://doi.org/10.3233/JAD-150704
33. Bosetti F, Koenig JI, Ayata C, Back SA, Becker K, Broderick JP et al (2017) Translational stroke research: vision and opportunities. Stroke 48:2632-2637

34. Bradshaw EM, Chibnik LB, Keenan BT, Ottoboni L, Raj T, Tang A et al (2013) CD33 Alzheimer's disease locus: altered monocyte function and amyloid biology. Nat Neurosci 16:848-850

35. Brambilla R (2019) Neuroinflammation, the thread connecting neurological disease: cluster: "Neuroinflammatory mechanisms in neurodegenerative disorders." Acta Neuropathol 137:689-691. https://doi.org/10.1007/s00401-019-02009-9

36. Brelstaff J, Tolkovsky AM, Ghetti B, Goedert M, Spillantini MG (2018) Living neurons with tau filaments aberrantly expose phosphatidylserine and are phagocytosed by microglia. Cell Rep 24(1939-1948):e1934. https://doi.org/10.1016/j.celrep.2018.07. 072

37. Brendecke SM, Prinz M (2015) Do not judge a cell by its cover-diversity of CNS resident, adjoining and infiltrating myeloid cells in inflammation. Semin Immunopathol 37:591605. https://doi.org/10.1007/s00281-015-0520-6

38. Brettschneider J, Toledo JB, Van Deerlin VM, Elman L, McCluskey L, Lee VM et al (2012) Microglial activation correlates with disease progression and upper motor neuron clinical symptoms in amyotrophic lateral sclerosis. PLoS ONE 7:e39216. https://doi.org/10.1371/journal.pone.0039216

39. Burke SA, Wen L, King NJ (2004) Routes of inoculation and the immune response to a resolving genital flavivirus infection in a novel murine model. Immunol Cell Biol 82:174-183. https://doi.org/10.1046/j.0818-9641.2004.01239.x

40. Burrows DJ, McGown A, Jain SA, De Felice M, Ramesh TM, Sharrack B et al (2019) Animal models of multiple sclerosis: from rodents to zebrafish. Mult Scler 25:306-324. https://doi. org/10.1177/1352458518805246

41. Butovsky O, Jedrychowski MP, Moore CS, Cialic R, Lanser AJ, Gabriely G et al (2014) Identification of a unique TGF- $\beta$ dependent molecular and functional signature in microglia. Nat Neurosci 17:131-143. https://doi.org/10.1038/nn.3599

42. Butovsky O, Koronyo-Hamaoui M, Kunis G, Ophir E, Landa G, Cohen $\mathrm{H}$ et al (2006) Glatiramer acetate fights against Alzheimer's disease by inducing dendritic-like microglia expressing insulin-like growth factor 1 . Proc Natl Acad Sci USA 103:11784-11789. https://doi.org/10.1073/pnas.0604681103

43. Butovsky O, Landa G, Kunis G, Ziv Y, Avidan H, Greenberg N et al (2006) Induction and blockage of oligodendrogenesis by differently activated microglia in an animal model of multiple sclerosis. J Clin Invest 116:905-915. https://doi.org/10.1172/ JCI26836

44. Butovsky O, Siddiqui S, Gabriely G, Lanser AJ, Dake B, Murugaiyan $\mathrm{G}$ et al (2012) Modulating inflammatory monocytes with a unique microRNA gene signature ameliorates murine ALS. J Clin Invest 122:3063-3087. https://doi.org/10.1172/ JCI62636

45. Buttgereit A, Lelios I, Yu X, Vrohlings M, Krakoski NR, Gautier EL et al (2016) Sall1 is a transcriptional regulator defining microglia identity and function. Nat Immunol 17:1397-1406. https://doi.org/10.1038/ni.3585

46. Calabrese M, Magliozzi R, Ciccarelli O, Geurts JJ, Reynolds R, Martin R (2015) Exploring the origins of grey matter damage in multiple sclerosis. Nat Rev Neurosci 16:147-158. https://doi.org/ 10.1038/nrn3900

47. Cassidy JM, Cramer SC (2017) Spontaneous and therapeuticinduced mechanisms of functional recovery after stroke. Transl Stroke Res 8:33-46

48. Chakrabarty P, Ceballos-Diaz C, Beccard A, Janus C, Dickson D, Golde TE et al (2010) IFN-gamma promotes complement expression and attenuates amyloid plaque deposition in amyloid beta 
precursor protein transgenic mice. J Immunol 184:5333-5343. https://doi.org/10.4049/jimmunol.0903382

49. Chakrabarty P, Herring A, Ceballos-Diaz C, Das P, Golde TE (2011) Hippocampal expression of murine TNFalpha results in attenuation of amyloid deposition in vivo. Mol Neurodegener 6:16. https://doi.org/10.1186/1750-1326-6-16

50. Chakrabarty P, Jansen-West K, Beccard A, Ceballos-Diaz C, Levites Y, Verbeeck C et al (2010) Massive gliosis induced by interleukin-6 suppresses Abeta deposition in vivo: evidence against inflammation as a driving force for amyloid deposition. Faseb J 24:548-559. https://doi.org/10.1096/fj.09-141754

51. Chamorro Á, Dirnagl U, Urra X, Planas AM (2016) Neuroprotection in acute stroke: targeting excitotoxicity, oxidative and nitrosative stress, and inflammation. The Lancet Neurology $15: 869-881$

52. Chan G, White CC, Winn PA, Cimpean M, Replogle JM, Glick LR et al (2015) CD33 modulates TREM2: convergence of Alzheimer loci. Nat Neurosci 18:1556-1558

53. Cheeran MC, Hu S, Sheng WS, Rashid A, Peterson PK, Lokensgard JR (2005) Differential responses of human brain cells to West Nile virus infection. J Neurovirol 11:512-524. https://doi.org/10.1080/13550280500384982

54. Chen BP, Kuziel WA, Lane TE (2001) Lack of CCR2 results in increased mortality and impaired leukocyte activation and trafficking following infection of the central nervous system with a neurotropic coronavirus. J Immunol 167:4585-4592

55. Chen H-R, Sun Y-Y, Chen C-W, Kuo Y-M, Kuan IS, Tiger Li Z-R et al (2020) Fate mapping via CCR2-CreER mice reveals monocyte-to-microglia transition in development and neonatal stroke. Sci Adv 6:eabb2119. https://doi.org/10.1126/sciadv. abb2119

56. Chen S-H, Tian D-Y, Shen Y-Y, Cheng Y, Fan D-Y, Sun H-L et al (2020) Amyloid-beta uptake by blood monocytes is reduced with ageing and Alzheimer's disease. Transl Psychiatry 10:1-11

57. Chen SH, Oyarzabal EA, Hong JS (2016) Critical role of the Mac1/NOX2 pathway in mediating reactive microgliosis-generated chronic neuroinflammation and progressive neurodegeneration. Curr Opin Pharmacol 26:54-60. https://doi.org/10.1016/j. coph.2015.10.001

58. Chen WW, Zhang X, Huang WJ (2016) Role of neuroinflammation in neurodegenerative diseases (review). Mol Med Rep 13:3391-3396. https://doi.org/10.3892/mmr.2016.4948

59. Chhatbar C, Detje CN, Grabski E, Borst K, Spanier J, Ghita L et al (2018) Type I interferon receptor signaling of neurons and astrocytes regulates microglia activation during viral encephalitis. Cell Rep 25(118-129):e114. https://doi.org/10.1016/j.celrep. 2018.09.003

60. Chu HX, Broughton BR, Ah Kim H, Lee S, Drummond GR, Sobey CG (2015) Evidence that Ly6Chi monocytes are protective in acute ischemic stroke by promoting M2 macrophage polarization. Stroke 46:1929-1937

61. Clayton K, Delpech JC, Herron S, Iwahara N, Ericsson M, Saito T et al (2021) Plaque associated microglia hyper-secrete extracellular vesicles and accelerate tau propagation in a humanized APP mouse model. Mol Neurodegener 16:18. https://doi.org/10.1186/ s13024-021-00440-9

62. Coleman P, Federoff H, Kurlan R (2004) A focus on the synapse for neuroprotection in Alzheimer disease and other dementias. Neurology 63:1155-1162. https://doi.org/10.1212/01.wnl.00001 40626.48118.0a

63. Condello C, Yuan P, Schain A, Grutzendler J (2015) Microglia constitute a barrier that prevents neurotoxic protofibrillar Abeta42 hotspots around plaques. Nat Commun 6:6176. https:// doi.org/10.1038/ncomms7176
64. Constantinescu CS, Farooqi N, O'Brien K, Gran B (2011) Experimental autoimmune encephalomyelitis (EAE) as a model for multiple sclerosis (MS). Br J Pharmacol 164:1079-1106

65. Croisier E, Moran LB, Dexter DT, Pearce RK, Graeber MB (2005) Microglial inflammation in the parkinsonian substantia nigra: relationship to alpha-synuclein deposition. J Neuroinflammation 2:14. https://doi.org/10.1186/1742-2094-2-14

66. Cronk JC, Filiano AJ, Louveau A, Marin I, Marsh R, Ji E et al (2018) Peripherally derived macrophages can engraft the brain independent of irradiation and maintain an identity distinct from microglia. J Exp Med 215:1627-1647. https://doi.org/10.1084/ jem.20180247

67. Croxford AL, Lanzinger M, Hartmann FJ, Schreiner B, Mair F, Pelczar P et al (2015) The cytokine GM-CSF drives the inflammatory signature of CCR2+ monocytes and licenses autoimmunity. Immunity 43:502-514

68. Cummings J, Lee G, Ritter A, Sabbagh M, Zhong K (2020) Alzheimer's disease drug development pipeline: 2020. Alzheimers Dement (N Y) 6:e12050. https://doi.org/10.1002/trc2.12050

69. Cummings JL, Morstorf T, Zhong K (2014) Alzheimer's disease drug-development pipeline: few candidates, frequent failures. Alzheimers Res Ther 6:37. https://doi.org/10.1186/alzrt269

70. Cusick MF, Libbey JE, Patel DC, Doty DJ, Fujinami RS (2013) Infiltrating macrophages are key to the development of seizures following virus infection. J Virol 87:1849-1860

71. Da Mesquita S, Louveau A, Vaccari A, Smirnov I, Cornelison RC, Kingsmore KM et al (2018) Functional aspects of meningeal lymphatics in ageing and Alzheimer's disease. Nature 560:185191. https://doi.org/10.1038/s41586-018-0368-8

72. Davison AM, King NJ (2011) Accelerated dendritic cell differentiation from migrating Ly6C(lo) bone marrow monocytes in early dermal West Nile virus infection. J Immunol 186:2382-2396. https://doi.org/10.4049/jimmunol.1002682

73. Davison AM, King NJ (2011) Accelerated dendritic cell differentiation from migrating Ly6Clo bone marrow monocytes in early dermal west nile virus infection. J Immunol 186:2382-2396

74. Deczkowska A, Keren-Shaul H, Weiner A, Colonna M, Schwartz M, Amit I (2018) Disease-associated microglia: a universal immune sensor of neurodegeneration. Cell 173:1073-1081. https://doi.org/10.1016/j.cell.2018.05.003

75. Dejanovic B, Huntley MA, De Maziere A, Meilandt WJ, Wu $\mathrm{T}$, Srinivasan K et al (2018) Changes in the synaptic proteome in tauopathy and rescue of tau-induced synapse loss by C1q antibodies. Neuron 100(1322-1336):e1327. https://doi.org/10. 1016/j.neuron.2018.10.014

76. Dela Cruz CS, Kang MJ (2018) Mitochondrial dysfunction and damage associated molecular patterns (DAMPs) in chronic inflammatory diseases. Mitochondrion 41:37-44. https://doi.org/ 10.1016/j.mito.2017.12.001

77. Dendrou CA, Fugger L, Friese MA (2015) Immunopathology of multiple sclerosis. Nat Rev Immunol 15:545-558. https://doi.org/ 10.1038/nri3871

78. DePaula-Silva AB, Gorbea C, Doty DJ, Libbey JE, Sanchez JMS, Hanak TJ et al (2019) Differential transcriptional profiles identify microglial- and macrophage-specific gene markers expressed during virus-induced neuroinflammation. J Neuroinflammation 16:152. https://doi.org/10.1186/s12974-019-1545-x

79. DePaula-Silva AB, Hanak TJ, Libbey JE, Fujinami RS (2017) Theiler's murine encephalomyelitis virus infection of SJL/J and C57BL/6J mice: models for multiple sclerosis and epilepsy. J Neuroimmunol 308:30-42

80. Diamond MS, Shrestha B, Marri A, Mahan D, Engle M (2003) $B$ cells and antibody play critical roles in the immediate defense of disseminated infection by West Nile encephalitis virus. J Virol 77:2578-2586. https://doi.org/10.1128/jvi.77.4.2578-2586.2003 
81. Dimitrijevic OB, Stamatovic SM, Keep RF, Andjelkovic AV (2007) Absence of the chemokine receptor CCR2 protects against cerebral ischemia/reperfusion injury in mice. Stroke 38:1345-1353

82. Dionisio-Santos DA, Olschowka JA, O'Banion MK (2019) Exploiting microglial and peripheral immune cell crosstalk to treat Alzheimer's disease. J Neuroinflammation 16:74. https:// doi.org/10.1186/s12974-019-1453-0

83. Dirnagl U (2016) Thomas Willis lecture: is translational stroke research broken, and if so, how can we fix it? Stroke 47:2148-2153

84. Dirnagl U, Endres M (2014) Found in translation: preclinical stroke research predicts human pathophysiology, clinical phenotypes, and therapeutic outcomes. Stroke 45:1510-1518

85. Dirnagl U, Iadecola C, Moskowitz MA (1999) Pathobiology of ischaemic stroke: an integrated view. Trends Neurosci 22:391-397

86. Drummond E, Wisniewski T (2017) Alzheimer's disease: experimental models and reality. Acta Neuropathol 133:155-175. https://doi.org/10.1007/s00401-016-1662-x

87. Dubois B, Villain N, Frisoni GB, Rabinovici GD, Sabbagh M, Cappa $S$ et al (2021) Clinical diagnosis of Alzheimer's disease: recommendations of the International Working Group. Lancet Neurol 20:484-496. https://doi.org/10.1016/S1474-4422(21) 00066-1

88. Dumas AA, Borst K, Prinz M (2021) Current tools to interrogate microglial biology. Neuron 109:2805-2819. https://doi.org/10. 1016/j.neuron.2021.07.004

89. El Khoury J, Toft M, Hickman SE, Means TK, Terada K, Geula C et al (2007) Ccr2 deficiency impairs microglial accumulation and accelerates progression of Alzheimer-like disease. Nat Med 13:432-438

90. Eldahshan W, Fagan SC, Ergul A (2019) Inflammation within the neurovascular unit: focus on microglia for stroke injury and recovery. Pharmacol Res 147:104349. https://doi.org/10.1016/j. phrs.2019.104349

91. Eme-Scolan E, Dando SJ (2020) Tools and approaches for studying microglia in vivo. Front Immunol 11:583647. https://doi.org/ 10.3389/fimmu.2020.583647

92. Ergul A, Elgebaly MM, Middlemore M-L, Li W, Elewa H, Switzer JA et al (2007) Increased hemorrhagic transformation and altered infarct size and localization after experimental stroke in a rat model type 2 diabetes. BMC Neurol 7:1-7

93. Faden AI, Loane DJ (2015) Chronic neurodegeneration after traumatic brain injury: Alzheimer disease, chronic traumatic encephalopathy, or persistent neuroinflammation? Neurotherapeutics 12:143-150. https://doi.org/10.1007/s13311-014-0319-5

94. Fahrenhold M, Rakic S, Classey J, Brayne C, Ince PG, Nicoll JAR et al (2018) TREM2 expression in the human brain: a marker of monocyte recruitment? Brain Pathol 28:595-602. https://doi.org/10.1111/bpa.12564

95. Feigin VL, Lawes CM, Bennett DA, Anderson CS (2003) Stroke epidemiology: a review of population-based studies of incidence, prevalence, and case-fatality in the late 20th century. Lancet Neurol 2:43-53

96. Fekete R, Cserep C, Lenart N, Toth K, Orsolits B, Martinecz B et al (2018) Microglia control the spread of neurotropic virus infection via P2Y12 signalling and recruit monocytes through P2Y12-independent mechanisms. Acta Neuropathol 136:461482. https://doi.org/10.1007/s00401-018-1885-0

97. Festoff BW, Sajja RK, van Dreden P, Cucullo L (2016) HMGB1 and thrombin mediate the blood-brain barrier dysfunction acting as biomarkers of neuroinflammation and progression to neurodegeneration in Alzheimer's disease. J Neuroinflammation 13:194. https://doi.org/10.1186/s12974-016-0670-z
98. Fife BT, Huffnagle GB, Kuziel WA, Karpus WJ (2000) CC chemokine receptor 2 is critical for induction of experimental autoimmune encephalomyelitis. J Exp Med 192:899-906

99. Fischer MT, Wimmer I, Hoftberger R, Gerlach S, Haider L, Zrzavy T et al (2013) Disease-specific molecular events in cortical multiple sclerosis lesions. Brain 136:1799-1815. https://doi. org/10.1093/brain/awt110

100. Fisher M, Feuerstein G, Howells DW, Hurn PD, Kent TA, Savitz SI et al (2009) Update of the stroke therapy academic industry roundtable preclinical recommendations. Stroke 40:2244-2250

101. Flanary BE, Sammons NW, Nguyen C, Walker D, Streit WJ (2007) Evidence that aging and amyloid promote microglial cell senescence. Rejuvenation Res 10:61-74. https://doi.org/10.1089/ rej.2006.9096

102. Foidl BM, Humpel C (2020) Can mouse models mimic sporadic Alzheimer's disease? Neural Regen Res 15:401-406. https://doi. org/10.4103/1673-5374.266046

103. Fonseca MI, Chu SH, Hernandez MX, Fang MJ, Modarresi L, Selvan P et al (2017) Cell-specific deletion of C1qa identifies microglia as the dominant source of C1q in mouse brain. J Neuroinflammation 14:48. https://doi.org/10.1186/s12974-017-0814-9

104. Forner S, Baglietto-Vargas D, Martini AC, Trujillo-Estrada L, LaFerla FM (2017) Synaptic impairment in Alzheimer's disease: a dysregulated symphony. Trends Neurosci 40:347-357. https:// doi.org/10.1016/j.tins.2017.04.002

105. Franceschi C, Campisi J (2014) Chronic inflammation (inflammaging) and its potential contribution to age-associated diseases. J Gerontol A Biol Sci Med Sci 69(Suppl 1):S4-9. https://doi.org/ 10.1093/gerona/glu057

106. Friedman BA, Srinivasan K, Ayalon G, Meilandt WJ, Lin H, Huntley MA et al (2018) Diverse brain myeloid expression profiles reveal distinct microglial activation states and aspects of Alzheimer's disease not evident in mouse models. Cell Rep 22:832-847. https://doi.org/10.1016/j.celrep.2017.12.066

107. Funk KE, Klein RS (2019) CSF1R antagonism limits local restimulation of antiviral CD8+ T cells during viral encephalitis. J Neuroinflammation 16:22. https://doi.org/10.1186/ s12974-019-1397-4

108. Funk KE, Mirbaha H, Jiang H, Holtzman DM, Diamond MI (2015) Distinct therapeutic mechanisms of tau antibodies: promoting microglial clearance versus blocking neuronal uptake. J Biol Chem 290:21652-21662. https://doi.org/10.1074/jbc.M115. 657924

109. Gaber T, Strehl C, Buttgereit F (2017) Metabolic regulation of inflammation. Nat Rev Rheumatol 13:267-279

110. Gao HM, Zhou H, Zhang F, Wilson BC, Kam W, Hong JS (2011) HMGB1 acts on microglia Mac1 to mediate chronic neuroinflammation that drives progressive neurodegeneration. J Neurosci 31:1081-1092. https://doi.org/10.1523/JNEUROSCI.3732-10. 2011

111. Garber C, Soung A, Vollmer LL, Kanmogne M, Last A, Brown $\mathrm{J}$ et al (2019) T cells promote microglia-mediated synaptic elimination and cognitive dysfunction during recovery from neuropathogenic flaviviruses. Nat Neurosci 22:1276-1288. https:// doi.org/10.1038/s41593-019-0427-y

112. Gardner LE, White JD, Eimerbrink MJ, Boehm GW, Chumley MJ (2016) Imatinib methanesulfonate reduces hyperphosphorylation of tau following repeated peripheral exposure to lipopolysaccharide. Neuroscience 331:72-77. https://doi.org/10.1016/j.neuro science.2016.06.007

113. Garwood CJ, Cooper JD, Hanger DP, Noble W (2010) Antiinflammatory impact of minocycline in a mouse model of tauopathy. Front Psychiatry 1:136. https://doi.org/10.3389/fpsyt.2010. 00136 
114. Geissmann F, Jung S, Littman DR (2003) Blood monocytes consist of two principal subsets with distinct migratory properties. Immunity 19:71-82

115. Geissmann F, Manz MG, Jung S, Sieweke MH, Merad M, Ley K (2010) Development of monocytes, macrophages, and dendritic cells. Science 327:656-661. https://doi.org/10.1126/scien ce. 1178331

116. Gelderblom M, Leypoldt F, Steinbach K, Behrens D, Choe CU, Siler DA et al (2009) Temporal and spatial dynamics of cerebral immune cell accumulation in stroke. Stroke 40:1849-1857. https://doi.org/10.1161/STROKEAHA.108.534503

117. Gergely S, Bernadett M, Nikolett L, Zsuzsanna K, Barbara O, Linda J et al (2016) Microglia protect against brain injury and their selective elimination dysregulates neuronal network activity after stroke. Nat Commun. https://doi.org/10.1038/ncomm s11499

118. Gerhauser I, Hansmann F, Puff C, Kumnok J, Schaudien D, Wewetzer K et al (2012) Theiler's murine encephalomyelitis virus induced phenotype switch of microglia in vitro. J Neuroimmunol 252:49-55. https://doi.org/10.1016/j.jneuroim.2012.07. 018

119. Gerrits E, Brouwer N, Kooistra SM, Woodbury ME, Vermeiren Y, Lambourne $\mathrm{M}$ et al (2021) Distinct amyloid-beta and tau-associated microglia profiles in Alzheimer's disease. Acta Neuropathol 141:681-696. https://doi.org/10.1007/ s00401-021-02263-w

120. Getts DR, Matsumoto I, Müller M, Getts MT, Radford J, Shrestha B et al (2007) Role of IFN- $\gamma$ in an experimental murine model of West Nile virus-induced seizures. J Neurochem 103:1019-1030

121. Getts DR, Terry RL, Getts MT, Deffrasnes C, Müller M, van Vreden $C$ et al (2014) Therapeutic inflammatory monocyte modulation using immune-modifying microparticles. Science translational medicine. https://doi.org/10.1126/scitranslmed.3007563

122. Getts DR, Terry RL, Getts MT, Müller M, Rana S, Deffrasnes C et al (2012) Targeted blockade in lethal West Nile virus encephalitis indicates a crucial role for very late antigen (VLA)-4-dependent recruitment of nitric oxide-producing macrophages. $\mathbf{J}$ Neuroinflammation 9:246

123. Getts DR, Terry RL, Getts MT, Müller M, Rana S, Shrestha B et al (2008) Ly6c+ "inflammatory monocytes" are microglial precursors recruited in a pathogenic manner in West Nile virus encephalitis. J Exp Med 205:2319-2337. https://doi.org/10.1084/ jem. 20080421

124. Giladi A, Wagner LK, Li H, Dörr D, Medaglia C, Paul F et al (2020) Cxcl10+ monocytes define a pathogenic subset in the central nervous system during autoimmune neuroinflammation. Nat Immunol 21:525-534

125. Giles DA, Duncker PC, Wilkinson NM, Washnock-Schmid JM, Segal BM (2018) CNS-resident classical DCs play a critical role in CNS autoimmune disease. J Clin Invest 128:5322-5334. https://doi.org/10.1172/JCI123708

126. Ginhoux F, Greter M, Leboeuf M, Nandi S, See P, Gokhan S et al (2010) Fate mapping analysis reveals that adult microglia derive from primitive macrophages. Science 330:841-845

127. Gliem M, Mausberg AK, Lee JI, Simiantonakis I, van Rooijen N, Hartung HP et al (2012) Macrophages prevent hemorrhagic infarct transformation in murine stroke models. Ann Neurol 71:743-752

128. Goldmann T, Wieghofer P, Jordão MJC, Prutek F, Hagemeyer N, Frenzel K et al (2016) Origin, fate and dynamics of macrophages at central nervous system interfaces. Nat Immunol 17:797

129. Goldmann T, Wieghofer P, Muller PF, Wolf Y, Varol D, Yona S et al (2013) A new type of microglia gene targeting shows TAK1 to be pivotal in CNS autoimmune inflammation. Nat Neurosci 16:1618-1626. https://doi.org/10.1038/nn.3531
130. Gomez Perdiguero E, Klapproth K, Schulz C, Busch K, Azzoni $\mathrm{E}$, Crozet L et al (2015) Tissue-resident macrophages originate from yolk-sac-derived erythro-myeloid progenitors. Nature 518:547-551. https://doi.org/10.1038/nature13989

131. Grabert K, Sehgal A, Irvine KM, Wollscheid-Lengeling E, Ozdemir DD, Stables J et al (2020) A transgenic line that reports CSF1R protein expression provides a definitive marker for the mouse mononuclear phagocyte system. J Immunol 205:31543166. https://doi.org/10.4049/jimmunol.2000835

132. Graeber MB (2014) Neuroinflammation: no rose by any other name. Brain Pathol 24:620-622. https://doi.org/10.1111/bpa. 12192

133. Grassivaro F, Menon R, Acquaviva M, Ottoboni L, Ruffini F, Bergamaschi A et al (2020) Convergence between microglia and peripheral macrophages phenotype during development and neuroinflammation. J Neurosci 40:784-795

134. Green KN, Hume DA (2021) On the utility of CSF1R inhibitors. Proc Natl Acad Sci USA. https://doi.org/10.1073/pnas.20196 95118

135. Greter M, Helft J, Chow A, Hashimoto D, Mortha A, AgudoCantero J et al (2012) GM-CSF controls nonlymphoid tissue dendritic cell homeostasis but is dispensable for the differentiation of inflammatory dendritic cells. Immunity 36:1031-1046

136. Greter M, Heppner FL, Lemos MP, Odermatt BM, Goebels N, Laufer T et al (2005) Dendritic cells permit immune invasion of the CNS in an animal model of multiple sclerosis. Nat Med $11: 328-334$

137. Greter M, Lelios I, Croxford AL (2015) Microglia versus myeloid cell nomenclature during brain inflammation. Front Immunol 6:249. https://doi.org/10.3389/fimmu.2015.00249

138. Guerrero BL, Sicotte NL (2020) Microglia in multiple sclerosis: friend or foe? Front Immunol 11:374. https://doi.org/10.3389/ fimmu.2020.00374

139. Guilliams M, Ginhoux F, Jakubzick C, Naik SH, Onai N, Schraml BU et al (2014) Dendritic cells, monocytes and macrophages: a unified nomenclature based on ontogeny. Nat Rev Immunol 14:571-578

140. Guzman-Martinez L, Maccioni RB, Andrade V, Navarrete LP, Pastor MG, Ramos-Escobar N (2019) Neuroinflammation as a common feature of neurodegenerative disorders. Front Pharmacol 10:1008. https://doi.org/10.3389/fphar.2019.01008

141. Hafezi W, Lorentzen EU, Eing BR, Muller M, King NJ, Klupp B et al (2012) Entry of herpes simplex virus type 1 (HSV-1) into the distal axons of trigeminal neurons favors the onset of nonproductive, silent infection. PLoS Pathog 8:e1002679. https://doi. org/10.1371/journal.ppat.1002679

142. Hall AM, Roberson ED (2012) Mouse models of Alzheimer's disease. Brain Res Bull 88:3-12. https://doi.org/10.1016/j.brain resbull.2011.11.017

143. Hammond MD, Taylor RA, Mullen MT, Ai Y, Aguila HL, Mack $\mathrm{M}$ et al (2014) CCR2+ Ly6Chi inflammatory monocyte recruitment exacerbates acute disability following intracerebral hemorrhage. J Neurosci 34:3901-3909

144. Hanna RN, Carlin LM, Hubbeling HG, Nackiewicz D, Green AM, Punt JA et al (2011) The transcription factor NR4A1 (Nur77) controls bone marrow differentiation and the survival of Ly6C- monocytes. Nat Immunol 12:778

145. Hanninen A, Jaakkola I, Salmi M, Simell O, Jalkanen S (1997) Ly-6C regulates endothelial adhesion and homing of CD8(+) T cells by activating integrin-dependent adhesion pathways. Proc Natl Acad Sci USA 94:6898-6903. https://doi.org/10.1073/pnas. 94.13.6898

146. Hanninen A, Maksimow M, Alam C, Morgan DJ, Jalkanen S (2011) Ly6C supports preferential homing of central memory CD8+ T cells into lymph nodes. Eur J Immunol 41:634-644. https://doi.org/10.1002/eji.201040760 
147. Hawkes CA, McLaurin J (2009) Selective targeting of perivascular macrophages for clearance of beta-amyloid in cerebral amyloid angiopathy. Proc Natl Acad Sci USA 106:1261-1266. https://doi.org/10.1073/pnas.0805453106

148. Hendrickx DAE, van Eden CG, Schuurman KG, Hamann J, Huitinga I (2017) Staining of HLA-DR, Iba1 and CD68 in human microglia reveals partially overlapping expression depending on cellular morphology and pathology. J Neuroimmunol 309:12-22. https://doi.org/10.1016/j.jneuroim.2017.04.007

149. Heneka MT, Kummer MP, Latz E (2014) Innate immune activation in neurodegenerative disease. Nat Rev Immunol 14:463477. https://doi.org/10.1038/nri3705

150. Heppner FL, Greter M, Marino D, Falsig J, Raivich G, Hovelmeyer $\mathrm{N}$ et al (2005) Experimental autoimmune encephalomyelitis repressed by microglial paralysis. Nat Med 11:146-152. https://doi.org/10.1038/nm1177

151. Hong J, Kim BS (2018) Regulatory T cell-mediated tissue repair. Adv Exp Med Biol 1064:221-233. https://doi.org/10.1007/978981-13-0445-3_14

152. Hong S, Beja-Glasser VF, Nfonoyim BM, Frouin A, Li S, Ramakrishnan S et al (2016) Complement and microglia mediate early synapse loss in Alzheimer mouse models. Science 352:712-716. https://doi.org/10.1126/science.aad8373

153. Hopp SC, Lin Y, Oakley D, Roe AD, DeVos SL, Hanlon D et al (2018) The role of microglia in processing and spreading of bioactive tau seeds in Alzheimer's disease. J Neuroinflammation 15:269. https://doi.org/10.1186/s12974-018-1309-z

154. Hossmann K-A (2012) The two pathophysiologies of focal brain ischemia: implications for translational stroke research. J Cereb Blood Flow Metab 32:1310-1316

155. Howe CL, LaFrance-Corey RG, Sundsbak RS, LaFrance SJ (2012) Inflammatory monocytes damage the hippocampus during acute picornavirus infection of the brain. J Neuroinflammation 9:50

156. Howell OW, Reeves CA, Nicholas R, Carassiti D, Radotra B, Gentleman SM et al (2011) Meningeal inflammation is widespread and linked to cortical pathology in multiple sclerosis. Brain 134:2755-2771. https://doi.org/10.1093/brain/awr182

157. Howells DW, Porritt MJ, Rewell SS, O'collins V, Sena ES, Van Der Worp HB et al (2010) Different strokes for different folks: the rich diversity of animal models of focal cerebral ischemia. J Cereb Blood Flow Metab 30:1412-1431

158. Howells DW, Sena ES, Macleod MR (2014) Bringing rigour to translational medicine. Nat Rev Neurol 10:37-43

159. Hume DA (2008) Differentiation and heterogeneity in the mononuclear phagocyte system. Mucosal Immunol 1:432-441. https:// doi.org/10.1038/mi.2008.36

160. Iadecola C, Anrather J (2011) The immunology of stroke: from mechanisms to translation. Nat Med 17:796-808

161. International Multiple Sclerosis Genetics C (2019) Multiple sclerosis genomic map implicates peripheral immune cells and microglia in susceptibility. Science 5:5. https://doi.org/10.1126/ science.aav7188

162. Ising C, Venegas C, Zhang S, Scheiblich H, Schmidt SV, VieiraSaecker A et al (2019) NLRP3 inflammasome activation drives tau pathology. Nature 575:669-673. https://doi.org/10.1038/ s41586-019-1769-z

163. Ivan DC, Walthert S, Berve K, Steudler J, Locatelli G (2020) Dwellers and trespassers: mononuclear phagocytes at the borders of the central nervous system. Front Immunol 11:609921. https:// doi.org/10.3389/fimmu.2020.609921

164. Ivan DC, Walthert S, Locatelli G (2021) Central nervous system barriers impact distribution and expression of iNOS and arginase-1 in infiltrating macrophages during neuroinflammation. Front Immunol. https://doi.org/10.3389/fimmu.2021.666961
165. Izikson L, Klein RS, Charo IF, Weiner HL, Luster AD (2000) Resistance to experimental autoimmune encephalomyelitis in mice lacking the CC chemokine receptor (CCR2). J Exp Med 192:1075-1080

166. Jaakkola I, Merinen M, Jalkanen S, Hanninen A (2003) Ly6C induces clustering of LFA-1 (CD11a/CD18) and is involved in subtype-specific adhesion of CD8 T cells. J Immunol 170:12831290. https://doi.org/10.4049/jimmunol.170.3.1283

167. Jackson L, Dong G, Althomali W, Sayed MA, Eldahshan W, Baban B et al (2019) Delayed administration of angiotensin II type 2 receptor (AT2R) agonist compound 21 prevents the development of post-stroke cognitive impairment in diabetes through the modulation of microglia polarization. Transl Stroke Res 5:5. https://doi.org/10.1007/s12975-019-00752-5

168. Jackson L, Dumanli S, Johnson MH, Fagan SC, Ergul A (2020) Microglia knockdown reduces inflammation and preserves cognition in diabetic animals after experimental stroke. J Neuroinflammation 17:137. https://doi.org/10.1186/s12974-020-01815-3

169. James RE, Schalks R, Browne E, Eleftheriadou I, Munoz CP, Mazarakis ND et al (2020) Persistent elevation of intrathecal pro-inflammatory cytokines leads to multiple sclerosis-like cortical demyelination and neurodegeneration. Acta Neuropathol Commun 8:66. https://doi.org/10.1186/s40478-020-00938-1

170. Jickling GC, Liu D, Ander BP, Stamova B, Zhan X, Sharp FR (2015) Targeting neutrophils in ischemic stroke: translational insights from experimental studies. J Cereb Blood Flow Metab 35:888-901. https://doi.org/10.1038/jcbfm.2015.45

171. Jin R, Yang G, Li G (2010) Inflammatory mechanisms in ischemic stroke: role of inflammatory cells. J Leukoc Biol 87:779-789

172. Jin WN, Shi SX, Li Z, Li M, Wood K, Gonzales RJ et al (2017) Depletion of microglia exacerbates postischemic inflammation and brain injury. J Cereb Blood Flow Metab 37:2224-2236. https://doi.org/10.1177/0271678X17694185

173. Joost E, Jordao MJC, Mages B, Prinz M, Bechmann I, Krueger M (2019) Microglia contribute to the glia limitans around arteries, capillaries and veins under physiological conditions, in a model of neuroinflammation and in human brain tissue. Brain Struct Funct 224:1301-1314. https://doi.org/10.1007/ s00429-019-01834-8

174. Jordão MJC, Sankowski R, Brendecke SM, Sagar A, Locatelli G, Tai Y-H et al (2019) Single-cell profiling identifies myeloid cell subsets with distinct fates during neuroinflammation. Science 363:eaat7554. https://doi.org/10.1126/science.aat7554

175. Kassem-Moussa H, Graffagnino C (2002) Nonocclusion and spontaneous recanalization rates in acute ischemic stroke: a review of cerebral angiography studies. Arch Neurol 59:1870-1873

176. Katan M, Luft A (2018) Global burden of stroke. Semin Neurol 38:208-211. https://doi.org/10.1055/s-0038-1649503

177. Kaushik DK, Bhattacharya A, Mirzaei R, Rawji KS, Ahn Y, Rho JM et al (2019) Enhanced glycolytic metabolism supports transmigration of brain-infiltrating macrophages in multiple sclerosis. J Clin Investig 129:3277-3292

178. Kawai T, Akira S (2006) Innate immune recognition of viral infection. Nat Immunol 7:131-137. https://doi.org/10.1038/ ni1303

179. Keren-Shaul H, Spinrad A, Weiner A, Matcovitch-Natan O, Dvir-Szternfeld R et al (2017) A unique microglia type associated with restricting development of Alzheimer's disease. Cell 169(1276-1290):e1217. https://doi.org/10.1016/j.cell.2017.05. 018

180. Khaw YM, Tierney A, Cunningham C, Soto-Diaz K, Kang E, Steelman AJ et al (2021) Astrocytes lure CXCR2-expressing CD4(+) T cells to gray matter via TAK1-mediated chemokine 
production in a mouse model of multiple sclerosis. Proc Natl Acad Sci USA 5:5. https://doi.org/10.1073/pnas.2017213118

181. Kierdorf K, Erny D, Goldmann T, Sander V, Schulz C, Perdiguero EG et al (2013) Microglia emerge from erythromyeloid precursors via Pu.1- and Irf8-dependent pathways. Nat Neurosci 16:273-280. https://doi.org/10.1038/nn.3318

182. Kierdorf K, Masuda T, Jordao MJC, Prinz M (2019) Macrophages at CNS interfaces: ontogeny and function in health and disease. Nat Rev Neurosci 20:547-562. https://doi.org/10.1038/ s41583-019-0201-x

183. King IL, Dickendesher TL, Segal BM (2009) Circulating Ly-6C+ myeloid precursors migrate to the CNS and play a pathogenic role during autoimmune demyelinating disease. Blood J Am Soc Hematol 113:3190-3197

184. King NJ, Getts DR, Getts MT, Rana S, Shrestha B, Kesson AM (2007) Immunopathology of flavivirus infections. Immunol Cell Biol 85:33-42. https://doi.org/10.1038/sj.icb.7100012

185. King NJC, Van Vreden C, Terry RL, Getts DR, Yeung AWS, Teague-Getts $M$ et al (2011) The immunopathogenesis of neurotropic flavivirus infection. InTech, London

186. Kipp M, Nyamoya S, Hochstrasser T, Amor S (2017) Multiple sclerosis animal models: a clinical and histopathological perspective. Brain Pathol 27:123-137. https://doi.org/10.1111/bpa.12454

187. Kitazawa M, Oddo S, Yamasaki TR, Green KN, LaFerla FM (2005) Lipopolysaccharide-induced inflammation exacerbates tau pathology by a cyclin-dependent kinase 5 -mediated pathway in a transgenic model of Alzheimer's disease. J Neurosci 25:8843-8853. https://doi.org/10.1523/JNEUROSCI.2868-05. 2005

188. Klein RS, Garber C, Funk KE, Salimi H, Soung A, Kanmogne $M$ et al (2019) Neuroinflammation During RNA Viral Infections. Annu Rev Immunol 37:73-95. https://doi.org/10.1146/ annurev-immunol-042718-041417

189. Ko H-J, Brady JL, Ryg-Cornejo V, Hansen DS, Vremec D, Shortman K et al (2014) GM-CSF-responsive monocytederived dendritic cells are pivotal in Th17 pathogenesis. J Immunol 192:2202-2209

190. Komuczki J, Tuzlak S, Friebel E, Hartwig T, Spath S, Rosenstiel P et al (2019) Fate-mapping of GM-CSF expression identifies a discrete subset of inflammation-driving $\mathrm{T}$ helper cells regulated by cytokines IL-23 and IL-1 $\beta$. Immunity 50:12891304.e1286

191. Krasemann S, Madore C, Cialic R, Baufeld C, Calcagno N, El Fatimy R et al (2017) The TREM2-APOE pathway drives the transcriptional phenotype of dysfunctional microglia in neurodegenerative diseases. Immunity 47(566-581):e569. https://doi. org/10.1016/j.immuni.2017.08.008

192. Kronenberg G, Uhlemann R, Richter N, Klempin F, Wegner S, Staerck L et al (2018) Distinguishing features of microglia-and monocyte-derived macrophages after stroke. Acta Neuropathol 135:551-568

193. Kuhlmann T, Ludwin S, Prat A, Antel J, Bruck W, Lassmann H (2017) An updated histological classification system for multiple sclerosis lesions. Acta Neuropathol 133:13-24. https://doi.org/ 10.1007/s00401-016-1653-y

194. Kwon HS, Koh SH (2020) Neuroinflammation in neurodegenerative disorders: the roles of microglia and astrocytes. Transl Neurodegener 9:42. https://doi.org/10.1186/s40035-020-00221-2

195. Labrecque N, Cermakian N (2015) Circadian clocks in the immune system. J Biol Rhythms 30:277-290. https://doi.org/ $10.1177 / 0748730415577723$

196. Lassmann H, Bradl M (2017) Multiple sclerosis: experimental models and reality. Acta Neuropathol 133:223-244. https://doi. org/10.1007/s00401-016-1631-4
197. Lassmann H, Zimprich F, Vass K, Hickey WF (1991) Microglial cells are a component of the perivascular glia limitans. J Neurosci Res 28:236-243. https://doi.org/10.1002/jnr.490280211

198. Lei F, Cui N, Zhou C, Chodosh J, Vavvas DG, Paschalis EI (2020) CSF1R inhibition by a small-molecule inhibitor is not microglia specific; affecting hematopoiesis and the function of macrophages. Proc Natl Acad Sci USA 117:23336-23338. https://doi.org/10.1073/pnas.1922788117

199. Lewis ND, Hill JD, Juchem KW, Stefanopoulos DE, Modis LK (2014) RNA sequencing of microglia and monocyte-derived macrophages from mice with experimental autoimmune encephalomyelitis illustrates a changing phenotype with disease course. J Neuroimmunol 277:26-38. https://doi.org/10.1016/j.jneuroim. 2014.09.014

200. Lim JK, Obara CJ, Rivollier A, Pletnev AG, Kelsall BL, Murphy PM (2011) Chemokine receptor Ccr2 is critical for monocyte accumulation and survival in West Nile virus encephalitis. J Immunol 186:471-478

201. Locatelli G, Theodorou D, Kendirli A, Jordao MJC, Staszewski O, Phulphagar K et al (2018) Mononuclear phagocytes locally specify and adapt their phenotype in a multiple sclerosis model. Nat Neurosci 21:1196-1208. https://doi.org/10.1038/ s41593-018-0212-3

202. Locatelli G, Wortge S, Buch T, Ingold B, Frommer F, Sobottka B et al (2012) Primary oligodendrocyte death does not elicit anti-CNS immunity. Nat Neurosci 15:543-550. https://doi.org/ 10.1038/nn.3062

203. Lodygin D, Hermann M, Schweingruber N, Flugel-Koch C, Watanabe T, Schlosser C et al (2019) beta-Synuclein-reactive T cells induce autoimmune CNS grey matter degeneration. Nature 566:503-508. https://doi.org/10.1038/s41586-019-0964-2

204. Low D, Ginhoux F (2018) Recent advances in the understanding of microglial development and homeostasis. Cell Immunol 330:68-78. https://doi.org/10.1016/j.cellimm.2018.01.004

205. Lucchinetti C, Bruck W, Parisi J, Scheithauer B, Rodriguez M, Lassmann H (2000) Heterogeneity of multiple sclerosis lesions: implications for the pathogenesis of demyelination. Ann Neurol 47:707-717. https://doi.org/10.1002/1531-8249(200006)47:6\% 3c707::aid-ana3\%3e3.0.co;2-q

206. Luo H, Winkelmann ER, Zhu S, Ru W, Mays E, Silvas JA et al (2018) Peli1 facilitates virus replication and promotes neuroinflammation during West Nile virus infection. J Clin Invest 128:4980-4991. https://doi.org/10.1172/JCI99902

207. Macleod MR, Fisher M, O'collins V, Sena ES, Dirnagl U, Bath $\mathrm{PM}$ et al (2009) Good laboratory practice: preventing introduction of bias at the bench. Stroke 40:e50-e52

208. Macrae I (2011) Preclinical stroke research-advantages and disadvantages of the most common rodent models of focal ischaemia. Br J Pharmacol 164:1062-1078

209. Madden K (2003) West Nile virus infection and its neurological manifestations. Clin Med Res 1:145-150. https://doi.org/10. 3121/cmr.1.2.145

210. Marik C, Felts PA, Bauer J, Lassmann H, Smith KJ (2007) Lesion genesis in a subset of patients with multiple sclerosis: a role for innate immunity? Brain 130:2800-2815

211. Marinelli S, Basilico B, Marrone MC, Ragozzino D (2019) Microglia-neuron crosstalk: Signaling mechanism and control of synaptic transmission. Semin Cell Dev Biol 94:138-151. https:// doi.org/10.1016/j.semcdb.2019.05.017

212. Marioni RE, Harris SE, Zhang Q, McRae AF, Hagenaars SP, Hill WD et al (2018) GWAS on family history of Alzheimer's disease. Transl Psychiatry 8:99. https://doi.org/10.1038/ s41398-018-0150-6

213. Masters CL, Bateman R, Blennow K, Rowe CC, Sperling RA, Cummings JL (2015) Alzheimer's disease. Nat Rev Dis Primers 1:15056. https://doi.org/10.1038/nrdp.2015.56 
214. Masuda T, Amann L, Sankowski R, Staszewski O, Lenz M, Snaidero PDE et al (2020) Novel Hexb-based tools for studying microglia in the CNS. Nat Immunol 21:802-815. https://doi.org/ 10.1038/s41590-020-0707-4

215. Masuda T, Sankowski R, Staszewski O, Prinz M (2020) Microglia heterogeneity in the single-cell era. Cell Rep 30:1271-1281. https://doi.org/10.1016/j.celrep.2020.01.010

216. Mattiace LA, Davies P, Yen SH, Dickson DW (1990) Microglia in cerebellar plaques in Alzheimer's disease. Acta Neuropathol 80:493-498. https://doi.org/10.1007/BF00294609

217. McColl B, Howells D, Rothwell N, Denes A (2010) Modeling risk factors and confounding effects in stroke. Rodent models of stroke. Springer, Berlin, pp 93-119

218. McColl BW, Rothwell NJ, Allan SM (2007) Systemic inflammatory stimulus potentiates the acute phase and CXC chemokine responses to experimental stroke and exacerbates brain damage via interleukin-1- and neutrophil-dependent mechanisms. J Neurosci 27:4403-4412. https://doi.org/10.1523/JNEUROSCI.537606.2007

219. McGeer PL, Akiyama H, Itagaki S, McGeer EG (1989) Activation of the classical complement pathway in brain tissue of Alzheimer patients. Neurosci Lett 107:341-346. https://doi.org/ 10.1016/0304-3940(89)90843-4

220. McKinsey GL, Lizama CO, Keown-Lang AE, Niu A, Santander N, Larpthaveesarp A et al (2020) A new genetic strategy for targeting microglia in development and disease. Elife. https://doi.org/10.7554/eLife.54590

221. McQuade A, Blurton-Jones M (2019) Microglia in Alzheimer's disease: exploring how genetics and phenotype influence risk. J Mol Biol 431:1805-1817. https://doi.org/10.1016/j.jmb.2019. 01.045

222. Meilandt WJ, Ngu H, Gogineni A, Lalehzadeh G, Lee SH, Srinivasan K et al (2020) Trem2 deletion reduces late-stage amyloid plaque accumulation, elevates the Abeta42:Abeta40 ratio, and exacerbates axonal dystrophy and dendritic spine loss in the PS2APP Alzheimer's mouse model. J Neurosci 40:1956-1974. https://doi.org/10.1523/JNEUROSCI.1871-19. 2019

223. Mena H, Cadavid D, Rushing EJ (2004) Human cerebral infarct: a proposed histopathologic classification based on 137 cases. Acta Neuropathol 108:524-530

224. Mendiola AS, Ryu JK, Bardehle S, Meyer-Franke A, Ang KK, Wilson C et al (2020) Transcriptional profiling and therapeutic targeting of oxidative stress in neuroinflammation. Nat Immunol 21:513-524. https://doi.org/10.1038/s41590-020-0654-0

225. Merkler D, Ernsting T, Kerschensteiner M, Bruck W, Stadelmann C (2006) A new focal EAE model of cortical demyelination: multiple sclerosis-like lesions with rapid resolution of inflammation and extensive remyelination. Brain 129:1972-1983. https://doi. org/10.1093/brain/awl135

226. Meyer-Luehmann M, Spires-Jones TL, Prada C, Garcia-Alloza M, de Calignon A, Rozkalne A et al (2008) Rapid appearance and local toxicity of amyloid-beta plaques in a mouse model of Alzheimer's disease. Nature 451:720-724. https://doi.org/10. 1038/nature06616

227. Michaud J-P, Bellavance M-A, Préfontaine P, Rivest S (2013) Real-time in vivo imaging reveals the ability of monocytes to clear vascular amyloid beta. Cell Rep 5:646-653

228. Mildner A, Mack M, Schmidt H, Brück W, Djukic M, Zabel MD et al (2009) CCR2+Ly-6Chi monocytes are crucial for the effector phase of autoimmunity in the central nervous system. Brain 132:2487-2500. https://doi.org/10.1093/brain/awp144

229. Mildner A, Schlevogt B, Kierdorf K, Böttcher C, Erny D, Kummer MP et al (2011) Distinct and non-redundant roles of microglia and myeloid subsets in mouse models of Alzheimer's disease. J Neurosci 31:11159-11171
230. Mildner A, Schmidt H, Nitsche M, Merkler D, Hanisch U-K, Mack M et al (2007) Microglia in the adult brain arise from Ly6ChiCCR2+ monocytes only under defined host conditions. Nat Neurosci 10:1544-1553. https://doi.org/10.1038/nn2015

231. Miller SD, McMahon EJ, Schreiner B, Bailey SL (2007) Antigen presentation in the CNS by myeloid dendritic cells drives progression of relapsing experimental autoimmune encephalomyelitis. Ann N Y Acad Sci 1103:179-191

232. Mishra MK, Yong VW (2016) Myeloid cells - targets of medication in multiple sclerosis. Nat Rev Neurol 12:539-551. https:// doi.org/10.1038/nrneurol.2016.110

233. Moreno MA, Burns T, Yao P, Miers L, Pleasure D, Soulika AM (2016) Therapeutic depletion of monocyte-derived cells protects from long-term axonal loss in experimental autoimmune encephalomyelitis. J Neuroimmunol 290:36-46. https://doi.org/ 10.1016/j.jneuroim.2015.11.004

234. Moseman EA, Blanchard AC, Nayak D, McGavern DB (2020) T cell engagement of cross-presenting microglia protects the brain from a nasal virus infection. Sci Immunol. https://doi.org/10. 1126/sciimmunol.abb1817

235. Mrdjen D, Pavlovic A, Hartmann FJ, Schreiner B, Utz SG, Leung BP et al (2018) High-dimensional single-cell mapping of central nervous system immune cells reveals distinct myeloid subsets in health, aging, and disease. Immunity 48(380-395):e386. https:// doi.org/10.1016/j.immuni.2018.01.011

236. Mundt S, Mrdjen D, Utz SG, Greter M, Schreiner B, Becher B (2019) Conventional DCs sample and present myelin antigens in the healthy CNS and allow parenchymal T cell entry to initiate neuroinflammation. Sci Immunol. https://doi.org/10.1126/sciim munol.aau8380

237. Murray KO, Garcia MN, Rahbar MH, Martinez D, Khuwaja SA, Arafat RR et al (2014) Survival analysis, long-term outcomes, and percentage of recovery up to 8 years post-infection among the houston West Nile virus cohort. PLoS ONE. https://doi.org/ 10.1371/journal.pone.0102953

238. Naert G, Rivest S (2011) CC chemokine receptor 2 deficiency aggravates cognitive impairments and amyloid pathology in a transgenic mouse model of Alzheimer's disease. J Neurosci 31:6208-6220

239. Naghavi M, Abajobir AA, Abbafati C, Abbas KM, Abd-Allah F, Abera SF et al (2017) Global, regional, and national age-sex specific mortality for 264 causes of death, 1980-2016: a systematic analysis for the Global Burden of Disease Study 2016. The Lancet 390:1151-1210

240. Nash KR, Lee DC, Hunt JB Jr, Morganti JM, Selenica ML, Moran P et al (2013) Fractalkine overexpression suppresses tau pathology in a mouse model of tauopathy. Neurobiol Aging 34:1540-1548. https://doi.org/10.1016/j.neurobiolaging.2012.12. 011

241. Nelson PT, Alafuzoff I, Bigio EH, Bouras C, Braak H, Cairns NJ et al (2012) Correlation of Alzheimer disease neuropathologic changes with cognitive status: a review of the literature. J Neuropathol Exp Neurol 71:362-381. https://doi.org/10.1097/NEN. 0b013e31825018f7

242. Nikić I, Merkler D, Sorbara C, Brinkoetter M, Kreutzfeldt M, Bareyre FM et al (2011) A reversible form of axon damage in experimental autoimmune encephalomyelitis and multiple sclerosis. Nat Med 17:495-499

243. Nissen JC, Thompson KK, West BL, Tsirka SE (2018) Csf1R inhibition attenuates experimental autoimmune encephalomyelitis and promotes recovery. Exp Neurol 307:24-36. https://doi. org/10.1016/j.expneurol.2018.05.021

244. Nour M, Scalzo F, Liebeskind D (2013) Ischemia-reperfusion injury in stroke. Interv Neurol 1:185-199

245. Okamoto K, Aoki K (1963) Development of a strain of spontaneously hypertensive rats. Jpn Circ J 27:282-293 
246. Olah M, Menon V, Habib N, Taga MF, Ma Y, Yung CJ et al (2020) Single cell RNA sequencing of human microglia uncovers a subset associated with Alzheimer's disease. Nat Commun 11:6129. https://doi.org/10.1038/s41467-020-19737-2

247. Omalu BI, Shakir AA, Wang G, Lipkin WI, Wiley CA (2003) Fatal fulminant pan-meningo-polioencephalitis due to West Nile virus. Brain Pathol 13:465-472. https://doi.org/10.1111/j.17503639.2003.tb00477.x

248. Otxoa-de-Amezaga A, Miro-Mur F, Pedragosa J, Gallizioli M, Justicia C, Gaja-Capdevila N et al (2019) Microglial cell loss after ischemic stroke favors brain neutrophil accumulation. Acta Neuropathol 137:321-341. https://doi.org/10.1007/ s00401-018-1954-4

249. Park J, Wetzel I, Marriott I, Dreau D, D’Avanzo C, Kim DY et al (2018) A 3D human triculture system modeling neurodegeneration and neuroinflammation in Alzheimer's disease. Nat Neurosci 21:941-951. https://doi.org/10.1038/s41593-018-0175-4

250. Pasciuto E, Burton OT, Roca CP, Lagou V, Rajan WD, Theys T et al (2020) Microglia require CD4 T cells to complete the fetalto-adult transition. Cell 182(625-640):e624. https://doi.org/10. 1016/j.cell.2020.06.026

251. Passlick B, Flieger D, Ziegler-Heitbrock HW (1989) Identification and characterization of a novel monocyte subpopulation in human peripheral blood. Blood 74:2527-2534. https://doi.org/ 10.1182/blood.v74.7.2527.2527

252. Patrick E, Olah M, Taga M, Klein HU, Xu J, White CC et al (2021) A cortical immune network map identifies distinct microglial transcriptional programs associated with beta-amyloid and Tau pathologies. Transl Psychiatry 11:50. https://doi.org/10. 1038/s41398-020-01175-9

253. Perez-Gracia E, Blanco R, Carmona M, Carro E, Ferrer I (2009) Oxidative stress damage and oxidative stress responses in the choroid plexus in Alzheimer's disease. Acta Neuropathol 118:497-504. https://doi.org/10.1007/s00401-009-0574-4

254. Piccio L, Buonsanti C, Mariani M, Cella M, Gilfillan S, Cross AH et al (2007) Blockade of TREM-2 exacerbates experimental autoimmune encephalomyelitis. Eur J Immunol 37:1290-1301. https://doi.org/10.1002/eji.200636837

255. Poliani PL, Wang Y, Fontana E, Robinette ML, Yamanishi Y, Gilfillan S et al (2015) TREM2 sustains microglial expansion during aging and response to demyelination. J Clin Invest 125:2161-2170. https://doi.org/10.1172/JCI77983

256. Popescu BF, Lucchinetti CF (2012) Meningeal and cortical grey matter pathology in multiple sclerosis. BMC Neurol 12:11. https://doi.org/10.1186/1471-2377-12-11

257. Praet J, Guglielmetti C, Berneman Z, Van der Linden A, Ponsaerts P (2014) Cellular and molecular neuropathology of the cuprizone mouse model: clinical relevance for multiple sclerosis. Neurosci Biobehav Rev 47:485-505. https://doi.org/10.1016/j. neubiorev.2014.10.004

258. Prince MJ, Wimo A, Guerchet MM, Ali GC, Wu Y-T, Prina M (2015) World Alzheimer report 2015-the Global Impact of Dementia: an analysis of prevalence, incidence, cost and trends.

259. Prinz M, Jung S, Priller J (2019) Microglia biology: one century of evolving concepts. Cell 179:292-311. https://doi.org/10. 1016/j.cell.2019.08.053

260. Prinz M, Priller J (2010) Tickets to the brain: role of CCR2 and CX3CR1 in myeloid cell entry in the CNS. J Neuroimmunol 224:80-84. https://doi.org/10.1016/j.jneuroim.2010.05.015

261. Prinz M, Tay TL, Wolf Y, Jung S (2014) Microglia: unique and common features with other tissue macrophages. Acta Neuropathol 128:319-331. https://doi.org/10.1007/s00401-014-1267-1

262. Prokop S, Miller KR, Drost N, Handrick S, Mathur V, Luo J et al (2015) Impact of peripheral myeloid cells on amyloid- $\beta$ pathology in Alzheimer's disease-like mice. J Exp Med 212:1811-1818
263. Quick ED, Seitz S, Clarke P, Tyler KL (2017) Minocycline has anti-inflammatory effects and reduces cytotoxicity in an ex vivo spinal cord slice culture model of West Nile virus infection. J Virol. https://doi.org/10.1128/JVI.00569-17

264. Rangaraju S, Dammer EB, Raza SA, Rathakrishnan P, Xiao H, Gao $T$ et al (2018) Identification and therapeutic modulation of a pro-inflammatory subset of disease-associated-microglia in Alzheimer's disease. Mol Neurodegener 13:24. https://doi.org/ 10.1186/s13024-018-0254-8

265. Ransohoff RM (2012) Animal models of multiple sclerosis: the good, the bad and the bottom line. Nat Neurosci 15:1074-1077. https://doi.org/10.1038/nn.3168

266. Ransohoff RM, Perry VH (2009) Microglial physiology: unique stimuli, specialized responses. Annu Rev Immunol 27:119-145. https://doi.org/10.1146/annurev.immunol.021908.132528

267. Rasmussen S, Wang Y, Kivisakk P, Bronson RT, Meyer M, Imitola J et al (2007) Persistent activation of microglia is associated with neuronal dysfunction of callosal projecting pathways and multiple sclerosis-like lesions in relapsing-remitting experimental autoimmune encephalomyelitis. Brain 130:2816-2829. https://doi.org/10.1093/brain/awm219

268. Remington LT, Babcock AA, Zehntner SP, Owens T (2007) Microglial recruitment, activation, and proliferation in response to primary demyelination. Am J Pathol 170:1713-1724. https:// doi.org/10.2353/ajpath.2007.060783

269. Ritzel RM, Patel AR, Grenier JM, Crapser J, Verma R, Jellison ER et al (2015) Functional differences between microglia and monocytes after ischemic stroke. J Neuroinflammation 12:106. https://doi.org/10.1186/s12974-015-0329-1

270. Roh JS, Sohn DH (2018) Damage-associated molecular patterns in inflammatory diseases. Immune Netw 18:e27. https://doi.org/ 10.4110/in.2018.18.e27

271. Rohl C, Lucius R, Sievers J (2007) The effect of activated microglia on astrogliosis parameters in astrocyte cultures. Brain Res 1129:43-52. https://doi.org/10.1016/j.brainres.2006.10.057

272. Samaan Z, McDermid Vaz S, Bawor M, Potter TH, Eskandarian S, Loeb M (2016) Neuropsychological impact of West Nile virus infection: an extensive neuropsychiatric assessment of 49 cases in Canada. PLoS ONE 11:e0158364. https://doi.org/10. 1371/journal.pone.0158364

273. Sampson BA, Ambrosi C, Charlot A, Reiber K, Veress JF, Armbrustmacher V (2000) The pathology of human West Nile Virus infection. Hum Pathol 31:527-531. https://doi.org/10.1053/hp. 2000.8047

274. Sanchez J, DePaula-Silva A, Doty D, Truong A, Libbey J, Fujinami R (2019) Microglial cell depletion is fatal with low level picornavirus infection of the central nervous system. J Neurovirol 25:415-421. https://doi.org/10.1007/s13365-019-00740-3

275. Saresella M, Marventano I, Piancone F, La Rosa F, Galimberti D, Fenoglio C et al (2020) IL-33 and its decoy sST2 in patients with Alzheimer's disease and mild cognitive impairment. J Neuroinflammation 17:1-10

276. Sato K, Sasaguri H, Kumita W, Inoue T, Kurotaki Y, Nagata K et al (2020) A non-human primate model of familial Alzheimer's disease. BioRxiv. https://doi.org/10.1101/2020.08.24.264259

277. Savarin C, Dutta R, Bergmann CC (2018) Distinct gene profiles of bone marrow-derived macrophages and microglia during neurotropic coronavirus-induced demyelination. Front Immunol 9:1325

278. Schirmer L, Albert M, Buss A, Schulz-Schaeffer WJ, Antel JP, Brück W et al (2009) Substantial early, but nonprogressive neuronal loss in multiple sclerosis (MS) spinal cord. Ann Neurol 66:698-704

279. Seitz S, Clarke P, Tyler KL (2018) Pharmacologic depletion of microglia increases viral load in the brain and enhances mortality 
in murine models of flavivirus-induced encephalitis. J Virol. https://doi.org/10.1128/JVI.00525-18

280. Serbina NV, Pamer EG (2006) Monocyte emigration from bone marrow during bacterial infection requires signals mediated by chemokine receptor CCR2. Nat Immunol 7:311-317. https://doi. org/10.1038/ni1309

281. Shechter R, Miller O, Yovel G, Rosenzweig N, London A, Ruckh J et al (2013) Recruitment of beneficial M2 macrophages to injured spinal cord is orchestrated by remote brain choroid plexus. Immunity 38:555-569

282. Shen Y, Lue L, Yang L, Roher A, Kuo Y, Strohmeyer R et al (2001) Complement activation by neurofibrillary tangles in Alzheimer's disease. Neurosci Lett 305:165-168. https://doi.org/10. 1016/s0304-3940(01)01842-0

283. Sheng JG, Bora SH, Xu G, Borchelt DR, Price DL, Koliatsos VE (2003) Lipopolysaccharide-induced-neuroinflammation increases intracellular accumulation of amyloid precursor protein and amyloid beta peptide in APPswe transgenic mice. Neurobiol Dis 14:133-145. https://doi.org/10.1016/s0969-9961(03)00069-x

284. Shi Q, Chowdhury S, Ma R, Le KX, Hong S, Caldarone BJ et al (2017) Complement C3 deficiency protects against neurodegeneration in aged plaque-rich APP/PS1 mice. Sci Transl Med. https://doi.org/10.1126/scitranslmed.aaf6295

285. Shi Q, Colodner KJ, Matousek SB, Merry K, Hong S, Kenison JE et al (2015) Complement C3-deficient mice fail to display age-related hippocampal decline. J Neurosci 35:13029-13042. https://doi.org/10.1523/JNEUROSCI.1698-15.2015

286. Shi Y, Holtzman DM (2018) Interplay between innate immunity and Alzheimer disease: APOE and TREM2 in the spotlight. Nat Rev Immunol 18:759-772. https://doi.org/10.1038/ s41577-018-0051-1

287. Simard AR, Soulet D, Gowing G, Julien J-P, Rivest S (2006) Bone marrow-derived microglia play a critical role in restricting senile plaque formation in Alzheimer's disease. Neuron 49:489-502

288. Skaper SD, Facci L, Zusso M, Giusti P (2018) An inflammation-centric view of neurological disease: beyond the neuron. Front Cell Neurosci 12:72. https://doi.org/10.3389/fncel.2018. 00072

289. Slavin AJ, Soos JM, Stuve O, Patarroyo JC, Weiner HL, Fontana A et al (2001) Requirement for endocytic antigen processing and influence of invariant chain and H-2M deficiencies in CNS autoimmunity. J Clin Investig 108:1133-1139

290. Sommer CJ (2017) Ischemic stroke: experimental models and reality. Acta Neuropathol 133:245-261

291. Song WM, Colonna M (2018) The identity and function of microglia in neurodegeneration. Nat Immunol 19:1048-1058. https://doi.org/10.1038/s41590-018-0212-1

292. Soreq L, Rose J, Soreq E, Hardy J, Trabzuni D, Cookson MR et al (2017) Major shifts in glial regional identity are a transcriptional hallmark of human brain aging. Cell Rep 18:557-570

293. Sosa RA, Murphey C, Ji N, Cardona AE, Forsthuber TG (2013) The kinetics of myelin antigen uptake by myeloid cells in the central nervous system during experimental autoimmune encephalomyelitis. J Immunol 191:5848-5857. https://doi.org/10.4049/ jimmunol.1300771

294. Sosna J, Philipp S, Albay R 3rd, Reyes-Ruiz JM, Baglietto-Vargas D, LaFerla FM et al (2018) Early long-term administration of the CSF1R inhibitor PLX3397 ablates microglia and reduces accumulation of intraneuronal amyloid, neuritic plaque deposition and pre-fibrillar oligomers in 5XFAD mouse model of Alzheimer's disease. Mol Neurodegener 13:11. https://doi.org/ 10.1186/s13024-018-0244-X

295. Spangenberg E, Severson PL, Hohsfield LA, Crapser J, Zhang J, Burton EA et al (2019) Sustained microglial depletion with CSF1R inhibitor impairs parenchymal plaque development in an
Alzheimer's disease model. Nat Commun 10:3758. https://doi. org/10.1038/s41467-019-11674-z

296. Spangenberg EE, Lee RJ, Najafi AR, Rice RA, Elmore MR et al (2016) Eliminating microglia in Alzheimer's mice prevents neuronal loss without modulating amyloid-beta pathology. Brain 139:1265-1281. https://doi.org/10.1093/brain/aww016

297. Spath S, Komuczki J, Hermann M, Pelczar P, Mair F, Schreiner $B$ et al (2017) Dysregulation of the cytokine GM-CSF induces spontaneous phagocyte invasion and immunopathology in the central nervous system. Immunity 46:245-260

298. Spiteri AG, Terry RL, Wishart CL, Ashhurst TM, Campbell IL, Hofer MJ et al (2021) High-parameter cytometry unmasks microglial cell spatio-temporal response kinetics in severe neuroinflammatory disease. J Neuroinflammation 18:166. https:// doi.org/10.1186/s12974-021-02214-y

299. Spiteri AG, Wishart CL, King NJC (2020) Immovable object meets unstoppable force? Dialogue between resident and peripheral myeloid cells in the inflamed Brain. Front Immunol 11:600822. https://doi.org/10.3389/fimmu.2020.600822

300. Stephan AH, Madison DV, Mateos JM, Fraser DA, Lovelett EA, Coutellier L et al (2013) A dramatic increase of C1q protein in the CNS during normal aging. J Neurosci 33:13460-13474. https://doi.org/10.1523/JNEUROSCI.1333-13.2013

301. Stowe AM, Adair-Kirk TL, Gonzales ER, Perez RS, Shah AR, Park TS et al (2009) Neutrophil elastase and neurovascular injury following focal stroke and reperfusion. Neurobiol Dis 35:82-90. https://doi.org/10.1016/j.nbd.2009.04.006

302. Streit WJ, Miller KR, Lopes KO, Njie E (2008) Microglial degeneration in the aging brain-bad news for neurons? Front Biosci 13:3423-3438. https://doi.org/10.2741/2937

303. Streit WJ, Walter SA, Pennell NA (1999) Reactive microgliosis. Prog Neurobiol 57:563-581. https://doi.org/10.1016/s03010082(98)00069-0

304. Sy M, Kitazawa M, Medeiros R, Whitman L, Cheng D, Lane TE et al (2011) Inflammation induced by infection potentiates tau pathological features in transgenic mice. Am J Pathol 178:28112822. https://doi.org/10.1016/j.ajpath.2011.02.012

305. Symon L, Crockard H, Dorsch CN, Branston N, Juhasz J (1975) Local cerebral blood flow and vascular reactivity in a chronic stable stroke in baboons. Stroke 6:482-492

306. Szepesi Z, Manouchehrian O, Bachiller S, Deierborg T (2018) Bidirectional microglia-neuron communication in health and disease. Front Cell Neurosci 12:323. https://doi.org/10.3389/fncel. 2018.00323

307. Tan J, Ni D, Ribeiro RV, Pinget GV, Macia L (2021) How changes in the nutritional landscape shape gut immunometabolism. Nutrients. https://doi.org/10.3390/nu13030823

308. Tan J, Ni D, Wali JA, Cox DA, Pinget GV, Taitz J et al (2021) Dietary carbohydrate, particularly glucose, drives B cell lymphopoiesis and function. iScience 24:102835. https://doi.org/10. 1016/j.isci.2021.102835

309. Tanabe S, Saitoh S, Miyajima H, Itokazu T, Yamashita T (2019) Microglia suppress the secondary progression of autoimmune encephalomyelitis. Glia 67:1694-1704. https://doi.org/10.1002/ glia. 23640

310. Terry RL, Deffrasnes C, Getts DR, Minten C, Van Vreden C, Ashhurst TM et al (2015) Defective inflammatory monocyte development in IRF8-deficient mice abrogates migration to the West Nile virus-infected brain. J Innate Immun 7:102-112

311. Thanopoulou K, Fragkouli A, Stylianopoulou F, Georgopoulos S (2010) Scavenger receptor class B type I (SR-BI) regulates perivascular macrophages and modifies amyloid pathology in an Alzheimer mouse model. Proc Natl Acad Sci USA 107:2081620821. https://doi.org/10.1073/pnas.1005888107 
312. Thome AD, Faridar A, Beers DR, Thonhoff JR, Zhao W, Wen $S$ et al (2018) Functional alterations of myeloid cells during the course of Alzheimer's disease. Mol Neurodegener 13:1-11

313. Traka M, Podojil JR, McCarthy DP, Miller SD, Popko B (2016) Oligodendrocyte death results in immune-mediated CNS demyelination. Nat Neurosci 19:65-74. https://doi.org/10.1038/nn. 4193

314. Tsunoda I, Kuang LQ, Theil DJ, Fujinami RS (2000) Antibody association with a novel model for primary progressive multiple sclerosis: induction of relapsing-remitting and progressive forms of EAE in H2s mouse strains. Brain Pathol 10:402-418. https:// doi.org/10.1111/j.1750-3639.2000.tb00272.x

315. Tun NN, Arunagirinathan G, Munshi SK, Pappachan JM (2017) Diabetes mellitus and stroke: a clinical update. World J Diabetes 8:235-248. https://doi.org/10.4239/wjd.v8.i6.235

316. Utz SG, See P, Mildenberger W, Thion MS, Silvin A, Lutz M et al (2020) Early fate defines microglia and non-parenchymal brain macrophage development. Cell 181(557-573):e518. https:// doi.org/10.1016/j.cell.2020.03.021

317. Van Hove H, Martens L, Scheyltjens I, De Vlaminck K, Pombo Antunes AR, De Prijck S et al (2019) A single-cell atlas of mouse brain macrophages reveals unique transcriptional identities shaped by ontogeny and tissue environment. Nat Neurosci 22:1021-1035. https://doi.org/10.1038/s41593-019-0393-4

318. van Olst L, Rodriguez-Mogeda C, Picon C, Kiljan S, James RE, Kamermans A et al (2021) Meningeal inflammation in multiple sclerosis induces phenotypic changes in cortical microglia that differentially associate with neurodegeneration. Acta Neuropathol 141:881-899. https://doi.org/10.1007/ s00401-021-02293-4

319. Van Rooijen N (1989) The liposome-mediated macrophage "suicide" technique. J Immunol Methods 124:1-6. https://doi. org/10.1016/0022-1759(89)90178-6

320. Van Rooijen N, Sanders A (1994) Liposome mediated depletion of macrophages: mechanism of action, preparation of liposomes and applications. J Immunol Methods 174:83-93. https://doi.org/10.1016/0022-1759(94)90012-4

321. van Rooijen N, van Nieuwmegen R (1984) Elimination of phagocytic cells in the spleen after intravenous injection of liposome-encapsulated dichloromethylene diphosphonate. An enzyme-histochemical study. Cell Tissue Res 238:355-358. https://doi.org/10.1007/BF00217308

322. van Wageningen TA, Vlaar E, Kooij G, Jongenelen CAM, Geurts JJG, van Dam AM (2019) Regulation of microglial TMEM119 and P2RY12 immunoreactivity in multiple sclerosis white and grey matter lesions is dependent on their inflammatory environment. Acta Neuropathol Commun 7:206. https://doi.org/10.1186/s40478-019-0850-z

323. Varol C, Landsman L, Fogg DK, Greenshtein L, Gildor B, Margalit R et al (2007) Monocytes give rise to mucosal, but not splenic, conventional dendritic cells. J Exp Med 204:171-180

324. Vasek MJ, Garber C, Dorsey D, Durrant DM, Bollman B, Soung A et al (2016) A complement-microglial axis drives synapse loss during virus-induced memory impairment. Nature 534:538-543. https://doi.org/10.1038/nature18283

325. Vitek MP, Araujo JA, Fossel M, Greenberg BD, Howell GR, Rizzo SJS et al (2020) Translational animal models for Alzheimer's disease: an Alzheimer's Association Business Consortium Think Tank. Alzheimers Dement (N Y) 6:e12114. https:// doi.org/10.1002/trc2.12114

326. Voet S, Prinz M, van Loo G (2019) Microglia in central nervous system inflammation and multiple sclerosis pathology. Trends Mol Med 25:112-123. https://doi.org/10.1016/j.molmed.2018.11.005

327. Vogel DY, Vereyken EJ, Glim JE, Heijnen PD, Moeton M, van der Valk P et al (2013) Macrophages in inflammatory multiple sclerosis lesions have an intermediate activation status. J Neuroinflammation 10:35. https://doi.org/10.1186/ 1742-2094-10-35

328. Vogels T, Murgoci AN, Hromadka T (2019) Intersection of pathological tau and microglia at the synapse. Acta Neuropathol Commun 7:109. https://doi.org/10.1186/s40478-019-0754-y

329. Vora NM, Holman RC, Mehal JM, Steiner CA, Blanton J, Sejvar $\mathrm{J}$ (2014) Burden of encephalitis-associated hospitalizations in the United States, 1998-2010. Neurology 82:443-451. https://doi. org/10.1212/WNL.0000000000000086

330. Vos T, Abajobir AA, Abate KH, Abbafati C, Abbas KM, Abd-Allah F et al (2017) Global, regional, and national incidence, prevalence, and years lived with disability for 328 diseases and injuries for 195 countries, 1990-2016: a systematic analysis for the Global Burden of Disease Study 2016. Lancet 390:1211-1259

331. Waisman A, Ginhoux F, Greter M, Bruttger J (2015) Homeostasis of microglia in the adult brain: review of novel microglia depletion systems. Trends Immunol 36:625-636. https://doi.org/10. 1016/j.it.2015.08.005

332. Walker DG, Lue LF (2015) Immune phenotypes of microglia in human neurodegenerative disease: challenges to detecting microglial polarization in human brains. Alzheimers Res Ther 7:56. https://doi.org/10.1186/s13195-015-0139-9

333. Walker KA (2018) Inflammation and neurodegeneration: chronicity matters. Aging (Albany NY) 11:3-4. https://doi.org/10. 18632/aging.101704

334. Waltl I, Käufer C, Bröer S, Chhatbar C, Ghita L, Gerhauser I et al (2018) Macrophage depletion by liposome-encapsulated clodronate suppresses seizures but not hippocampal damage after acute viral encephalitis. Neurobiol Dis 110:192-205

335. Waltl I, Käufer C, Gerhauser I, Chhatbar C, Ghita L, Kalinke U et al (2018) Microglia have a protective role in viral encephalitisinduced seizure development and hippocampal damage. Brain Behav Immun. https://doi.org/10.1016/j.bbi.2018.09.006

336. Wang J, Gu BJ, Masters CL, Wang Y-J (2017) A systemic view of Alzheimer disease-insights from amyloid- $\beta$ metabolism beyond the brain. Nat Rev Neurol 13:612-623

337. Wang Y, Lobigs M, Lee E, Mullbacher A (2003) CD8+ T cells mediate recovery and immunopathology in West Nile virus encephalitis. J Virol 77:13323-13334. https://doi.org/10.1128/ jvi.77.24.13323-13334.2003

338. Wang Y, Ulland TK, Ulrich JD, Song W, Tzaferis JA, Hole JT et al (2016) TREM2-mediated early microglial response limits diffusion and toxicity of amyloid plaques. J Exp Med 213:667675. https://doi.org/10.1084/jem.20151948

339. Wattananit S, Tornero D, Graubardt N, Memanishvili T, Monni E, Tatarishvili J et al (2016) Monocyte-derived macrophages contribute to spontaneous long-term functional recovery after stroke in mice. J Neurosci 36:4182-4195

340. Weatherhead JE, Miller VE, Garcia MN, Hasbun R, Salazar L, Dimachkie MM et al (2015) Long-term neurological outcomes in West Nile virus-infected patients: an observational study. Am J Trop Med Hyg 92:1006-1012. https://doi.org/10.4269/ajtmh. 14-0616

341. Weber MS, Prod'homme T, Youssef S, Dunn SE, Rundle CD, Lee L et al (2007) Type II monocytes modulate T cell-mediated central nervous system autoimmune disease. Nat Med 13:935-943

342. Werneburg S, Jung J, Kunjamma RB, Ha SK, Luciano NJ, Willis $\mathrm{CM}$ et al (2020) Targeted complement inhibition at synapses prevents microglial synaptic engulfment and synapse loss in demyelinating disease. Immunity 52(167-182):e167. https://doi.org/ 10.1016/j.immuni.2019.12.004

343. Werner Y, Mass E, Ashok Kumar P, Ulas T, Handler K, Horne A et al (2020) Cxcr4 distinguishes HSC-derived monocytes from 
microglia and reveals monocyte immune responses to experimental stroke. Nat Neurosci 23:351-362. https://doi.org/10.1038/ s41593-020-0585-y

344. Wheeler DL, Sariol A, Meyerholz DK, Perlman S (2018) Microglia are required for protection against lethal coronavirus encephalitis in mice. J Clin Invest 128:931-943. https://doi.org/10.1172/ JCI97229

345. Wilkins HM, Weidling IW, Ji Y, Swerdlow RH (2017) Mitochondria-derived damage-associated molecular patterns in neurodegeneration. Front Immunol 8:508. https://doi.org/10.3389/fimmu. 2017.00508

346. Wimmer I, Scharler C, Zrzavy T, Kadowaki T, Modlagl V, Rojc K et al (2019) Microglia pre-activation and neurodegeneration precipitate neuroinflammation without exacerbating tissue injury in experimental autoimmune encephalomyelitis. Acta Neuropathol Commun 7:14. https://doi.org/10.1186/s40478-019-0667-9

347. Wlodarczyk A, Benmamar-Badel A, Cedile O, Jensen KN, Kramer I, Elsborg NB et al (2018) CSF1R stimulation promotes increased neuroprotection by CD11c+ microglia in EAE. Front Cell Neurosci 12:523. https://doi.org/10.3389/fncel.2018.00523

348. Wlodarczyk A, Cedile O, Jensen KN, Jasson A, Mony JT, Khorooshi R et al (2015) Pathologic and protective roles for microglial subsets and bone marrow- and blood-derived myeloid cells in central nervous system inflammation. Front Immunol 6:463. https://doi.org/10.3389/fimmu.2015.00463

349. Wlodarczyk A, Holtman IR, Krueger M, Yogev N, Bruttger J, Khorooshi R et al (2017) A novel microglial subset plays a key role in myelinogenesis in developing brain. EMBO J 36:32923308. https://doi.org/10.15252/embj.201696056

350. Wlodarczyk A, Lobner M, Cedile O, Owens T (2014) Comparison of microglia and infiltrating $\mathrm{CD} 11 \mathrm{c}(+)$ cells as antigen presenting cells for $\mathrm{T}$ cell proliferation and cytokine response. J Neuroinflammation 11:57. https://doi.org/10.1186/1742-2094-11-57

351. Wolf Y, Shemer A, Levy-Efrati L, Gross M, Kim JS, Engel A et al (2018) Microglial MHC class II is dispensable for experimental autoimmune encephalomyelitis and cuprizone-induced demyelination. Eur J Immunol 48:1308-1318. https://doi.org/10. 1002/eji.201847540

352. Wylot B, Mieczkowski J, Niedziolka S, Kaminska B, Zawadzka M (2019) Csf1 deficiency dysregulates glial responses to demyelination and disturbs CNS white matter remyelination. Cells. https://doi.org/10.3390/cells9010099

353. Xiang Y, Bu X-L, Liu Y-H, Zhu C, Shen L-L, Jiao S-S et al (2015) Physiological amyloid-beta clearance in the periphery and its therapeutic potential for Alzheimer's disease. Acta Neuropathol 130:487-499

354. Xiao Y, Jin J, Chang M, Chang JH, Hu H, Zhou X et al (2013) Peli1 promotes microglia-mediated CNS inflammation by regulating Traf3 degradation. Nat Med 19:595-602. https://doi.org/ 10.1038/nm.3111

355. Yamasaki R, Lu H, Butovsky O, Ohno N, Rietsch AM, Cialic R et al (2014) Differential roles of microglia and monocytes in the inflamed central nervous system. J Exp Med 211:1533-1549. https://doi.org/10.1084/jem.20132477

356. Yang T, Guo R, Zhang F (2019) Brain perivascular macrophages: Recent advances and implications in health and diseases. CNS Neurosci Ther 25:1318-1328. https://doi.org/10.1111/cns.13263

357. Yeh FL, Wang Y, Tom I, Gonzalez LC, Sheng M (2016) TREM2 binds to apolipoproteins, including APOE and CLU/APOJ, and thereby facilitates uptake of amyloid-beta by microglia. Neuron 91:328-340. https://doi.org/10.1016/j.neuron.2016.06.015
358. Yogev N, Frommer F, Lukas D, Kautz-Neu K, Karram K, Ielo D et al (2012) Dendritic cells ameliorate autoimmunity in the CNS by controlling the homeostasis of PD-1 receptor(+) regulatory T cells. Immunity 37:264-275. https://doi.org/10.1016/j.immuni 2012.05.025

359. Yona S, Kim KW, Wolf Y, Mildner A, Varol D, Breker M et al (2013) Fate mapping reveals origins and dynamics of monocytes and tissue macrophages under homeostasis. Immunity 38:79-91. https://doi.org/10.1016/j.immuni.2012.12.001

360. Yong HYF, Rawji KS, Ghorbani S, Xue M, Yong VW (2019) The benefits of neuroinflammation for the repair of the injured central nervous system. Cell Mol Immunol 16:540-546. https:// doi.org/10.1038/s41423-019-0223-3

361. Yuan P, Condello C, Keene CD, Wang Y, Bird TD, Paul SM et al (2016) TREM2 haplodeficiency in mice and humans impairs the microglia barrier function leading to decreased amyloid compaction and severe axonal dystrophy. Neuron 92:252-264. https:// doi.org/10.1016/j.neuron.2016.09.016

362. Zabala A, Vazquez-Villoldo N, Rissiek B, Gejo J, Martin A, Palomino A et al (2018) P2X4 receptor controls microglia activation and favors remyelination in autoimmune encephalitis. EMBO Mol Med. https://doi.org/10.15252/emmm.201708743

363. Zaid A, Tharmarajah K, Mostafavi H, Freitas JR, Sheng K-C, Foo S-S et al (2020) Modulation of monocyte-driven myositis in alphavirus infection reveals a role for $\mathrm{CX} 3 \mathrm{CR} 1^{+}$macrophages in tissue repair. Mbio 11:e03353-19. https://doi.org/10.1128/mBio. 03353-19

364. Zhang Y, Chen K, Sloan SA, Bennett ML, Scholze AR, O'Keeffe $S$ et al (2014) An RNA-sequencing transcriptome and splicing database of glia, neurons, and vascular cells of the cerebral cortex. J Neurosci 34:11929-11947. https://doi.org/10.1523/JNEUR OSCI.1860-14.2014

365. Zhao R, Hu W, Tsai J, Li W, Gan WB (2017) Microglia limit the expansion of beta-amyloid plaques in a mouse model of Alzheimer's disease. Mol Neurodegener 12:47. https://doi.org/10.1186/ s13024-017-0188-6

366. Zhao Y, Wu X, Li X, Jiang LL, Gui X, Liu Y et al (2018) TREM2 is a receptor for beta-amyloid that mediates microglial function. Neuron 97(1023-1031):e1027. https://doi.org/10.1016/j.neuron. 2018.01.031

367. Zhu B, Bando Y, Xiao S, Yang K, Anderson AC, Kuchroo VK et al (2007) CD11b+Ly-6C(hi) suppressive monocytes in experimental autoimmune encephalomyelitis. J Immunol 179:52285237. https://doi.org/10.4049/jimmunol.179.8.5228

368. Zimmermann J, Hafezi W, Dockhorn A, Lorentzen EU, Krauthausen M, Getts DR et al (2017) Enhanced viral clearance and reduced leukocyte infiltration in experimental herpes encephalitis after intranasal infection of CXCR3-deficient mice. J Neurovirol 23:394-403. https://doi.org/10.1007/s13365-016-0508-6

369. Zrzavy T, Machado-Santos J, Christine S, Baumgartner C, Weiner HL, Butovsky O et al (2018) Dominant role of microglial and macrophage innate immune responses in human ischemic infarcts. Brain Pathol 28:791-805

Publisher's Note Springer Nature remains neutral with regard to jurisdictional claims in published maps and institutional affiliations. 